\title{
What is the impact of the Libyan Study Abroad Scholarship Programme on returning university-level English teachers?
}

By

Nwara Abdulhamid

A thesis submitted to the Faculty of Graduate and Postdoctoral Affairs in partial fulfilment of the requirement of the degree of Master of Arts in Applied Linguistics and Discourse Studies

School of Linguistics and Language Studies Carleton University, Ottawa, Ontario, Canada June 2011

(C) Copyright 2011, Nwara Abdulhamid 
Library and Archives

Canada

Published Heritage Branch

395 Wellington Street Ottawa ON K1A ON4 Canada
Bibliothèque et

Archives Canada

Direction du

Patrimoine de l'édition

395 , rue Wellington

Ottawa ON K1A 0N4

Canada
Your file Votre référence

ISBN: 978-0-494-83140-3

Our file Notre référence

ISBN: 978-0-494-83140-3
NOTICE:

The author has granted a nonexclusive license allowing Library and Archives Canada to reproduce, publish, archive, preserve, conserve, communicate to the public by telecommunication or on the Internet, loan, distribute and sell theses worldwide, for commercial or noncommercial purposes, in microform, paper, electronic and/or any other formats.

The author retains copyright ownership and moral rights in this thesis. Neither the thesis nor substantial extracts from it may be printed or otherwise reproduced without the author's permission.
AVIS:

L'auteur a accordé une licence non exclusive permettant à la Bibliothèque et Archives Canada de reproduire, publier, archiver, sauvegarder, conserver, transmettre au public par télécommunication ou par l'Internet, prêter, distribuer et vendre des thèses partout dans le monde, à des fins commerciales ou autres, sur support microforme, papier, électronique et/ou autres formats.

L'auteur conserve la propriété du droit d'auteur et des droits moraux qui protège cette thèse. $\mathrm{Ni}$ la thèse ni des extraits substantiels de celle-ci ne doivent être imprimés ou autrement reproduits sans son autorisation.
In compliance with the Canadian Privacy Act some supporting forms may have been removed from this thesis.

While these forms may be included in the document page count, their removal does not represent any loss of content from the thesis.
Conformément à la loi canadienne sur la protection de la vie privée, quelques formulaires secondaires ont été enlevés de cette thèse.

Bien que ces formulaires aient inclus dans la pagination, il n'y aura aucun contenu manquant.

\section{Canadä}




\section{ABSTRACT}

Since 1972, Libya has made considerable efforts to improve teacher standards and to attend to the needs of Libyan public institutions and academia, by funding students to pursue graduate and post-graduate studies abroad. However, since the introduction of the Libyan Study Abroad Scholarship Programme the impact of such programme on returning university-level English teachers has not been examined. By using questionnaires, followed by semi-structured interviews this study investigates the impact of the Libyan Study Abroad Scholarship Programme on teachers' beliefs and classroom practices of three returning university-level English teachers. It examines the teachers' accounts of whether it changed their approaches to teaching, and the nature of those changes. Analyses of the data provide a promising indication that this programme for professional development has had an impact on teachers and their classroom practices. In addition, the analyses found that teacher' beliefs and perception of effective instruction is an important predictor of these outcomes. It also highlighted factors such as student culture, the prevalent Libyan culture of learning, and the lack of supporting resources , which may impede the implementation of teachers' innovative classroom practices. Suggestions are offered in relation to these findings in order to support returning university level teachers after the completion of their degrees abroad. The relationships uncovered in this study between the Libyan Study Abroad Scholarship Programme and future classroom practices of returning university teachers have implications for curriculum innovation, teacher enhancement programmes, and for language classroom research. 


\section{DEDICATION}

To all the martyrs of Libya, and in particular those of Misurata, who died for the sake of a free Libyan Nation 


\section{ACKNOWLEDGEMENTS}

Much of the satisfaction in completing this research work has not only come from the understanding that I have made a learning journey in which I gained new skills and acquired knowledge which I did not have prior to I conducting this research, but also as a result of this study it may help to build a better education system for the new free Libya

First and foremost I thank Allah, the Almighty, for the perseverance to complete this study, and it would have not been possible without the help and support of many individuals. I wish to acknowledge and express my gratitude and thanks to these people for their precious contributions.

First, I owe my sincere gratitude to my supervisor Janna Fox, for all the time and expertise given during the course of this study. Her expertise in the field, encouragement, supervision, and support from the start to the finalised product enabled me to develop an understanding of the subject, as well as helping me grow as a researcher along the way. I am also grateful to Devon Woods, for his generosity in offering me his understanding, encouragement, and advice when I most needed them, and his care for and interest in my work.

I would like to give thanks to my beloved family for being my source of strength and inspiration during this journey. My father and mother who believed in me and made me the person I am today. My thanks also goes to my four brothers Weal, Ayoub, Mohammed and Abdulhamid, my sister Asia, and uncle Mustafa, who have all been supportive in many ways. I am grateful to have all of them in my life.

My thanks also go to my dear friends, in particular Maureen, who never hesitated to offer a hand or suggestions during difficult times. I cannot thank them enough for their continuous 
support and friendship which helped me overcome the difficulties of living away from home and family in the current Libyan political situation. My honest appreciation is also extended to the three teachers who participated in the study. I am truly grateful for their time, effort, and commitment.

Finally, and above all, I am grateful to my husband, Jamal, and my two children, Jihad and Maria, who helped me find the strength to continue when things got tough. I would have not made it without their unwavering love and their sacrifices on my behalf. 


\section{Contents}

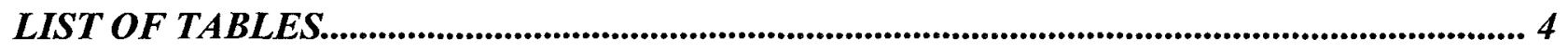

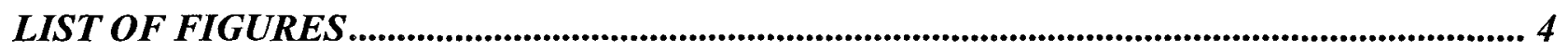

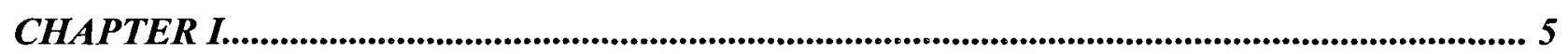

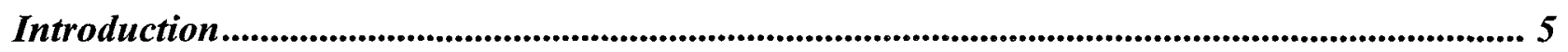

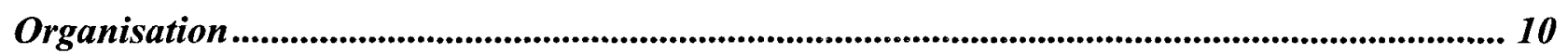

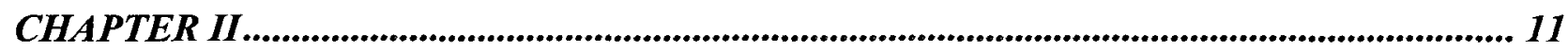

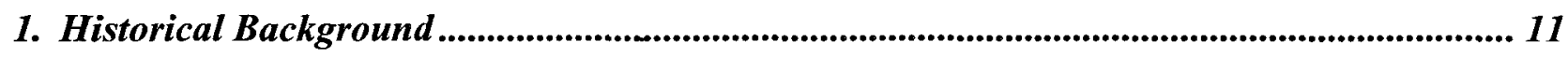

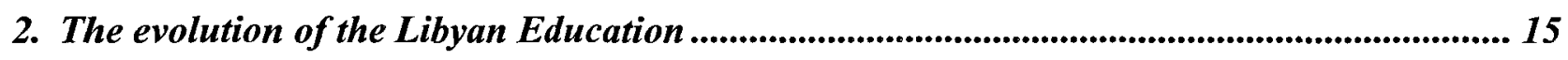

3. The characteristics of the educational and classroom culture ........................................... 22

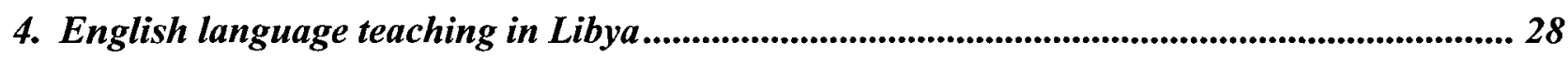

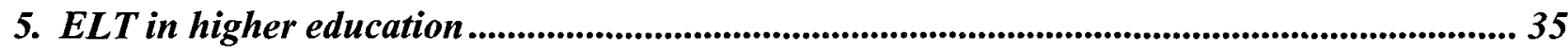

6. The Libyan Study Abroad Scholarship Programme .................................................... 37

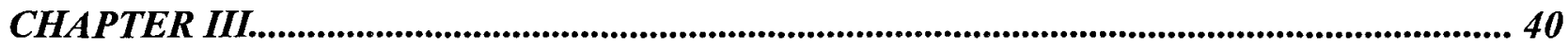

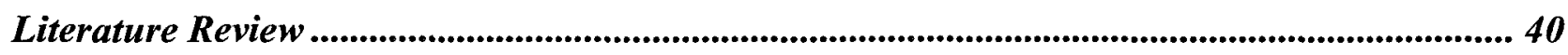

1) Educational Innovation............................................................................................42

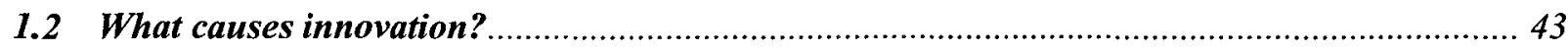

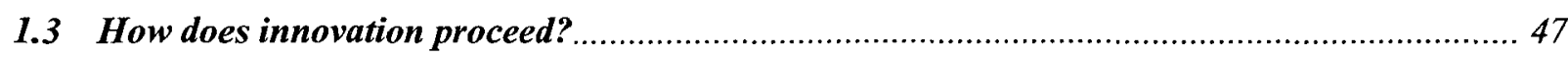

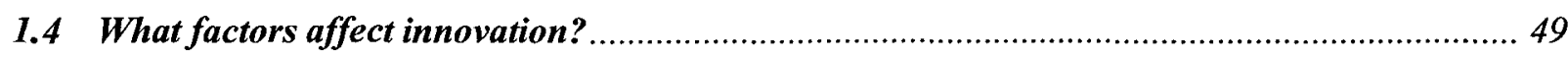

1.5 What is the role of the teacher in bringing about innovation? .......................................... 56

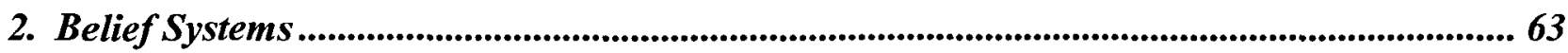

2.1 What are beliefs and why is it important to study the belief systems? ................................. 63

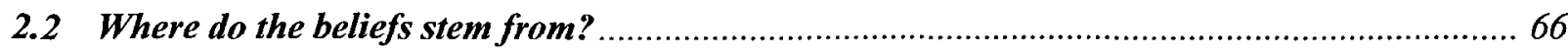

2.3 The relationship between teachers' belief, innovation and classroom practices .................... 68

3. Educational Programmes and classroom practices ........................................................... 71 
METHODOLOGY

1. Selecting a research approach ............................................................................................... 77

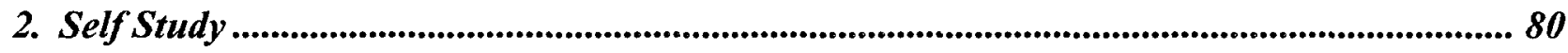

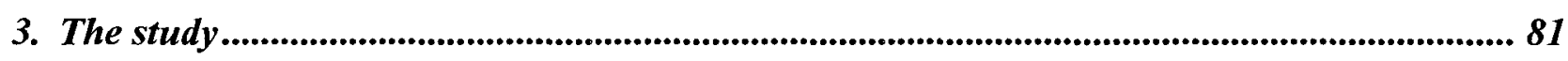

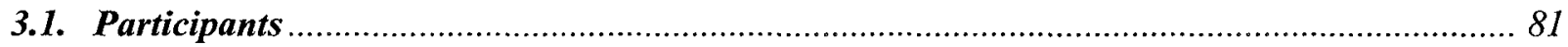

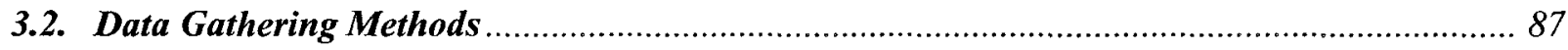

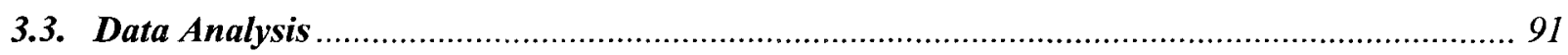

Chapter V

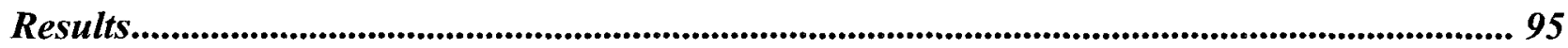

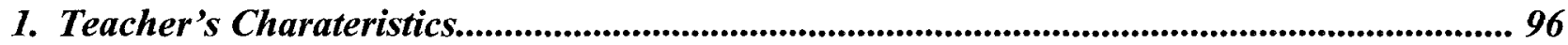

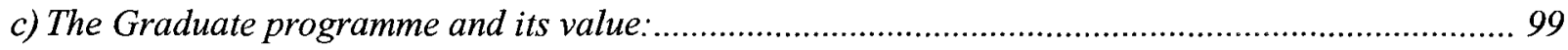

2. Significant concepts within graduate studies and how they affected teachers' beliefs and current practices.......................................................................................................................... 101

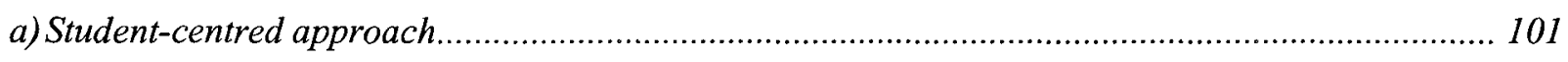

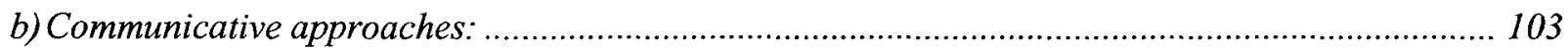

c) The effects of these experienced concepts on the two teachers beliefs system ............................. 104

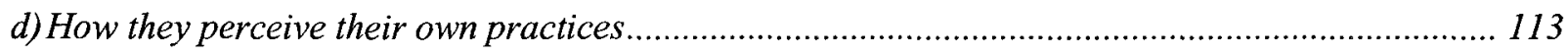

3. Implementing innovative practices and obstacles that surfaced ...................................... 116

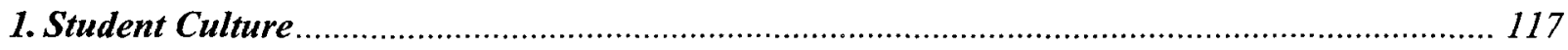

- Students' levels :............................................................................................................. 118

- Students disinterest in the whole learning concept: ........................................................... 120

2. The dominant Libyan educational/earning culture .......................................................... 121

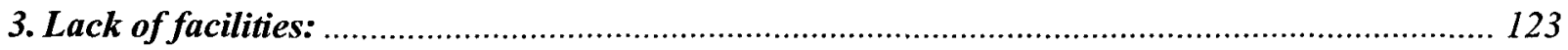

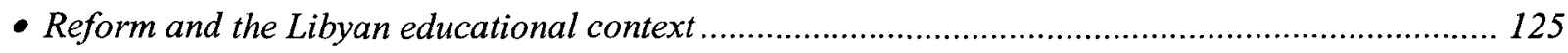

4. Graduate studies and how it informed teaching practices...................................................... 127

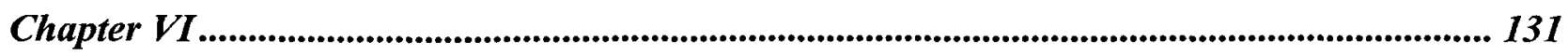




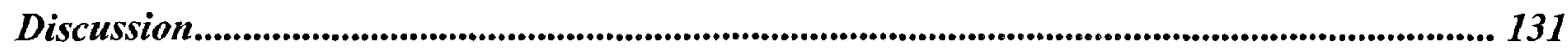

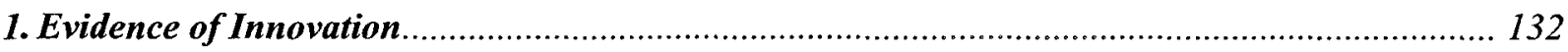

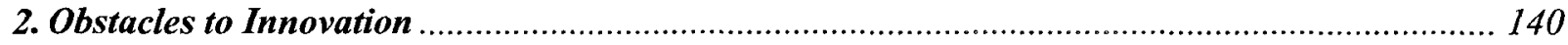

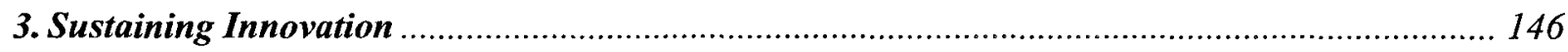

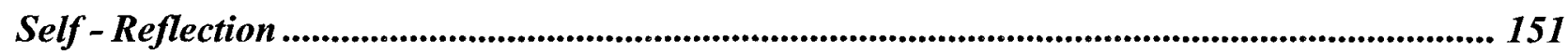

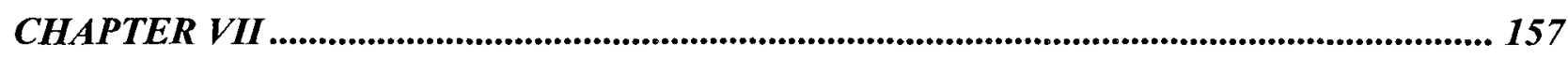

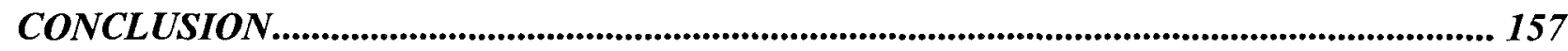

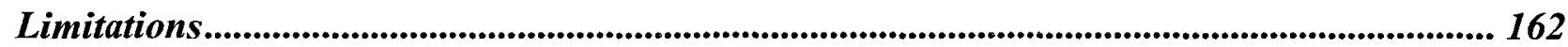

Implications and future research............................................................................................................. 164

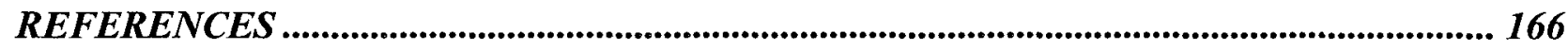

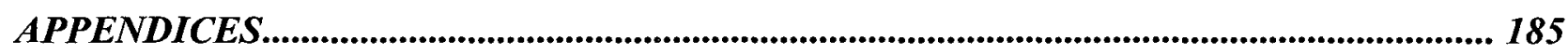

Appendix I: Ethics Approval Form ...................................................................................................... 185

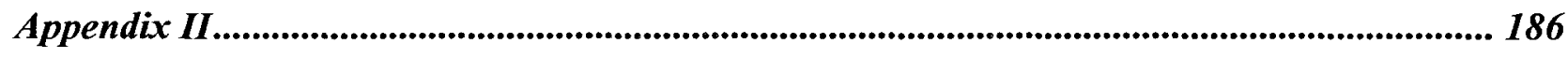

Questionnaire ................................................................................................................................................... 186

Appendix III .......................................................................................................................................... 194

Interview Questions........................................................................................................................................... 194

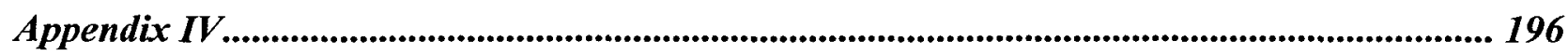

Interview Transcripts .................................................................................................................................... 196

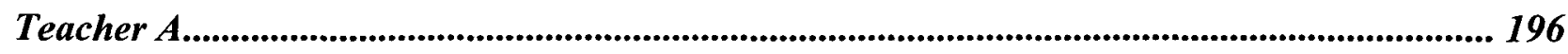

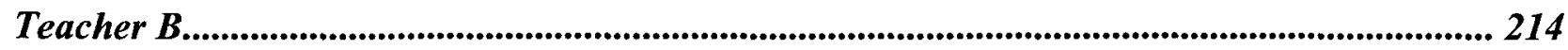




\section{LIST OF FIGURES}

\begin{tabular}{|l|l|c|}
\hline Figure \# & \multicolumn{1}{|c|}{ Title } & Page \# \\
Figure 1 & A Map of Libya & 11 \\
Figure 2 & Hypothesised theoretical model of factors affecting teachers' implementation & 53 \\
Figure 3 & Elements of a professional development system & 73 \\
Figure 4 & The concept map of Teachers A and B & 139 \\
Figure 5 & Cycle for implementing and sustaining innovation & 150 \\
Figure 6 & My concept map of professional success prior to graduate studies & 153 \\
Figure 7 & My concept map of professional success after graduate studies & 155 \\
\hline
\end{tabular}

\section{LIST OF TABLES}

\begin{tabular}{|l|l|c|}
\hline Table \# & \multicolumn{1}{|c|}{ Title } & Page \# \\
Table 1 & Basic and Intermediate education: Student/Teacher ratio & 21 \\
Table 2 & Number of students in Libyan higher education institutions in 2005 & 22 \\
Table 3 & Development of domestic higher education, 1972-2005 & 22 \\
Table 4 & Courses taken at Libyan universities for a Bachelor of Arts in English & 36 \\
Table 5 & Development of Libyan higher education students overseas, 1970-2005 & 38 \\
Table 6 & Number of students in English speaking higher education institutions abroad & 39 \\
& from 2005-2011 & 85 \\
\hline
\end{tabular}




\section{CHAPTER I}

As an individual passes from one situation to another, his world, his environment, expands or contracts. He does not find himself living in another world but in a different part or aspect of one and the same world. What he has learned in the way of knowledge and skill in one situation becomes an instrument of understanding and dealing effectively with the situations which follow (Dewey, 1938, p. 44).

\section{Introduction}

Thousands of teachers have taken part (and continue to take part) in the Libyan Study Abroad Scholarship Programme with the intention of improving their professional practice. Upon the completion of their degrees and return to their classrooms, are they prepared and set to employ innovative practices, novel curriculum material, and new subject matter knowledge in unique ways to develop and enhance their students' learning?

From an educational perspective the Libyan Study Abroad Scholarship Programme may be perceived as a teacher development or enhancement programme. The fact that so many teachers have been involved in the Study Abroad Scholarship Programme may suggest that teachers are anxious about the quality of their classroom rituals and interested in acquiring innovative teaching approaches that may improve the quality of their students' learning. In addition, the 
increase in financial support from the Libyan government highlights the fact that change is a desired objective for the Libyan nation as well as the Libyan teachers.

Knowing that the objective of the Libyan Study Abroad Scholarship Programme is to develop "the capacity of Libyan citizens to address the needs of Libyan public institutions, academia and Libyan society as a whole through the pursuit of graduate and post-graduate studies", and being an English teacher currently participating in the Libyan Study Abroad Scholarship Programme, has sparked my interest in investigating the implications of such a programme. I am interested in knowing how this scholarship programme will impact future classroom practices on returning university-level English teachers. I am also interested in exploring and examining teachers' accounts of change in their classroom practices.

It is important to note that this study took place just prior to the political breakout of the February $17^{\text {th }}$ Revolution (2011). It seems as a snapshot, like a snapshot in a photo album of Libya's education system prior to the 2011 Revolution. Education will be even more important in the future rebuilding of Libya, but it is impossible for me to speculate on that future within this thesis.

Extensive research has taken place with regards to whether or not teachers sustain change in their classroom practices after undergoing a teacher enhancement programme. However, research has seldom been capable of verifying maintained changes in classroom approaches amongst those teachers who have participated in enhancement programmes (Briscoe, 1991). In

\footnotetext{
${ }^{1}$ Libyan-North American Scholarship program http://www.cbie.ca/data/libya/Home/default.htm
} 
fact, Tikunoff and Ward (1983) argue that change in teachers' classroom practices have not been persistent because teachers have been regarded as consumers and not implementers.

As this study is focussing on English language instruction, it is argued that English language teaching is perceived both as a profession and as an educational specialisation, which involves specific knowledge that is acquired by means of academic study and applied experience. Early literature on teacher training stated that although academic programmes that focus on teacher education can be interesting, they do not inform teachers' classroom practices (Hargreaves, 1989). It has been proposed that teachers who enrol in such academic programmes either ignore or forget the common characteristics of their academic studies when they start to teach in the classroom. In this study, I hope to either support or refute the above notion that teachers do not sustain new practices after participating in either teacher development or academic programmes.

Current research has emphasized that valued teacher qualifications such as certification status and degree (including teachers with master's degrees) in the field are considerably and definitely correlated with established and effective classroom practices and teaching (Darling-Hammond, 2000). Along the same lines, Fox (2008), drawing on the work of Woods (1996), argued that EFL teachers' beliefs, assumptions and knowledge or "BAK" are influenced by their graduate studies (Master's degree). Fox further emphasized that EFL teacher' classroom practices are closely related to what teachers have learned from graduate studies. Fox considered teacher development as "an important contributing factor in change" (2005, p. 270), and her (2008) study further added that there should be more research into the area of how graduate studies informs classroom practices of a teacher. 
Another important factor in change is curriculum, which can be defined as layered, dynamic, and multidimensional activity occurring within contexts of situation and culture (Halliday, 2001) and sensitive to time, person and place (Fox, 2011, personal communication); “...curriculum itself may be viewed as a kind of rhetorical accomplishment, and curricular renewal may be observed in changes in the ways a community speaks about what it does and engages in doing it" (Fox, 2009, p. 27). However, change in curricula does not always entail change in teacher practice. It is argued by Freeman and Richards (1996) and Woods (1996) that there is a need to examine teacher practices and beliefs because teachers are not transparent individuals who accomplish curriculum policies and objectives as given by their administrators. Rather, they are more or less entities who filter, absorb, and employ the curriculum policy based on their own beliefs and educational context. Within the domain of curriculum policy, any form of innovative implementation in a classroom ought to be assisted within the teacher's own teaching philosophy. More understanding of how a group of teachers in a specific educational culture or context may inform innovation in curriculum policy that might be possible in an educational culture is needed (Breen, Hird, Milton, Oliver \& Thwaite, 2001).

This study examined teachers' accounts of the impact of the Libyan Study Abroad Scholarship Programme; I believe that reflections on the impact of study abroad on teaching practices may play a role in supporting more effective teaching, and reflection is crucial for teacher learning process.

From the literature and work of Dewey that centred on the nature of thinking, problem solving, democracy, and educative development, an idea of teaching emerges that blends the 
practice of reflection with the practice of education (Dinkelman, 2003). Dewey (1916) stated that "[ $[$ ] he sole direct path to enduring improvement of methods of instruction and learning consists in centring on the conditions which exact, promote, and test thinking. Thinking is the method of intelligent learning" (p. 153).

In addition, opportunities to reflect about experience may mediate and promote development and progress (Kolb, 1984). Along the same lines, Olson (1982) argues that we "need to learn more about the theories teachers have about their work, and to learn the language teachers use to describe and explain their actions. Such knowledge can then become the starting point for effective curriculum renewal" (p.24). Thus, it could be argued that education is a paradigm integrated and combined with the concept of reflection.

In response to Fox (2008), Woods (1996), Olson (1982) and Breen et al (2001), I examined the accounts of the impact of the Libyan Study Abroad Scholarship Programme on three returning university-level English teachers' classroom practices. I am interested in examining the teachers' accounts of changes (if any) in their approaches to teaching. I aim to examine whether or not university level English teachers' accounts of their classroom practices and perceptions of teaching were informed by their graduate studies. I will also be investigating whether or not these graduates believe they are able to implement what they have acquired from studying abroad in their Libyan classrooms. If not, what is obstructing them?

This thesis addressed the following main question:

1. What is the impact of the Libyan Study Abroad Scholarship Programme on returning university level English teachers? 
This question addressed by looking at the following:

1. The accounts of changes in approaches to teaching of returning university level English teachers'

2. The changes (if any) and how they were informed by graduate studies

3. Whether or not these graduates are able to implement what they have acquired from studying abroad to their Libyan classrooms.

\section{Organisation}

This thesis is divided into seven chapters. Chapter Two examines the historical background of Libya, and provides a description of the evolution of the Libyan educational system and the way it functions. It also presents the characteristics of the educational and classroom culture, the historical context for the emergence of English language teaching (ELT) in Libya and an overview of the Libyan Study Abroad Scholarship Programme. Chapter Three is a theoretical review of the educational literature with regards to innovation, teacher beliefs and teacher enhancement programmes. Chapter Four explains the methodology employed in this study with a description of the participants, the instruments and procedures of data collection, and the analysis of the data. Chapter Five presents the findings of the study that are discussed in Chapter Six, the findings revealed that programmes for professional development( such as the Libyan Study Abroad Scholarship Programme) do have an impact on teachers and their classroom practices.. The final chapter (Seven) of this thesis concludes the whole study with some implications for curriculum innovation, teacher enhancement programmes, and for language classroom research. 


\section{CHAPTER II}

It is necessary at the outset of the thesis to shed some light on the macro context of this study. This chapter sets the stage for the subsequent chapters. A brief description of the historical background of Libya, the Libyan educational system and the way it functions, the characteristics of the educational and classroom culture, a description of the English language situation teaching in Libya, and the Libyan Study Abroad Scholarship Programme up until the outbreak of the Febuary 17 revolution is provided below.

\section{Historical Background}

\section{Figure 1}

\section{A map of Libya}

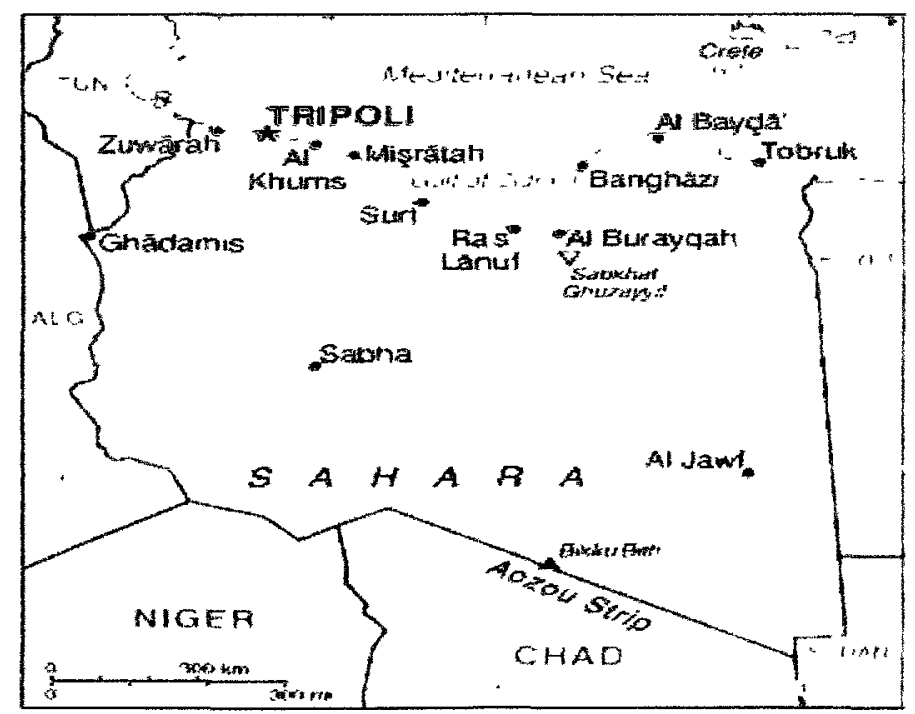


Libya has an area of 1.7 million .sq. km, and is located on the North African coast of the Mediterranean Sea. This vast territory is as large as France, Spain, Italy and Germany put together, and $90 \%$ is desert land (Dughri, 1980). It has a population of approximately $6,276,632^{2}$ with the capital Tripoli estimated at 1.7 million (Maghur, 2010).

From about 700 B.C., Libya was subject to wave after wave of invasion. In 1551 Turkey entered Libya and it became part of its growing Ottoman empire. The Turkish conquest prevailed until the 1911 Italian invasion. The Turkish control over Libya had a long-term impeding effect on the country, in terms of social, economical, educational and political development. Libya was also remote from other European countries that were emerging during the period of the Turkish invasion (Dughri, 1980).

The Italians began their occupation in 1911, and were met with violent resistance from the Libyan population. The Italian government left Libya with a legacy of buildings, roads, ports and other public equipment and mechanisms (Dughri, 1980). However, it must be acknowledged that Libya had paid dearly for the cost of what the Italians left behind. Libyans were forced to leave their farms, deprived of political rights, left without economic benefits, and not considered in terms of any social reforms. In addition, the Italian colonisation did not pay attention to education. It did not aim to develop and promote education like the French did in Algeria. No Libyan received education or training; consequently, there were shortages of teachers, skilled workers, technicians and administrators (Country Studies, 1987).

2 This is what is documented in the literature that I found; however, current statistics after the February $17^{\text {th }}$ revolution reveal that the estimated population is at least 10 million. 
In 1943, Libya was occupied by the Allied forces. Tripolitania ${ }^{3}$ and Cyrenaica ${ }^{4}$ were governed by the British Empire and Fezzan ${ }^{5}$ by the French. The Italians were defeated in 1945 at Tobruk $^{6}$ and Libya's relationship with Britain became stronger. Libya was administrated by Britain from 1945 to 1952 (for seven years). At the same time as Libyan-British affairs improved, new business, trade and industry were generated between the two nations. As a result, English increasingly became the language of business (Blackwell, 2003). This Libyan-British relationship became even more established in 1953, after Libya gained full independence in 1951. An Anglo-Libyan treaty took place at that time; this treaty implied that the British would be given land in return for aid (UK Embassy, 2005).

After Libya's independence, oil investigation started in 1955 and oil was first exported in 1961. The oil discovery transformed Libya from being one of the poorest countries in the world to one of the most prosperous. However, the oil discovery did not solve all of the problems that Libya encountered during the sixties. As Libya grew wealthier there was a growing resentment within the nation itself. On the $1^{\text {st }}$ of September 1969, a revolution took place led by Colonel Muammar Al-Qadhafi. This regime was in place forty two years later (1969-2011). The Libyan 1969 revolution (known as Al-Fatah revolution) made changes to Libyan society; through the

3 A historic region of western Libya, centered around the coastal city of Tripoli

$4 \quad$ A historic region of north-eastern part of modern Libya

5 The Fezzan region touches the Libyan coastal zone in the north, the Libyan Desert in the east, the Tibesti massif of Chad to the south, and the Hoggar massif along with the Grand Erg Oriental of Algeria to the west.

6 A city located on the eastern Mediterranean coast of Libya and on the borders of Egypt. 
implementation of major political, social and economic reforms:“[p]olitical reform was at the heart of all changes" (Maghur, 2010, p.1).

Al-Fatah ${ }^{7}$ revolution was established on three underlying ideologies: socialism, freedom and unity. In the early seventies, Libya announced a cultural revolution. "Other countries, besides Arab-Islamic ones, were considered as imported cultures which were to be rejected, even opposed" (Maghur, 2010, p.5). By 1970, the Libyan government declared that both the American and British army bases were to be closed. Gradually by 1971, all libraries and any cultural association administrated by any foreign government were also closed. Foreign books, magazines and music were prohibited and private foreign schools were closed as well.

From 1984-1999 Libyan-British and Libyan-American relations deteriorated. Three major incidents in the Libyan history affected the Libyan political status with other countries around the world. These were: (1) the killing of the British police woman Yvonne Fletcher ${ }^{8}$ in April 1984; (2) the bombing in West Berlin ${ }^{9}$; and (3) the Lockerbie ${ }^{10}$ incident in 1988. As a result, the US and UN imposed sanctions on Libya in 1986 and 1992 respectively. Due to the US sanctions 1986-2004 and the UN trade ban from 1992-1999, Libya was isolated from the rest of the world

7 The noun Al-Fatah has not been modified by a definite article 'the' because in the Arabic language this noun has already been pre-modified by ' $A l$ '.

8 She was killed as she was on duty during a protest by Libyan opposition outside the Libyan embassy in London.

9 A bombing at a nightclub visited by the American military employees and the US stroke back with an air raid on Tripoli in 1986.

10 Pan Am Flight 103 was bombed over Scotland. 
and this isolation affected Libya dramatically. Resulting sanctions and trade embargoes caused import costs to increase, inflation in Libya's daily living expenses, and subjected Libyans to a declining standard of living (Country Profile, 2005).

It was not until 1999 that the UN suspended the sanctions off Libya after handing over the two suspects of the Lockerbie bombing. In 2003 , the eleven-year sanction was completely lifted. Accordingly, Libya re-emerged in the international political context, established new political, commercial, and business links with other parts of the world (Country Profile, 2005). This study is situated within this period of Libyan history just before the outbreak of the political conflict in February 2011.

Having briefly reviewed Libya's political and historical background, it is essential to shed some light on the evolution of Libya's educational system and how it was affected by the country's historical background and political status.

\section{The evolution of the Libyan Education}

\subsection{Development of education before independence}

Unfortunately, the history of education in Libya is not adequately documented and not much information on the development of Libya's educational institutions exists. This short history is based on the limited documentation available on this topic. 
The narration of education during the Islamic period (the medieval times) followed the Muslim education system as in Bagdad, Cairo and Tunisia. The Koran was the foundation stone of Islamic education. In Libya, the Islamic schools came to be known as Kuttabs ${ }^{I I}$. The Kuttab was to be attended by males only, up until the age of fifteen. After completing school, they would leave to take on practical work experience and training on their fathers' farms or engage in other technical work (Dughri, 1980).

In 1939, during the Italian colonisation, there were only 6,736 students enrolled in 64 primary schools in whole nation. Libyans were not entitled to any education beyond that of primary education, because they were considered inherently inferior to Italians. However, education started to improve somewhat during the Allied occupation. In October 1943, the British government opened new schools. The Libyan education system at that time faced a lack of qualified teachers, (there were only 170 teachers in Libya in 1943 according to Dughri 1980), and thus any large scale of educational improvement during those years was hindered. Throughout those years the Palestinian curriculum was used in Tripolitania and Egyptian in Cyrenaica. However, in 1949, Tripolitania's system adopted the Egyptian curriculum as well. It was not until 1951 after Libya's independence that a Libyan curriculum was implemented in the educational system for the first time (Dughri, 1980).

In Kuttab, the location would be a mosque, the student (only boys) would memorise passages from the Quran and write them on his wooden board. After the passage has been memorised the student would erase it and learn the subsequent passage. This would be an ongoing process until the whole Koran was learnt off by heart. 


\subsection{Development of education since independence (1951-2011)}

At the time of independence in 1951 , fewer than ten percent of the adult population had undergone education in Libya. Thus, the newly independent Libyan government began by focussing on fundamentals for an appropriate school system and "opened the doors to education for a large number of students in the shortest possible time" (Dughri, 1980, p.35). In 1951, the Libyan government recognised that education should be the right for every Libyan, and education became both compulsory (up until secondary level) and free. Education at that time was seen as a critical factor that would contribute to both social and economic development of the country. In 1954 (three years after independence), the authorised census confirmed that 81.1\% of the Libyan population was illiterate (Otman \& Karlberg, 2007). However, by 1969, $50 \%$ of the children from six to eleven years of age were enrolled in primary schools. The 1969 revolution, and the establishment of modern Libya ${ }^{12}$, brought with it "changes" (although few) to the educational system. Primary schools increased in number and the importance of education was emphasised even more. By 2004, the figure for illiteracy had fallen dramatically to 12.6 per cent (Otman \& Karlberg, 2007).

In Economic and Social Achievements, which is an official handbook published by the Libyan Secretariat of Planning encompassing the government's rationales between 1970-1977,

${ }^{12}$ The Great Arab Popular Socialist Libyan Jamahiriya was the official name of Libya after the AlFata revolution, although in this thesis, it will be referred to simply as "Libya" 
education and vocational training principles ${ }^{13}$ are summarised as follows: "[t]he education and training policies are directed towards the objectives of raising a generation which is able to shoulder the burden of responsibility"... and "assume leadership of a dynamic society dedicated to continual social change" (Cited in Otman \& Karlberg, 2007, p. 99). These guiding principles are coded into a range of programmes of "quantitative and qualitative nature" that represent the following constituents:

- The achievement of full compulsory education up to the preparatory or junior high level.

- Correcting the educational structure.

- Diversifying and promoting technical education so as to meet the needs of the economic and social development plans for manpower.

- Promoting higher education in such a way as to cope with scientific and technological progress. (Cited in Otman \& Karlberg, 2007, p. 99)

The Libyan educational system is highly centralised. The General People's Committee for education, mainly known as the Ministry of Education, is the highest administrative power in Libya with regards to education. Abou Jaafar (2003) asserts that the responsibility of the

${ }^{13}$ These rules are rather ironic; these are just words on paper. There is evidence of a considerable gap between rhetoric and reality, given the conflict that began in February 2011. 
Ministry of Education is to "set education and training plans, provide teachers, trainers... to meet the training needs of different sectors and organize and execute programmes in schools" (p. 16).

The Secretary of this committee is the person in charge of the educational system. This implies he (with the help of the committee members) is in charge of developing the nation's educational policy (Mohamed, 1987). In addition, the planning of the syllabus and the choice of textbook resources are typically accomplished by the expert inspectorate. Every group chooses the syllabus and textbooks for their assigned subject. The professional inspector usually has control on the decision making process, or in other words, guiding choices in one way or another. Additionally, the syllabus in Libya is characterised by its stability. When something is approved, it is expected to continue to function for an extended period of time. The system is homogeneous throughout Libya; similar arrangements and similar requirements in terms of curriculum and textbooks are implemented in all schools. Not only are the same textbooks used, but also the same pedagogy are adopted throughout the country (Mohamed, 1987).

Public school education in Libya is currently organised in an eleven year basis. The first level is primary education that runs for six years (form age 6-11). The subsequent level is preparatory education and it extends for three years (from age 12-14). The final level before university is secondary education, which leads to specialised colleges. This level lasts for three to four years depending on the discipline (from age 15-19). Education is compulsory in Libya up until the preparatory level (ninth grade). Otman and Karlberg (2007), cite the objectives of basic education in Libya, i.e. the years from six to fifteen years of age as: 
The fundamental basis for the education of the young generation aged 6 to 15. It aims at providing the pupil with necessary principles, behaviour, knowledge, expertise and practical skills. It deals with theoretical and practical issues, creates a link between youths and their different environments, and strengthens the relationship between the knowledge acquired in the school and the pupil's environment. This environment comprises knowledge, research, studies, and activities in all educational subjects. Basic education contributes also to integrate the school in its environment and provide the pupil with the chance of knowing his abilities and capacities and choosing his/her [future] path. (p. 101)

Higher education in Libya is comprised of universities, higher institutions and technical centres. Normal full-time studies at higher intuitions and technical centres run for three years, whereas; university study extends for four to six years.

Education is free in Libya, including university and teacher training. In fact, in the eighties the government even provided free boarding services for poor students and living allowances for them to join higher education (Dughri, 1980). Table 1 below represents the development of Libya's education after the 1969 revolution and student/teacher ratio in Libya: 


\section{Table 1}

\section{Basic $^{14}$ and Intermediate ${ }^{15}$ education: Student/Teacher ratio}

\begin{tabular}{lllllll}
\hline \hline Period & \multicolumn{3}{l}{ Basic Education } & \multicolumn{5}{c}{ Intermediate Education } \\
\cline { 2 - 7 } & $\begin{array}{l}\text { No. of } \\
\text { pupils }\end{array}$ & $\begin{array}{l}\text { No. Of } \\
\text { teachers }\end{array}$ & $\begin{array}{l}\text { Pupil/teacher } \\
\text { ratio }\end{array}$ & $\begin{array}{l}\text { No. of } \\
\text { pupils }\end{array}$ & $\begin{array}{l}\text { No. of } \\
\text { Teachers }\end{array}$ & $\begin{array}{l}\text { Pupil/teacher } \\
\text { ratio }\end{array}$ \\
\cline { 2 - 7 } $1969 / 70$ & 347100 & 13884 & 25 & 15300 & 1663 & 9.2 \\
$1975 / 76$ & 679500 & 32357 & 21 & 43300 & 4330 & 10.0 \\
$1979 / 80$ & 875000 & 54688 & 16 & 89500 & 7498 & 12.0 \\
$1985 / 86$ & 1045200 & 69680 & 15 & 148700 & 9294 & 16.0 \\
$1994 / 95$ & 1364900 & 74995 & 18.2 & 441300 & 35589 & 12.4 \\
$2000 / 01$ & 1202900 & 117931 & 10.2 & 380200 & 64441 & 5.9 \\
\hline
\end{tabular}

Source: Libyan National Authority for information and documentation, $2005^{16}$.

Table 1 indicates that the ratio decreased from 25 and 9.2 for basic and intermediate education in 1969 to 10.2 and 5.9 respectively in 2001 . It also indicates that the government had accomplished high levels of literacy amongst the younger population. These statistics provide evidence of an excellent level of performance both nationally and globally. The UNESCO, EFA Global Monitoring Report, 2005 stated that Libya was at the top of the scale. As for higher education, the tables below show how the number of students achieving tertiary, graduate and post-graduate education has increased.

\footnotetext{
14 Primary level education

15 Preparatory and Secondary schooling

16 It was difficult to find statistics for 2005-2010
} 
Table 2

Number of students in Libyan higher education

institutions in 2005

\begin{tabular}{ll}
\hline \hline & Number of Students \\
\hline Universities & 246,000 \\
Higher institutions & 3,286 \\
Higher medical institutes & 5,260 \\
Total & 254,546 \\
\hline \hline
\end{tabular}

Source: Libyan Ministry of Higher Education, 2006.

Table 3

Development of domestic higher education, 1972-2005

\begin{tabular}{ll}
\hline \hline $\begin{array}{l}\text { Students Masters/PhD } \\
\text { qualifications }\end{array}$ & Number of Students \\
\hline $1972-1973$ & Less than 80 \\
$1994-1995$ & 2350 \\
$1998-1999$ & 5627 \\
$2004-2005$ & 20000 \\
\hline
\end{tabular}

Source: Libyan Ministry of Higher Education, 2006

In addition, there is has been little if any difference between genders in the Libyan education system, in contrast with the days before independence where only boys had access to education (narrowly defined) in the Kuttab.

\section{The characteristics of the educational and classroom culture}

It is generally accepted that the educational norms and practices in a society are greatly influenced by the socio-cultural dynamics of the society itself (Coleman, 1996, Tudor, 2001). 
The general consensus is that the 'culture of learning' may be an influential factor with regards to what happens inside a language classroom and what is determined to be a successful language learning environment (Cortazzi and Jin, 1997).

In this study, the "culture of learning" implies that:

Behavior in language classrooms is set within taken-for-granted frameworks of expectations, attitudes, values and beliefs about what constitutes good learning, about how to teach or learn, whether and how to ask questions, what textbooks are for, and how language teaching relates to broader issues of the nature and purpose of education... Any particular culture of learning will have its roots in the educational, and, more broadly, cultural traditions of the community or society in which it is located. (Cortazzi and Jin, 1997, p. 169)

It is further argued by Cortazzi and Jin (1997) that learning is inborn in social interaction and originates from cultural norms, morals and expectations that spring from the learners' instant community or from the overall society itself. Not only does society influence the "culture of learning", but also the socio-economic circumstances of a particular culture play a role. It is believed that teachers and learners in a classroom may be unconscious of such culture and how it may shape the classroom practices and pedagogy. Thus, the 'culture of learning' may be perceived as "part of a hidden curriculum" (Cortazzi and Jin, 1997, p.169). 
Senior (2006) argues similarly that both teachers and students function within a sociocultural setting and their beliefs and expectations are influenced by the norms of that specific milieu. In addition, both students and teachers bring with them to any classroom a fixed set of beliefs and expectations about the classroom etiquettes, and what is to be taught and how it should be taught.

One of the main features of the Libyan educational culture is that Libyan students often take on the role of passive learners, i.e., to sit, listen and memorise the information passed on by the teacher. In Libya, classes are large by number; they are arranged in a traditional model with students listening as the teacher explains concepts and respond only to direct questioning (Aldabbus, 2008). It is very important to note here that Table 3 which indicates that the number of teachers is much higher than those of students is rather rhetorical; the reality indicates that there are more students (40-50 students in every class) than teachers within the Libyan educational context, knowing that for every full-time teacher there are two full-time supply teachers at least.

Classrooms are normally teacher-centred; teachers are perceived to be knowledgeable and have full command and competence of the subject matter being delivered to the students. It would be considered impolite to interrupt a teacher while he/she was delivering a class, or even to argue about the validity of any given information. Therefore, students show respect to their teacher by being silent. Students must accept what they are told and do as they are told in order to obtain their teachers' knowledge. They have very little knowledge of their own to add to the education process, and no right to question the legitimacy of what they are learning: "[ $t]$ he result 
of accepting such beliefs about teacher authority is an unacceptably passive and unequal role in learning for students, who are left with very limited opportunities for creative expression in the classroom" (O'Dwyer, 2006, p.3). Looking at this context from a student-centred learning perspective, students have few if any opportunities to become analytical, critical, or autonomous learners.

Because of the traditional role that a teacher has to inhabit in a Libyan classroom, the English language teaching (ELT) education system in Libya mainly stresses and concentrates on developing teachers' knowledge of the language and not on how to teach it. The focus is purely on raising the awareness of the semantic, syntactic and phonological knowledge of English. It is argued that by augmenting teachers' knowledge of English, they will be fully acquainted with and competent in it, and thus, would be in a superior position for delivering the acquired knowledge to language learners. In addition, the pressure to give only accurate and correct information may push teachers to develop only their linguistic knowledge rather than their classroom practices. It might even prevent teachers from implementing new approaches to language teaching, in order to not lose face and threaten their sense of security (Orafi, 2008).

Libya's classroom instruction (especially ELT) is test-driven; it is designed to train learners for high stakes exams and university access tests. These exams test rote memorisation of textbook content. ELT exams test rote memorisation of vocabulary and explicit grammar rules, and little attention is paid to listening and speaking skills (Al-Buseifl, 2003). Therefore, the Libyan student-teacher educational culture expects the teacher to teach in order to fully prepare students for exams, and therefore only teach what will be on the exam, i.e., "teach to the test". 
Thus, memorisation of facts and information holds prominence within the Libyan educational culture. In 2004, the Ministry of Education issued a report that highlights the dominance of memorisation skills within the Libyan education system and how it affects and impedes innovation and reform:

Education in Libya has a traditional character in methods and schemes. It is interested to supply students with information, but it does not care much for scientific thinking methods. Undoubtedly, the assurance on information learning by heart, for which the learner is awarded with high grades, is one of the obstacles of innovative thinking, and preparing students to knowledge production. (Libyan National Commission for Education, 2004, p. 65)

There is also a sustained belief that anybody can accomplish success in language learning and acquire an additional language just by conscientious work. Nevertheless, the interpretation of hard work is generally established by memorization and practice, even at university level.

Thus, it may be argued that the Libyan culture perceives education as a process of conveying information. A teacher's inability to answer a student's question may be perceived as an inadequacy of the teacher. Not only are teachers considered to be the main source of information, but also textbooks, which are also perceived as a fundamental component of the Libyan educational culture. "[T]extbooks represent the syllabus and dictate what should be taught in the classrooms" and [t]eachers teach according to textbooks...and achievement tests are 
designed based on the content of textbook" (Wang, 2006, p. 50). It can be argued here that within the Libyan educational context "textbooks used in classrooms are the curriculum" (Richards, 1998, p. 125). Students are given textbooks for all subject matters, and are expected to both comprehend and memorise what is articulated in these textbooks to pass exams.

The above classroom norms and dynamics may have been shaped by other dominating factors customary in the Libyan culture. Deeb and Deeb (1982), point out that prevailing Libyan cultural customs are based on Islamic moralities and regulation, and thus Libya can be viewed as a substantially conservative Islamic society. It is common in Libya for young children to be nurtured to respect their elders, to listen conscientiously, not to argue with elders, and not to participate in adult family discussions. If a child does so, he or she will be disciplined by their parents. In Libya, arguing is not just seen as impolite when it involves young children, but also amongst adults themselves. It is seen as impolite to disagree with someone's point of view. It is more important to save face in a conversation than to argue. In Islamic culture, as in Libyan culture, males and females who are not from the same family tree are prohibited from having close relationships (Orafi, 2008). Therefore, having mixed group work a prominent component, within a communicative classroom may be seen as a violation of Libyan socio-cultural norms.

The educational learning setting within a Libyan classroom is competitive rather than cooperative. A number of studies show that cooperative work and learning result in "higher individual achievement than do competitive or individualistic efforts" when properly implemented (Johnson, Johnson and Stanne, 2000, p. 13). Educators employ cooperative learning throughout North America, Europe, and other parts of the world. In accordance with 
Johnson et al (2000), research has established that a cooperative style of learning may promote:

(a) higher-level reasoning; (b) retention; (c) time on task; (d) transfer of learning, (e) achievement; motivation; ( $\mathrm{f}$ ) intrinsic motivation; ( $\mathrm{g}$ ) social and cognitive development, and moral reasoning. Despite the above, Libyan students tend to greatly compete with one another to achieve high passing marks. High grades are significantly regarded by the Libyan society. Libyan parents all wish to get good teachers for their offspring; they push them to study hard to pass the two notational high stakes exams.

In summary, it may be argued that both the religious and socio-cultural norms such as respect for elders, the avoidance of interruptions of or arguments with elders of the Libyan culture may have informed and justified traditional teacher-centred Libyan classroom practices. Having reviewed the evolution of the Libyan educational system and the characteristics of the Libyan educational culture, the subsequent section presents ELT in Libya.

\section{English language teaching in Libya}

The teaching of English in Libya dates back to the mid 1940s, after the end of World War II. As soon as the British began to govern the northern part of the country (Tripolitania and Cyrenaica), intensive English language programmes were organised, for whoever was interested in learning and acquiring the language. The initial English language series implemented in Libya was Basic Way to English by K.C. Odgen (Hashim, 1997). The books were based on the philosophy of using frequent vocabulary and facilitating the language learners' control of 
language structures within the scope of 850 words. The dominating teaching approach of that time was grammar-based. Memorisation of facts, vocabulary and grammatical structures were the main focus of their L2 instruction. Reading and writing were also emphasised as they were regarded as the basic skills of language (Hashim, 1997). In these classes, language development was pictured as the formation of habits and memorisation of structures. The focus was on the form, (or the ability to produce a grammatical response), rather than the meaning or general communicative ability of the student. Thus, this ELT pedagogy was aligned with traditional educational cultures in Libya that were discussed in the previous section.

From 1954, after the Anglo-Libyan treaty, English continued to be taught from grade five (the year before the end of primary level education), until the end of secondary education (grade 9). In the sixties, the Libyan education officials along with the English language teachers and inspectors stressed the need for a novel English language programme. They felt a need for a programme that would change the whole course of English language pedagogy in Libya. Consequently, this led the introduction and implementation of a new series known as English for Libya, developed by an inspector named Mustafa Gusbi. This series aimed to meet the Libyan language learners' linguistic and social needs (Hashim, 1997). This series was well established in Libya and implemented in the Libyan curriculum at the preparatory level (grade $7,8,9$ ). The objectives of teaching English in the preparatory level at that time were identified as the following:

The aim of teaching English in the preparatory level is to enable the learners, in three scholastic years, to understand spoken English and to 
speak the language fluently as well as to read and comprehend English texts of basic vocabulary and common structures and to be able to write a number of sentences on a certain subject. In this stage focus should be directed to all language skills since these are considered indivisible and integrative. A learner who cannot continue, his or her, education beyond this stage for one or another reason would find what he or she had learned of the English language could be helpful in his or her professional career. For those who would continue and went to secondary schools, would find that they had a solid background in the English language that qualify them for advanced levels in learning the language. (Cited in Hashim, 1997)

The Gusbi series was based on the audio-lingual methods of Lado $^{17}$ and was fully contextualized to the Libyan context. Names were Libyan, pictures and customs were also Libyan, and the emphasis was on spoken English ("Listen" and "Repeat"). Patterns practiced through oral-aural drills and scripted role play dialogues were the same as those in the textbooks. In order to implement this program at school level, thousands of native-speaking teachers (largely from the Peace Corps in the US) were brought to Libya to teach. There was a similar initiative for French during this period and many French speakers met the requirement for

17 A core principle behind this method is that language learning is habit formation. Drilling, repetition and over-learning are core elements of the teaching. 
service in the military by teaching French in Libyan classrooms (Fox, 2011, personal communication).

Hashim (1997) stated that later in the school year in 1970-71, the series English for Libya was revised by Mr. Gusbi together with R. John and it was entitled Further English for Libya. This series was intended to be an extension of its previous series English for Libya. It incorporated two textbooks, entitled Book 1 and Book 2, planned for the first and second year of secondary school education. However, in third year different textbooks were employed to match the student's literary and scientific specialisation ${ }^{18}$. However, after the Cultural Revolution in 1973, English was pulled back to grade 7 (the first year of Preparatory level education). Within the Cultural Revolution Act, as stated earlier on in the chapter, Al-Fatah regime closed all cultural association administrated by any foreign government and foreign language schools. Consequently, the revolutionary council revoked the contracts of all the foreign language teachers (English and French) who were forced to leave the country.

Until the mid-1980s English was still part of the school curriculum in Libya; however there was a change of policy in 1980, which reduced the predominance of foreign teachers in Libya at that time. This was accompanied by an Arabisation campaign (in response to the American air raid, and the US sanctions on Libya). Consequently, in 1986 ELT was withdrawn altogether from the Libyan educational system until 1992 (Elmabruk, 2008). Subsequently, the government banned the teaching of all foreign languages in schools, specifically English and French. School

18 The secondary level in Libya (up until 2000), as is the case in some Arab countries, is divided into two scientific and literary sections. Such division begins in the second year that is the 11 th grade. 
curricula were reorganised in favour of a renewed emphasis on scientific subjects, humanities, Arabic language and Koranic education, at the expense of English.

In 1986, regular students in grade seven had had no English language instruction. However, those who were lucky to have developed some English in spite of the policy could not improve beyond their level if they were in secondary education. Although English was banned in Basic and Intermediate education, it continued to be taught and was the medium of instruction in many tertiary-level institutions such as medicine, pharmacy, and engineering. Consequently, the gap in medium of education policy created enormous problems. Students who had enrolled in language faculties had limited linguistic competence, and in extreme cases no linguistic competence at all, and as a result students in scientific and technical faculties found their studies to be extremely challenging (Maghur, 2010).

The main long-term effect of the banning of English in Libya resulted in a whole generation of university graduates having little or no knowledge of English. Elmabruk (2008) further argues that the "consequences of this ill-advised withdrawal of English were far reaching, not just for learners, but also for teachers and inspectors alike" (p. 23). From 1986-1992, ELT teachers had to take on new jobs, and these included teaching geography, history, Arabic, and other topics. The effects were even more striking when the Libyan government re-emerged in international affairs in 1997, and began to promote foreign trade and investment. Many Libyans found themselves unable to integrate in the market due to their lack of English. Otman and Karlberg (2007) contend that the banning of English "[f]or Libya...proved to be a fundamental 
and disastrous mistake... [it] has set back Libya, in terms of educational quality, by two generations" ( p. 110).

When diplomatic relations began to improve in 1999 and with the development of Libya's relationship with the West and the suspension of the UN embargo in 1999, English resumed its position of importance in Libya as an international language. In addition, other social and economic factors have made the re-emergence of English of great importance in Libyan society. These included:

1. English is the main medium of communication within petroleum division.

2. A flood of foreign businesses have established regional offices in Libya creating a need for an English speaking staff.

3. There has been increasing growth in the tourism sector, and hence an essential need for local representatives and guides being able to communicate with holidaymakers and tour employees.

4. In job advertisements ${ }^{19}$ having English competency has become a fundamental requirement for employment for both governmental and foreign administrations.

In reaction to the above educational and market needs, the Libyan government reconsidered its ELT planning policy. As stated earlier, in 1954 English was taught from grade five, and after the reconsideration of Libya's ELT policy in 1999, a new English syllabus was implemented at the Primary education level. As of the school year 2006/07, English has been taught from grade five, like it was in 1954 but with a different pedagogical approach. With

19 Libya online job advertisement at: http://www.libyaonline.com/business/pages.php?cid=300 
regards to the educational reform, Abou Jaafar (2003) emphasised that laws and legislations have been approved in order to enhance and improve educational programs and teaching methods.

As Libya began modernisation and entered the age of globalization, it faced a set of challenges and regulations. A recent $\mathrm{BBC}$ series analysed such modernisation in the face of global trends in this way:

Governments across the world, from Chile to China, from Malta to Malaysia, have in the last few years embarked on ambitious educational reforms which will integrate English more deeply into the curriculum. English will cease to be a foreign language for many, perhaps most, of the world's citizens as it becomes repositioned as a "basic skill", to be learned by primary school children alongside other 21 st century skills in Information Technology. (Literacy Trust, 2005, cited in Otman \& Karlberg, 2007, p. 110)

The economic boom in Libya has to a great extent fuelled the demand of English. Hence, English was also booming. On the other hand, the Libyan workforce was still lacking language skills, and given the demands for English as discussed above, this dramatically affected employment opportunities. For a number of years there have been intensive English programmes taking place, such as sending Libyans for overseas courses (especially the UK), but they have not 
been able to fill in the gap of the urgent needs of the Libyan market (Maghur, 2010): "It is important to reiterate that in today's Libyan market it is English and English alone that is a passport for work" (p. 6).

\section{ELT in higher education}

Libyan university-level ELT classroom pedagogies inhabit more or less the same Libyan classroom characteristics discussed earlier on in section three of this chapter. These include teacher-centred approach, prominence of memorisation, students have few if any opportunities to become analytical, critical or autonomous learners and the teacher's role is to transmit information to the students, and the whole classroom instruction is test driven (personal communication).

In this section, I intended to give a detailed description of the undergraduate and graduate programmes at the three different universities of where the participants of this study were currently working. However, due to the current political situation (The February $17^{\text {th }}$ Revolution) in Libya that was still in place at the time of composing this thesis, it has been impossible to collect the data in this regard. By asking several friends who underwent a Bachelor of Arts in English programme at various cities in Libya, I was able to gather a picture of the most common courses at these universities. The programmes were either full-year or semester path, and it would be a four year or an eight semester programme. The following table summarises the courses that would be taken from year one to four to achieve a Bachelor of Arts in English: 


\section{Table 4}

Courses taken at Libyan universities for a Bachelor of Arts in English

\begin{tabular}{|l|l|l|l|}
\hline \multicolumn{1}{|c|}{$\mathbf{1}^{\text {st }}$ Year } & \multicolumn{1}{|c|}{$\mathbf{2}^{\text {nd }}$ Year } & \multicolumn{1}{c|}{$\mathbf{3}^{\text {rd }}$ Year } & \multicolumn{1}{c|}{$\mathbf{4}^{\text {th }}$ Year } \\
\hline Conversation & Conversation & Linguistics I & Linguistics II \\
\hline Grammar & Grammar & Phonetics II & Translation \\
\hline Comprehension & Comprehension & $\begin{array}{l}\text { Teaching } \\
\text { Methodology }\end{array}$ & Research Methodology \\
\hline Composition & Composition & Language Skills & English Literature/ Drama \\
\hline Arabic I & Phonetics I & Novels & Linguistic Skills \\
\hline Psychology & Poetry & $\begin{array}{l}\text { Academic } \\
\text { Writing }\end{array}$ & Academic Writing \\
\hline Political Culture & Political Culture & Language Skills & Arabic IV \\
\hline & Academic & $\begin{array}{l}\text { Language } \\
\text { Acquisition I }\end{array}$ & Language Acquisition II \\
\hline & Writing & Arabic III & Language Testing \\
\hline & & $\begin{array}{l}\text { Literary } \\
\text { Readings }\end{array}$ & Literature in ELT \\
\hline & & French I & French II \\
\hline
\end{tabular}

The above table indicates that such a degree will provide undergraduates with comprehensive insights into the field of English language teaching that vary from basic English language skills to complex English literary skills. 


\section{The Libyan Study Abroad Scholarship Programme}

The main aim of the Libyan Study Abroad Scholarship Programme is to "build the capacity of Libyan citizens to address the needs of the Libyan public institutions, academia and Libyan society as a whole through the pursuit of graduate and post-graduate studies." ${ }^{20}$ The role of the Ministry of Education and scientific Research as cited in the Canadian Bureau for International Education web site ${ }^{21}$ is to provide:

- Determination of rules and regulations

- Student recruitment and selection

- Sponsorship approval and documentation

- Pre-Departure Services - provide information on Libyan exit requirements and Canada/United States visa formalities

- Funding - issuing funds for programme expenditures, including travel to Canada/US, university tuition and required fees, health insurance, enrolment, living allowances, book allowances, computer allowance, settling-in allowance, conferences and seminars if applicable, travel expenses and other one-time expenses such as institutional application and notarization charges.

20 Libyan-North American Scholarship program http://www.cbie.ca/data/libya/Home/default.htm

21 http://www.cbie.ca/data/libya/Services/default.htm 
The Libyan Study Abroad Scholarship Programme dates back to the 1970's and continues to today's date. The following table highlights the number of Libyan students who received tertiary education abroad, in total for the years 1970-1980 and 1981-2004, and those studying abroad as on 2005 .

\section{Table 5}

Development of Libyan higher education students overseas, 1970-2005

\begin{tabular}{ll}
\hline \hline Period & $\begin{array}{l}\text { Total number of } \\
\text { Students }\end{array}$ \\
\hline $1972-1980$ & 5000 \\
$1981-2004$ & 7287 \\
2005 & 645 \\
Total & 12932 \\
\hline \hline
\end{tabular}

Source: Libyan Ministry of Higher Education, 2006

Luckily enough, before the outbreak of the February $17^{\text {th }}$ Revolution, I was able to get access to one of the documents issued by the Ministry of Education, which documents how many students participated in the Libyan Study Abroad Scholarship Programme. In total from 20052011 (January), there were 11046 Libyan students sent to fifty different countries. In English speaking countries there were 2782, 1623, 369, 581, and 2 sent to UK, United States, Australia, Canada, and New Zealand, respectively. The following table presents the number of students who were admitted for either Master's or PhD degrees: 
Table 6

Number of students in English speaking higher education institutions abroad from $2005-2011$

\begin{tabular}{lcl}
\hline \hline Country & $\begin{array}{l}\text { Number of Students } \\
\text { In Master's } \\
\text { Programmes }\end{array}$ & $\begin{array}{l}\text { Number of Students } \\
\text { In PhD Programmes }\end{array}$ \\
\hline UK & 1408 & 1019 \\
United States & 959 & 485 \\
Australia & 438 & 112 \\
Canada & 197 & 106 \\
New Zealand & 0 & 2 \\
Total & 6004 & 3444 \\
\hline
\end{tabular}

Unfortunately, the current political situation in Libya has prevented me from obtaining answers to the questions that I had addressed to the Ministry of Education. I had intended to investigate the objectives of the government in sending students abroad, the available funding, and the Ministry's of Education subsequent steps for re-integration for graduates and postgraduates returning home after completion of their degrees. It is now impossible to investigate these questions further, as the regime in question has collapsed and it is extremely difficult to obtain reliable information.

To sum, this chapter discussed the historical background of Libya, the Libyan educational system and the way it functions, the characteristics of the educational and classroom culture prior to the February Revolution. It also discussed the English language situation teaching in Libya and the Libyan Study Abroad Scholarship Programme, and the subsequent chapter presents the literature review for this study. 


\section{CHAPTER III}

Teaching is about making some kind of dent in the world so that the world is different than it was before you practiced your craft (Brookfield, 1990, p. 18).

\section{Literature Review}

In order to assess the impact of the Libyan Study Abroad Scholarship Programme on returning university level English teachers, which is the main focus of this thesis, I considered three interacting factors: innovation, teacher beliefs and teacher enhancement programmes. These are influential factors that play a role in change or enhancement of classroom practices. There are clearly other factors that influence classroom practices (Wang, 2006; $\mathrm{Hu}, 2002$; Fox, 2008, 2009), but in the context of the Libyan Study Abroad Scholarship Programme, innovation, teacher beliefs and teacher enhancement programmes appeared to be the most important.

The chapter is divided into three sections. The first section examines fundamental notions of educational innovation. Literature regarding innovation is summarised because anything that the three university-level teachers might implement from abroad after returning to their Libyan classrooms would be considered innovative in the Libyan context. As discussed in Chapter Two, foreign concepts or approaches would most likely be considered abnormal or alien to the 
classroom norms and dynamics that have shaped and are customary to Libyan educational culture. This section addresses the following questions:

\section{What is educational innovation?}

\section{What causes innovation?}

3. How does innovation proceed?

4. What factors affect innovation?

5. What is the role of the teacher in bringing about innovation?

The second section is devoted to the issue of teacher beliefs, since the accounts and reflections of the three teachers involved in this study may be rooted in their beliefs systems. This section is organised in terms of the following questions:

1. What are beliefs and why is it important to study the belief systems?

2. Where do the beliefs stem from?

3. The relationship between teachers' beliefs, innovation and classroom practices.

In the final section, I briefly discuss studies that have examined teacher educational programmes (including graduate studies) and how they inform classroom practices. Of particular interest are studies such as the one by Fox (2008), who found that graduate studies have an impact on how, and what teachers of English as Foreign Language (EFL) emphasize in their classrooms. 


\section{1) Educational Innovation}

\subsection{What is educational innovation?}

The notion of innovation has been defined in tremendously diverse ways throughout the educational literature. The majority of definitions appear to take into account one or more of the four significant expressions that illustrate innovation, namely: change, development, novelty or improvement (De Lano, Riley \& Crookes, 1994).

For example according to White (1993), innovation is a "deliberate effort, perceived as new and intended to bring about improvement... what is crucial in innovation is that it is change involving human intervention" (p. 244).

Innovation in the domain of second/foreign language teaching programmes is defined by $\mathrm{De}$ Lano et al. (1994) as "an informed change in an underlying philosophy of language teaching/learning, brought about by direct experience, research findings, or other means, resulting in an adaptation of pedagogic practices such that instruction is better able to promote language learning as it has come to be understood" (p. 489).

Much of the literature on language teaching innovation is concerned with how to bring about pedagogical change. Innovation may be pictured as a vehicle through which teachers may increase their awareness, become better acquainted with the profession, augment their knowledge and improve their practice in the field (De Lano et al., 1994). As Fullan and 
Stiegelbauer (1991) emphasize, "[w]e cannot develop institutions without developing the people in them" (p. 349).

Innovation within this study is not considered or interpreted as being constantly innovative and creative in terms of pedagogical approaches or always seeking novel activities to enhance learning. It is instead considered from the perspective of implementing established and sound approaches and concepts of teaching that are conventional in the Western classrooms, which are nonetheless foreign and new to Libyan educational and classroom culture. For example, the concept of a student-centred approach to teaching has been a goal of educational culture in many Western classrooms for some time. On the other hand, in the Libyan educational culture as discussed in Chapter Two, classrooms have typically been teacher-centred. Consequently, the employment of a student-centred approach by teachers, who may have experienced studentcentred learning themselves as a result of the Libyan Study Abroad Scholarship Programme within the Libyan context could be seen as innovative and new.

\subsection{What causes innovation?}

Educational change may occur because of (a) critical incidents, (b) research, and c) change agents (De Lano et al. 1994).

\section{a) Critical incidents}

Critical incidents can generate innovation as a result of problem recognition. Kelly (1969) proposes that an educational change may not be commenced, unless the current situation 
is deemed to be insufficient and inadequate by the stakeholders of an educational culture. Questioning the reliability of a programme, and the realisation that the existing systems are not generating the required results may promote dissatisfaction. In addition, dissatisfaction may be a product of an assessment of teaching procedures or sometimes programmes themselves. Stroller (1992) further adds that the more dissatisfied stakeholders are, the more likely they will enquire about original resolutions throughout innovation and the proposed innovation will be favourably supported.

\section{b) Research}

Change may be also rooted in the understanding and noticing of new teaching pedagogies, syllabus, and course materials. Fox argues that "[c]urriculum is often seen as a vehicle for innovation and renewal. We look for renewal by examining changes in the theories stakeholders have about academic work, the language they use to describe and explain their actions, their perceived needs, wants, and lacks" (Fox, 2011, Personal communication). This awareness may be obtained through research. However, Fullan and Stiegelbauer, (1991) argue that despite the fact that research can function as a principal source for innovative ideas, and research is often encouraged as a source of educational innovation, "the implications of making recommendations to pedagogy from research need to be carefully considered in order for changes to be well-founded"( De Lano et al., 1994, p. 490) . 


\section{c) Change agents}

Teachers are usually expected to deal with and accept change at classroom level. Such change often has its roots within the top-down decision making processes of stakeholders external to the classroom and teachers are required to carry out the change process (Orafi, 2008).

In an educational culture, change agents that function as a driving force exist at all levels of an educational system, amongst administrators, teachers and sometimes students. Scileppi (1988) claims that the significance of a change agent in an educational culture is not essentially central, however; the importance lies in that the change agents encourage, assist, facilitate and even nurture the educational culture. It is further added that the change agents' function is to convince or drive stakeholders to alter and adjust practices, to implement an innovation and employ it in suitable situations and contexts. Scileppi (1988) quixotically notes that:

The change agent should have personal characteristics such as an open mind, a good sense of humor, and a high tolerance for ambiguity. The change agent must not desire to lead but must strive to be a catalyst, organizing the group to use its own people power to obtain social change. (p. 169)

In order to ensure success in any intended innovation, change agents ought to have excellent social interaction abilities to promote a desire to change in others (De Lano et al., 1994). This is crucial since "only people can make change by altering their behavior. The real 
meaning of change lies in its human, not its material, component" (Hord, Rutherford, HulingAustin, and Hall, 1987: p. 7).

In sum, innovation may be occasioned by a critical incident, research or change agents, or even a combination of all three. Looking at these factors through the lens of my research focus, I predict that the three returning university-level English teachers, whose accounts of changes (if any) in their approaches to teaching are the focus of this thesis, might have been influenced by a critical incident that affected their teaching philosophies and altered their roles as teachers. If so the three teachers might have experienced dissatisfaction and deemed their current teaching approaches in Libya to be insufficient and inadequate. They might also have questioned the reliability of the current programme, if they realised that the existing educational system was not generating the required results. Alternatively, their dissatisfaction might also be seen as a byproduct of their Study Abroad Scholarship Programme, where they therefore might have witnessed and experienced more effective methods of both learning and teaching and became aware of research-intensive pedagogical approaches (Fox, 2009; Artemeva and Fox, 2010; Fox and Hartwick, 2011). They may themselves have become change agents or sought out others who were interested and engaged by the potential for innovation.

The following subsection explores the ways in which innovation proceeds. 


\subsection{How does innovation proceed?}

Fullan and Stiegelbauer (1991) note that there are three phases involved in an educational innovation: initiation, implementation, and continuation.

The first phase which is initiation can be described as the "process that leads up to and includes decisions to go ahead with a change" (De Lano et al., 1994, p.492). Beer (1980) further adds that the initiation stage in itself involves the following:

a) A diagnosis of the present situation.

b) A recommendation for improvement of the current situation through change.

Brindley and Hood (1990) and Kennedy (1988) argue that the diagnostic stage ought to consist of an evaluation of the general appropriateness of a scheme or approach. Consequently, the diagnosis phase should support the need for change. The second phase of innovation is implementation, or, in other words, the first efforts to put the proposed ideas into practice. Fullan and Stiegelbauer (1991) view implementation as incredibly significant because it is the means of achieving the target goals. However, they add that implementation can be also considered problematic because the key stakeholders in the process may be faced with unexpected and surprising challenges. One of the strategies for introducing the implementation of an innovation is known as the normative and re-educative strategy (Chin and Benne, 1976). "Underlying this strategy is the idea that people act according to the values and attitudes prevalent in a given society or culture, and that accepting change may require changes to deep-seated beliefs and behaviour" (Kennedy, 1987, p. 164). Therefore, in this strategy the final consumers of an innovation are those who identify the need for the change, hence; this strategy is a bottom-up 
process for implementation rather than a top-down one. Teachers take on the implementation of innovation with the normative and re-educative strategy perform a vital role because they operate as both originators of and collaborators in innovation (Markee, 1997).

The final phase which is continuation, is a period in which the "change is either accepted, built in and adopted over a period of time, or discarded" (De Lano et al., 1994, p.493). It is in this phase that "meaning and value" are allocated to the promoted and implemented innovation. Huberman and Miles (1984) emphasize that continuation heavily relies on the question whether or not change becomes part of or woven into the fabric of the educational organisation. Furthermore, continuation may be sustained if conditions allow for on-going support for and development of teachers under the rubric of teacher improvement and enhancement (Joyce 1990, Joyce and Showers 1988).

To sum up, although these phases may appear to be clear and simple on the surface, the procedure of innovation is not so easy in practice. This is due to the fact that innovation is not essentially linear. Proceedings occurring in a particular phase are capable of changing the outcomes that took place in earlier phases, and vice versa; what takes place at one particular point in an innovation process may powerfully influence and shape the following phases (Fullan and Stiegelbauer, 1991). Additionally, innovations in some contexts may be simpler to apply than others. There are also external and internal factors that may affect the entire implementation process of an innovation in an educational culture. The following subsection will review some of these factors. 


\subsection{What factors affect innovation?}

Several researchers in the field of educational innovation have endeavoured to classify and categorise factors that are powerful in stimulating and promoting innovation. Brindley and Hood (1990) identify political, individual, and professional factors as having an effect on implementing an innovation. Within the innovation literature, a number of characteristics of innovation have been proposed as "correlating with the rate and success of implementing and spreading an innovation" (White, 1993, pp.247-248). As noted by Kelly (1980), these include:

- Feasibility (this implies that there are institutional resources to support and sustain the innovation)

- Acceptability (this implies that the institutional philosophy corresponds with the innovation).

- Relevance (this implies that the perceived students needs correspond with the innovation).

Fullan (2001) further argues that the features and quality of the innovation in itself can have a fundamental influence on the implementation procedure. In line with Stroller (1992), these features include originality, clarity and compatibility with past practices, are expanded upon below:

\section{Originality}

This implies that the innovation consists of new practices that differ from the current practices. If an innovation is considered to be very simple, it might be viewed as not different enough from the current approaches, and thus, innovative attempts will not be considered meaningful. Clark, Lotto and Astuto (1984) state that "simple changes are the ones school 
systems are least likely to adopt and implement successfully", principally due to fact that they are not regarded as valuable (p. 56). Although Stroller (1992) remarks that innovation must be seen as sufficiently original so that it is viewed as novel, it should not be so original as to lie "outside the realm of acceptable norms, conventions, and expectations" of the situation where it is to be initiated (p. 150).

\section{Clarity}

Teachers are often asked to implement an innovation with no clear guide lines on how to incorporate innovation in practice. Fullan (2001) advises that "lack of clarity-diffuse goals and unspecified means of implementation—represents a major problem at the implementation stage; teachers and others find that the change is simply not very clear as to what it means in practice" (p.77). Fullan added with respect to lack of clarity that "[u]nclear and unspecified changes can cause great anxiety and frustration to those sincerely trying to implement them" $(2001$, p. 77$)$.

Compatibility with past practices is usually referred to as being a significant factor in shaping implementation. Stroller (1992) established that perceived compatibility can have undesirable consequences on the implementation of innovation in intensive English programmes. Stroller (1992) further argued that "support for an innovation may be jeopardized if it is perceived as being either too compatible or not compatible enough with current practices" (White, 1993, p. 249).

Other factors that affect implementation of innovation include teacher's beliefs (which will be dealt with in some detail in the following subsection of this chapter) and the sociocultural context. 


\section{Socio-cultural context}

As discussed in Chapter Two, the culture of learning can influence and shape both the dynamics of a classroom as well as an entire; educational system. The culture of learning is determined by the social and cultural norms of any given society or context (Cortazzi and Jin, 1997). Holliday (1994) further comments that "the culture of the classroom provides tradition and recipe for both teachers and students in the sense that there are tacit understandings about what sort of behaviour is acceptable" (p. 24). Therefore, it may be stressed that the sociocultural context where an innovation is to be implemented plays a fundamental role in either the employment or opposition of a curricular innovation.

If an innovation is applied without taking into account the socio-cultural milieu of the target society, clash and conflict may take place. In addition, if an innovation necessitates novel behaviours and responsibilities which may challenge and oppose the behaviours and responsibilities natural to and embedded in the target society and culture, the consumers of this innovation may not certainly acknowledge or take on these original responsibilities and behaviours (Orafi, 2008). Consequently, it may be argued that "the likelihood of an innovation to be adopted is always contingent on its appropriateness in a specific context of implementation" (Markee, 1997, p.84).

Warren (1987) extends the idea of context even further. He argues that it also comprises institutional cultural norms, potentials, and mechanisms for deciding what is and what is not acceptable in particular circumstances. From this perspective, context is recognised "to be intertwined with perspectives and includes the methodology a teacher uses, his or her instructional goals, and his or her beliefs and knowledge about subject matter and its relationship 
to what is appropriate or inappropriate to do with students" (Smith and Southerland, 2007, p. 400).

To underscore the importance of the socio-cultural context in curricular innovation, Shamim (1996) attempted to introduce the notion of process teaching in her English writing classes in Pakistan. However, her newly adopted classroom practices were met with resistance as there was a clash between teacher and student perceptions of classroom learning. Shamim explains that the resistance stemmed from the "[1] ack of 'fit' between the 'users' (learners) and the assumptions of the innovative methodology was largely as a result of 'value conflict'. [Thus], learners' beliefs and assumptions about the norms of appropriate classroom behaviours, which were entrenched in the culture of the community, clashed with the assumptions of the innovative methodology"(p. 119). Further, as Shamim outlines, "the affinity between their expectations of the etiquette of teacher/learner behaviour in the classroom and the culture of the community made it easier for them to reject the innovation" (p. 119).

The above experience led Shamim (1996) to argue that when initiating an educational innovation, the need for a change is not only restricted to teachers, but also ought to include students and in fact the whole community. In addition, if an innovation radically conflicts with local cultural norms of a target society, the innovation ought to be modified to fit the existing cultural norms before instigating it.

Within the sphere of factors affecting educational innovative implementation, Wang (2006), drawing on the work of Hu (2002), identifies factors that affected the implementation of communicative language teaching methodology (Savignon, 2002) in China. Wang (2006) classified factors affecting teachers' willingness to innovate in two broad spectrums: external 
and internal factors. External factors include textbooks, class size, cultural appropriateness, etc. and internal factors include beliefs system, personal concerns, and teaching method.

\section{Figure 2}

Hypothesised theoretical model of factors affecting teachers' implementation (Wang, 2006, p.73)

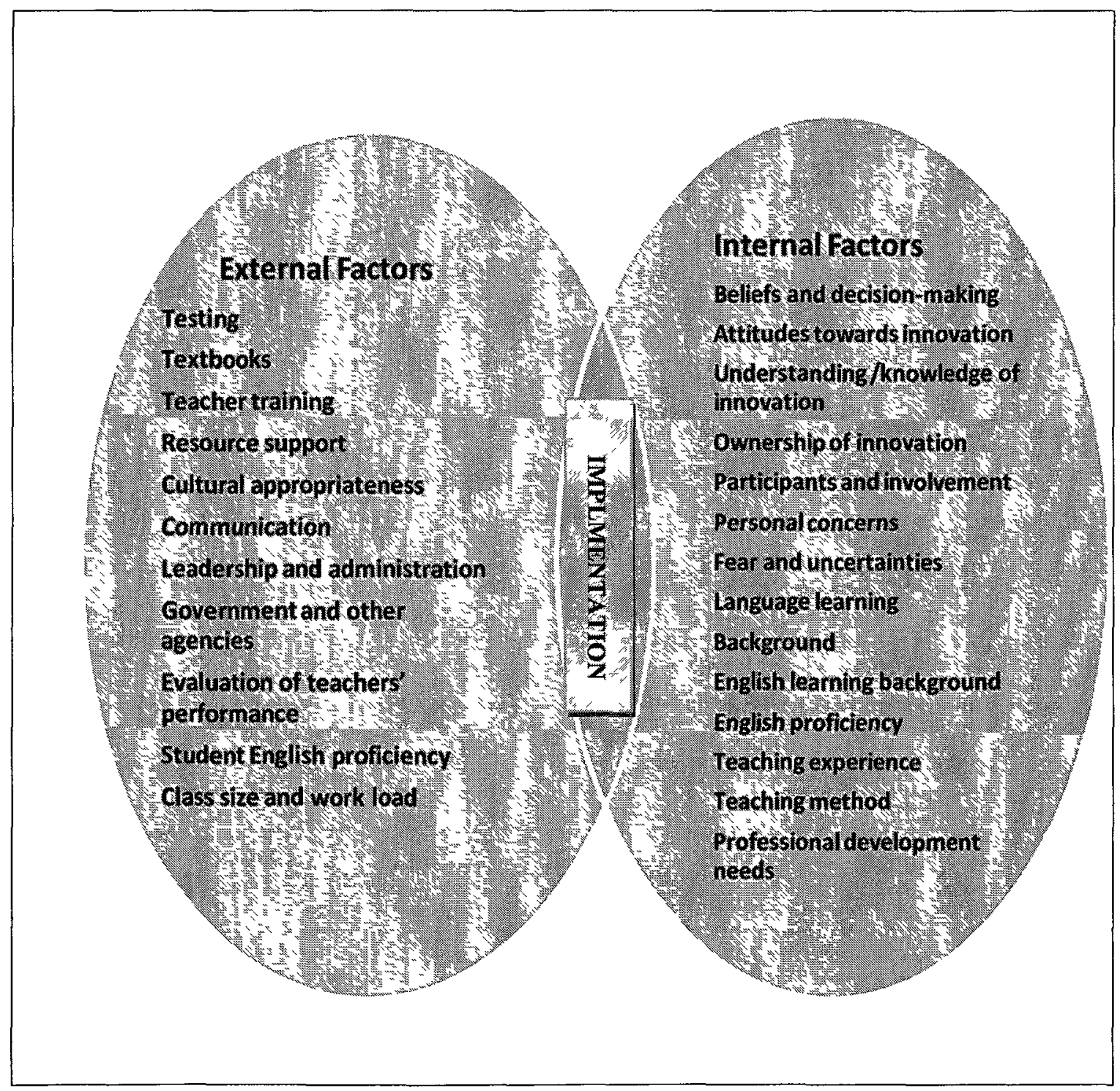


In the above representation Wang (2006) generated a thorough list of the factors that affected teacher's implementation in the Chinese tertiary context, which may indeed apply to other educational contexts including Libya. Thus, it is clearly that the implementation of any form of educational innovation can be a complex and difficult process. The following section will briefly elaborate on the four most prominent external factors that may impede the implementation of innovation at classroom level. As for the internal factors I will be only focusing on beliefs (in section two of this chapter), as this one of the focal points of this study.

\section{External Factors}

The four factors: testing, textbooks, teacher training, and resource support are identified in the literature as factors affecting any form of curriculum implementation, thus innovation.

\section{Testing}

Examinations and/or high-stakes tests exert a considerable impact on both the content of the subject matter and the pedagogy employed (Alderson and Wall, 1993; Wall, 2000). Test impact has been described in language education as "washback" (Alderson and Wall, 1993). Washback refers to not only to the effect it (test) has on teaching and learning, but also the effect it has on the entire educational system, the various stakeholders in the education process (Andrews, Cheng, Watanabe, and Curtis, 2004). Washback is seen as having a positive impact on classroom practices in that it guides teachers to focus on students' weaknesses. On the other 
hand, it can be argued that 'washback' can make effective language teaching more difficult (Prodromou, 1995). Whether tests have negative or positive effects, it can be concluded that tests are expected to cause some form of change in the classroom.

\section{Textbooks}

It is argued that textbooks may have a positive impact on teachers and classroom pedagogy during curriculum implementation (Harmer, 1991; Richards, 1998). These included: relieving teachers from the pressure of searching for material and providing a guide to teach more effectively. On the other hand, textbooks are condemned for impeding teacher development. They are seen as impeding development by:

1) absolving teachers of responsibility on a day to day basis;

2) leading to "the unjustifiable attributions of qualities of excellence, authority, and validity to published textbooks" (Richards, 1998, p. 131); and

3) causing a "reduction of the level of cognitive skills involved in the teaching if teaching decisions are largely based on the textbook and the teacher's manual" (Richards, 1998, p. 132).

\section{Teacher Training}

Stenhouse (1975) argues that without teacher professional development there can be no curriculum development. In accordance with Stenhous, Brindley and Hood (1990) state that continuous in-service training and professional development represent important means for any anticipated implementation. 


\section{Resource Support}

Resource support regarding human, material, and financial has been deemed to be essential in determining the successful implementation of an innovation (Li, 1998). Fullan and Miles (1992) further emphasize that:

Change demands additional resources for training, for substitutes, for new materials, for new space, and, above all, for time. Change is "resource-hungry" because of what it represents-developing solutions to complex problems, learning new skills, arriving at new insights, all carried out in a social setting already overloaded with demands. Such serious personal and collective development necessarily demands resources. (p. 750)

\subsection{What is the role of the teacher in bringing about innovation?}

Brookfield emphasizes that we teach to make a change in the world we are living in and that "[t]eaching is about making some kind of dent in the world so that the world is different than it was before [we] practiced [our] craft" (Brookfield, 1990, p. 18). In accordance with Brookfield, Palmer beautifully expresses that "teachers possess the power to create conditions that can help students to learn a great deal - or keep them from learning much at all. Teaching is the 
intentional act of creating those conditions, and good teaching requires that we understand the inner sources of both the intent and the act (Palmer, 1998, p. 6). Therefore, it can be clearly emphasized that teaching is not just a matter of instilling knowledge in students; it is more or less nurturing the students. As the American educator Horace Mann (1796-1859, cited in Pychyl, 2011), noted a "teacher who is attempting to teach without inspiring the pupil with a desire to learn is hammering on cold iron."

From a classroom pedagogy perspective an effective teacher is generally perceived to be the one who holds effective classroom practices. However, this notion may be challenged in that "the key to understanding the best teaching can be found not in particular practices or rules"... "[but]in the attitudes of the teachers, in their faith in their students' abilities to achieve, in their willingness to take their students seriously and to let them assume control of their own education,"... "in their commitment to let all policies and practices flow from central learning objectives and from a mutual respect and agreement between students and teachers" (Bain, 2004, pp. 78-79).

It can be certainly seen that the teacher is fundamentally essential for any educational system, and taking into account this crucial factor in any educational decision can be seen as vital. Therefore, "the teacher is an integral part of the curriculum constructed and enacted in classrooms" (Clandinin and Connelly, 1992, p. 363).

On the surface, some would argue teachers seem to be "eclectic" with regards to their classroom pedagogy and practices (Anning, 1988). Eventually, they develop practical abilities that necessitate how to deal and interact with a range of difficult factors within a classroom 
environment (Anning, 1988). The way teachers deal and interact with such factors is deeply stimulated by teachers' theoretical frameworks, which are established from both professional training and experiences as learners (from childhood and on), and in particular throughout their professional lives as teachers (Breen et al., 2001). In addition, it may be argued that teaching is fundamentally a cognitive - behavioural task that engages perceptions about learning. These attitudes are essentially developed from the society wherein the innovation is to be implemented (Kennedy, 1987). Thus, the change process ought to take this particular complexity into account.

Hopkins (2002) argues that "'real' improvement is achieved by modifying classroom practice and by adapting the organisational or management arrangements within the school to support teaching and learning" (p. 2). However, it appears the real process to be far more complex than this (Fox, 2005). Regardless of the huge amount of research and frequent interventions and innovations, it is rare to find change taking place or being maintained at the classroom level (Harris, 2003). Harris, Smylie \& Perry (1998) contend that although the logic of encouraging administrational and pedagogical change is indisputable, the connection between organisational change and the development and enhancement of classroom procedures is essentially too complex.

Primary data that supports the relationship between organisational change and improvements in classroom pedagogy is very limited. Commenting on this relationship Murphy (1993) notes that "there seems to be a 'slippery and unreliable' relationship between changing structures and improving teaching..." principally because "...changing structures is not 
synonymous with changing the beliefs, knowledge and understandings that underpin teachers pedagogical practice" (cited in Harris, 2003, p. 370).

From the above research it can be emphasised that without change in teachers, any educational innovation at the classroom level may not be successful or even implemented. In support for this claim Hargreaves (1989) holds the view that "change in the curriculum is not effected without some concomitant change in the teacher," since it is the teacher's responsibility to convey the curriculum at the classroom level. Thus, "[w] teacher believes, what the teacher assumes - all these things have powerful implications for the change process, for the ways in which curriculum policy is translated into curriculum practice" (p. 54).

Implementation of any curriculum innovation is strongly associated with "cultures of teaching" as described by Hargreaves (1992). In any teaching culture, it is always the teachers who play a determining role in modeling the quality and degree of implementation. The accomplishment of any curriculum reform and its employment depends greatly on whether or not teachers enthusiastically take part in the innovation process; they also have to be appreciated and acknowledged in the innovative process.

Both Atkin (1992) and Whitehead (1989) have stated that teachers attempt to make changes once they recognise the presence of a gap or inconsistency between their objectives and principles, and their current practices. Furthermore, it is believed by Hashweh $(2003$, p. 421$)$ that teachers experience accommodative changes when they:

(a) are internally motivated to learn; 
(b) [b]ecome aware of their implicit ideas and practices and critically examine them;

(c) construct alternative knowledge, beliefs, and practices; and

(d) resolve the conflicts between the prior set of ideas and practices and the new initiatives.

Hashweh also noted that the above conditions can only take place within a social environment that is characterized by cooperation, trust, reflection and thoughtfulness. Teachers can be internally motivated to change because, as Covey (1989) explained, "[p]eople are intrigued when they see good things happening in the lives of individuals, families and organizations... And their immediate request is very revealing of their basic paradigm. 'How do you do it?' Teach me the techniques"' (p. 40).

However, from a different perspective De Lano et al. (1994) emphasize that important concerns which may motivate teachers to take on change consist of not only an aspiration to promote enhanced learning for their students, but also the need for acknowledgment and respect. Therefore, innovation may encourage both professional development and classrooms development. There is a characteristic that continues to prevail in teaching culture, which is fundamental in impeding change: the culture of individualism. Before examining the phenomena of belief systems and innovation, the next section examines research relating to the culture of individualism. 


\section{Culture of individualism in teaching}

Research on the culture of individualism in teaching has established that on the whole the one enduring and persistent attribute of teaching is isolation. Lortie (1975) claimed that teachers are separated into a series of "egg crate-like compartments"; they are removed and cut off from each others' work. This is not only typical of primary and secondary teacher cultures but possibly even more the case in the higher education context. In a university context it is believed that there is less curriculum control over students and teachers (Fox, 2009; Wang and Cheng, 2005).

From my experience as a teacher assistant in Libya at one of the universities, I noticed that the majority of teachers developed the custom of working alone with their own students "in their respective classrooms under the "“one-teacher-package"” (Wang and Cheng, 2005, p.22). It was uncommon to see colleagues exchange ideas regarding subject content knowledge, material development, and pedagogy. None of the teachers would observe and attend a colleague's class. What also struck me was that the head of the department would never observe teachers' classroom pedagogy for evaluation purposes. Subsequently, teachers had no knowledge of what took place in neighbouring classes or how their colleagues managed and orchestrated their language classes. The department provided the teachers with some supplementary material to assist teachers in classes; the teachers may have believed that they did not need to cooperate with each other. Nevertheless, to augment teaching and learning, teachers do need to exchange instruction ideas and to learn from one another for the purposes of professional development. 
This isolation in the teaching culture not only impedes opportunities for professional development but also establishes a possible obstacle for implementing innovation in Libya (Flinders, 1988). In accordance with the above, Hargreaves (1993) confirmed that "[ $t]$ eacher individualism, teacher isolation, teacher privatism - the qualities and characteristics that fall under these closely associated labels have come to be widely perceived as significant threats or barriers to professional development, the implementation of change, and the development of shared educational goals" (p. 53).

In summary, innovation is anything that brings about development and it may arise because of (a) critical incidents, (b) research, and c) change agents. The three phases involved in an educational innovation are: initiation, implementation, and continuation. There are external and internal factors such beliefs and socio-cultural context that may affect the implementation of innovation. The teacher is a central part of the curriculum formation and how it is presented in the classroom. Teachers, however, typically work in isolation from one another and within a professional culture of isolationism or individualism that constrains and inhibits change. It can be concluded that any form of improvement, curriculum development, programme enhancement or curricula renewal, are not accomplished in a short time or fixed period. Rather, they entail ongoing dedication. Innovation is not a linear process; it is a complex, cyclic and contentious process.

The following section of this chapter is devoted to the examination of belief systems and their relation to any form of educational innovation. There is a need to examine teacher beliefs because teachers are not transparent individuals who accomplish curriculum policies and 
objectives as given by their administrators. Rather, they are more or less entities who filter, absorb, and employ the curriculum policy based on their own beliefs and educational context

\section{Belief Systems}

This section considers what beliefs are and why it is important to study beliefs systems. It considers the sources of beliefs and where they actually stem from. It concludes by elaborating the relationship between teachers' beliefs and innovation with regards to classroom practices.

\subsection{What are beliefs and why is it important to study the belief systems?}

Kelly (1969) considered man as a "scientist who tries to make sense of the universe, himself, and the situations he encounters. He makes hypotheses, tests them, and then forms personal constructs. The constructs are his theories and beliefs, his way of organising and making sense of the world, and they will change and be adapted with experience" (cited in Breen et al, 2001, p. $345)$.

Beliefs have been defined very differently by different researchers, however; Borg's (2001) definition may be the most suitable one for the purpose of my research. He argues that a belief can be seen as a "proposition which may be consciously or unconsciously held, is evaluative in that it is accepted as true by the individual, and is therefore imbued with emotive commitment; further, it serves as a guide to thought and behaviour" (p. 186). Borg further adds that beliefs 
play an important role in both teaching and life. They shape and help individuals become aware of the world, manipulate how innovative information is assumed and whether this information is acknowledged or not. "Beliefs colour memories with their evaluation and judgement, and serve to frame our understanding of events" (Borg, 2001, p.187).

Teachers' beliefs have long been the concern of language teaching (see, for example Woods, 1996). These are teachers' pedagogic beliefs, or the beliefs that are important to a particularized pedagogy. Calderhead (1995) claims that the most commonly explored issues in relation to teachers' beliefs are their philosophies about:

- Teaching

- Learning

- Learners

- Subject matter

- Self as a teacher

- The role of the teacher

Interest on teacher beliefs only started in the early nineties (Orafi, 2008). Teachers' beliefs were considered important because "[i]n order to better understand language teaching, we need to know it...". It may also be argued that an important situation for teachers "...accommodative change to occur is bringing these beliefs up to the level of consciousness" (Hashweh, 2003, p. 423). A wealth of research has been published since the nineties on the beliefs that teachers hold about both teaching and learning and the influence that these beliefs have on what takes place in largely western classrooms. The function and significance of beliefs have been the focus of studies in a number of central themes of interest to English language teaching experts. However, little research has taken place in the Middle East (in particular Libya) with regards to teachers' 
beliefs and classroom pedagogies. Therefore, I aim to see whether the established western research on teachers' and beliefs such as that provided by Woods (1996), who looked at the impact of ESL teachers' pedagogic beliefs on their classroom practices in North America ${ }^{22}$ applies to the Libyan context. He, like Freeman and Richards (1996), argued that we need to know:

more about language teachers: what they do, how they think, what they know, and how they learn. Specifically we need to understand more about how language teachers conceive of what they do: what they know about language teaching, and they think about their classroom practice. (p. 1)

The complexity of eliciting beliefs is evident, because personal philosophies may be largely intuitive and subconscious; teachers may even be unable to explain or put them into words. In addition, associated with this is the concern of self-worth and self-esteem; either subconsciously or not, "teachers may wish to promote a particular image of themselves". Additionally, "there is often a difference between espoused theory (theory claimed by a participant) and theory in action (what a participant does in the classroom)" (Breen et al, 2001, p. 345). Along the same lines, Hashweh (2003) adds that "Aristotelian" than "Newtonian" in character, teachers are frequently unconscious of their applied knowledge, beliefs and practices.

22. Borg (1998) also looked at teaches' beliefs of knowledge of grammar and teaching, and Cortazzi and Jin (2007) explored Beliefs within in curricular studies. 
This quality of knowledge renders it awkward to obtain, comment on, and or even expand on. Typically, teachers may not state what their assumptions are about learning. However, some of their beliefs about learning and classroom pedagogies may be elicited through questioning and searching, or in the course of observing classroom practice and discussing it, as demonstrated in the work of Woods (1996).

\subsection{Where do beliefs stem from?}

Breen et al. (2001) emphasizes that teachers' beliefs or personal philosophies about (a) language pedagogy, (b) the educational process, and (c) learning and teaching within this educational process are likely to be experienced from the process and appear to be become profoundly believed and mainly context-independent. "The pedagogic principles which have been shaped and generated by these more abstract and underlying beliefs serve to mediate between them and the teacher's on-going decision-making and actions with a particular class of learners in a particular teaching situation" (Breen et al., 2001, p. 472) .

Principles considerably manipulate and control how the teacher coordinates the interaction between (a) the learners, (b) teacher and learners, and (c) subject content in a specific classroom milieu with certain facilities. "Situational demands and constraints and the specific social relationships and ways of working (or culture) jointly developed with the learners in the class entail the teacher's selective reliance on particular principles and those practices that the teacher regards as expressions of them" (Breen, et al, 2001, p. 472). Teaching values are impulsive in shaping what the teacher does, and what the teacher observes in learners' behaviour. It can be argued that teachers' ideologies become more deep-rooted and well established with 
more and enhanced experiences (Munby 1982). Although it has been proposed by Claderhead (1988) that beliefs and values are hidden in practice, it may be stated that they might surface from the testing of practices. Consequently, it may be concluded that:

The [r]elationship between practices and principles is likely to be interactive; each will influence the other as the teacher works from day to day". Over time, a teacher may also evolve a framework of principles made up of 'core' principles that are applied across teaching situations and 'peripheral', more malleable principles that are thereby more adaptable to shifting contexts of work (Breen et al, 2001, p. 472).

Kindsvatter, Wilen, and Ishler (1988) suggest that teacher's beliefs system stem from the following:

1. Their own leaning experiences as a language learner. This reflects the notion that teachers teach they way they are taught. A number of researchers including Alrnarza, (1996) and William and Burden (1997) advocate that the well-established beliefs that teachers' hold during their early education may create attitudes that formulate problems for pre-service teacher instruction to have a fundamental impact on them.

2. Experiences of what brings about success.

3. Educational based principles. 
4. Principles derived from an approach or method. Teachers may regard a certain approach or teaching method as the most effective and seek to employ it in their classroom practices.

Thus, it is argued that beliefs are rooted in the whole educational system; they are initiated from the day we first walk into a classroom as young innocent learners, and are shaped; to the moment we become teachers ourselves. Therefore, beliefs are not just rooted in teachers, but in the whole educational context. I investigate how the three teachers' beliefs of concepts either come in line with or contradict beliefs that are evident in the Libyan educational context, which have existed for decades within the Libyan context. If the teachers' beliefs contradict or challenge existing educational beliefs how do they deal with such conflict?

\subsection{The relationship between teachers' belief, innovation and classroom practices}

Since teachers' beliefs operate as means for practices in a classroom setting, educational innovation is principally reliant on teachers' capability to both believe and behave in a different way about learning and teaching. It has been demonstrated in the research literature that teachers may cleave to knowledge, beliefs, and approaches to teaching in a manner that conflicts with those required for many innovative initiatives (Hashweh, 1996). 
Pajares (1992) emphasizes that modifying teacher' beliefs is an exceedingly difficult challenge, because beliefs about how to teach and how to learn are deep-rooted and entrenched by the time a person goes into higher education and are more or less at the stages of anti-change. In addition, as teachers devote both emotionally and intellectually in their beliefs, they tend to hold to them, except if these beliefs are amply questioned and the person cannot incorporate them into current theories. As a result, teachers "have variously welcomed, improved, deflected, co-opted, modified, and sabotaged outside efforts at reform" (Tyack \& Cuban, 1995, p. 7). Maintaining a reasonable level of independence, "[O]nce the classroom door [is] closed, [teachers can], if they [choose], comply only symbolically or fitfully or not at all with the mandates for change pressed on them by platoons of outside reformers" (Tyack \& Cuban, 1995, p. 9). Consequently, it is likely, that teachers purposely or inadvertently adapt or resist reforms more frequently than any other stakeholder, because at the end of the day it is the teacher who assumes responsibility for implementing reforms (Markee, 1997).

The way teachers adjust or adapt reforms more often than not is achieved by them filtering new concepts, new ways of being and doing, via their current beliefs framework (Pajares, 1992). Teachers incorporate these modified statements into what they previously believed about teaching and learning instead of changing their current beliefs. Consequently, it can be established that "even well-meaning teachers who maintain that they value proposed changes and believe they are embracing radically new practices may not implement reforms as intended by reformers" (Smith and Southerland, 2007, p.399).

For example, Smith and Southerland (2007) established that even though two science teachers recognised and were aware of the concepts put forward and encouraged by a reform 
agent, their beliefs regarding teaching and learning science were not in line with the ideas of the reform. Since their beliefs were not in accordance with the innovative intents, reform hardly had an impact on their teaching. English language teaching research has also reported similar results. Most research has described efforts of both introducing and implementing commutative curriculum and approaches to teaching in a grammar-based context. For example, Gorsuch (2000), in Japan observed that "[j]apanese teachers' current orientation towards foreign language learning seems to be that strong teacher control is desirable and that students need to memorize, use written mode, and be very accurate" (p. 137). Despite the fact that the educational reform plans emphasized the importance of developing students' communicative competence. Similar findings were reported by Li (1998) in her article about the attempts to reform language teaching practice in Korean classrooms.

The literature discussed above suggests that curricular reforms are typically not employed at classroom level as intended. This may be due in part to the dissonance between the ideologies of policy makers and teachers' beliefs; as well as; socio-cultural contexts which may not be accommodating to the changes about which the innovative policy is hoping to bring.

These notions inform the present study, which explores whether or not university-level teachers were able to implement any form of communicative or post-communicative approaches in their language classrooms, or any innovative approach in their Libyan classrooms, despite the dominance of the grammar-based approach within this ELT context and the customary norms for teacher and student culture. The final section of this chapter discusses how educational programmes may inform classroom practices. 


\section{Educational Programmes and classroom practices}

Situative $^{23}$ theorists conceive and hypothesize learning as changes in contribution and involvement in socially structured activities, and individuals' employment of knowledge as a characteristic of their participation in social practices (Borko, 2004). A number of researchers have contended that learning has both individual and socio-cultural qualities, and have represented the learning procedure as one of "enculturation and construction" (Borko, 2004, p.4). According to Cobb (1994), "learning should be viewed as both a process of active individual construction and a process of enculturation into the ...practices of wider society" (p. 13). In addition, teacher learning "is usefully understood as a process of increasing participation in the practice of teaching, and through this participation, a process of becoming knowledgeable in and out about teaching" (Alder, 2000, p. 37).

Putting this notion of learning into the perspective of the Libyan Study Abroad Scholarship Programme, it can be argued that graduate programmes are in one way or another a learning process that may promote changes and development not only in the individual but in the whole socio-cultural context of that person.

In any professional development programme there are significant factors that constitute that system. Borko (2004) summarised them as:

- The programme itself (this would include its objectives).

23 The term situative refers to a set of theoretical perspectives and lines of research with roots in various disciplines including anthropology, sociology and psychology" (Borko, 2004, p.4). 
- The teachers who are essentially learners in the scheme.

- The facilitators, those who direct teachers as they build new knowledge and procedures and strategies.

- The context in which the professional development takes place.

Below is a discussion of these key elements that form the whole professional system as Borko (2004) represented it. From my own experience as graduate student currently participating in a professional development or teacher enhancement programme, I have made some minor adaption to the figure in terms of how these factors interact with one another: 
Figure 3

Elements of a professional development system

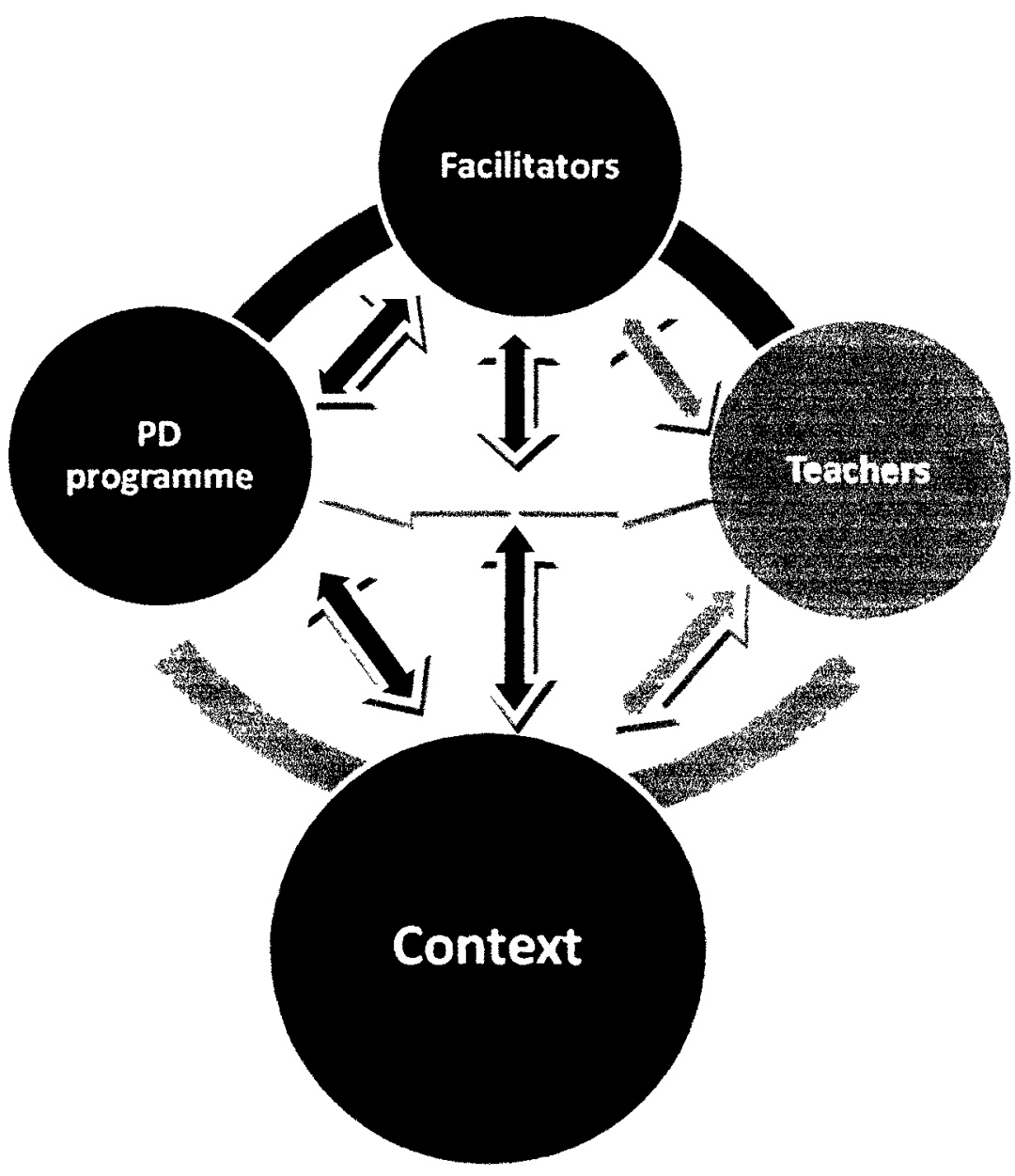

It is argued that those who participate in a teacher development programme, and who are just presented with a series of activities will not be capable of implementing them. They will only implement them if they have precisely the same beliefs and theories as the instructors, 
which in most cases are very much implausible (Breen et al., 2001). In addition, Adey, Hewitt, Hewitt, and Landau, (2004) indicated that "real change in practice will not arise from programs of instruction, especially when those programs take place in a centre removed from the teacher's own classroom" (p. 156).

Drawing on Adey et al.'s view it can be noted that the Libyan Study Abroad Programme is a teacher instructional programme that takes place in institutions far removed from the Libyan classroom context. These instructional programmes may take place either in the UK, Canada, USA or Australia. Whether or not these instructional programmes have resulted in changes to classroom practice will be the focus of subsequent chapters.

It is well established that teacher development is a very complex phenomena to deal with. Its achievement relies greatly on "a favourable context for learning and practical, engaging activities";...as well as, "[a]vailability of resources, flexible working conditions, support, and recognition can make all the difference in the desire of teachers to refine their practice" (LoucksHorsley, Harding, Arbuckle, Murray, Dubea, Williams, 1987, p. 7).

Furthermore, it is acknowledged that teacher development programmes that mainly rely on transmitting knowledge and in which the experts tell teachers how to implement classroom innovations may not be satisfactory and effective in enhancing or changing the values and opinions that teachers hold about how a classroom ought to function (Kennedy, 2005, Briscoe, 1999). This may be because,"[i]mages of classrooms which teachers have constructed from years of experience in schools, both as students and teachers, cannot be changed with words alone" (Briscoe, 1999, p. 198). Breen et al (2001) further stress that "[i]t seems that there is often a great 
difference in teacher development between input [from the trainer/expert], uptake [element which participants find interesting and consider transferable to classrooms, i.e. which match their own theory], and output [what is actually implemented in the participants classes]" (p. 247).

For example, Johnson, Monk, Swain (2000) emphasized that practices of Egyptian science teachers after attending a 12 week in-service program in England were not changed. Johnson et al., also indicated that the majority of the teachers were not capable of implementing the new ideas learnt from the course because of difficult internal and external factors such as large classes, lack of resources, students' conflict and resistance, and even opposition from the school administration. On these lines Briscoe (1999) contends that teachers must have time to try-out new ideas in their classrooms and build their knowledge about teaching "without fear of administrators evaluating them on the basis of traditional images. Teachers must be given the opportunity to form support networks for change and the time to observe each other and reflect on what works and what doesn't work" (p. 198).

In accordance with Johnson et al. (2000), Lamb (1996) describes the reactions of teachers' - one year; after participating in a short INSET $^{24}$ course. Lamb indicated that "what the tutors had said was not necessarily what participants had heard, or remembered later" (p. 73). In addition, after interviewing and observing the teaching it was indicated that "[a] great deal of our [Lamb and his two colleagues] original input had been lost, and what was taken up was reinterpreted by teachers to fit their own beliefs and their own concerns about what was important to them and their students" (p. 79). Lamb (1996) concluded that the limited practical

24 an acronym for $I N-$ Service Training 
changes that took place in the teachers' classroom practices were seldom likely to enhance and mediate student learning.

Normally in these types of programmes teachers often take the role of information consumers, as it is delivered by the instructors. The information is transmitted to the teachers without taking into account the teacher's educational and cultural context. In this respect Bax (2003) asserts that "[a]ny training course [educational enhancement programme] should make it a priority to teach not only the methodology but also a heightened awareness of contextual factors, and an ability to deal with them- in fact to put consideration of the context first and only then consider the teaching approach" (p. 283).

To conclude, the above literature strongly suggests that just attending and participating in teacher enhancement programmes may not bring about a change in teachers. Whether The Libyan Study Abroad Scholarship Programme has brought about change in the three university level teachers (who are the focus of this study) will be discussed in chapter five. The subsequent chapter (Chapter Four) report on how the data were collected and analysed. 


\section{CHAPTER IV}

\section{METHODOLOGY}

For some, their journey takes them into political, even hostile environments where they hope to change the circumstances of people's lives. For others, it is a journey of wonder where strange worlds are encountered and where they hope only to describe, explore, and understand (Schostack, 2002, p. 3).

This chapter describes how I identified a suitable framework for this research. I first describe why a qualitative approach was chosen to examine teachers' perceptions of graduate studies and how such study informed their classroom practices, as well as why a grounded theory approach (Charmaz, 2006) in particular was chosen. The subsequent section describes the study itself, the participants, the procedures followed for data collection and the analysis, which from my perspective can be seen as a fundamental component of grounded theory development.

\section{Selecting a research approach}

I believe that a researcher is faced with a critically important decision when initiating research, namely, if he or she should take a qualitative or quantitative approach. Will the research be describing a phenomenon or will it be examining a hypothesis and representing the results statistically? According to Senior (2006) there are both practical factors that may 
influence a researcher's choice of a particular approach. The practical factors include the openness to suitable research sites, the accessibility of keen participants and most importantly the time restriction.

I naturally felt that qualitative research methods were more suitable for a naturalistic setting such as a classroom than a quantitative method. In addition, a qualitative approach would allow me to explore the many factors that may be interacting with and/or influencing one another, as suggested by the work of Wang (2006) and Hu (2002) above. Figuratively speaking, I wanted to explore teachers' beliefs, assumptions and knowledge "through a wide angle lens rather than putting a preselected aspect of [beliefs] under the microscope" (Senior, 2006, p. 15). It should also be noted that qualitative researchers have one great advantage over their quantitative researchers in that they "can add new pieces to the research puzzle or conjure entire new puzzles-while we [qualitative researchers] gather data-and that can even occur late in the analysis" (Charmaz, 2006, p.14).

Additionally, another reason for choosing qualitative research lies in the fact that I was interested in presenting the findings descriptively. I felt that I had to present the data in adequate richness and detail to persuade the reader with the validity and sufficiency of my findings. Since the "key aspect of qualitative research is that its objective is not to produce findings that are capable of general application, but rather to produce results that resonate" (p.16). Resonate refers here to the ability of the research findings to be relative to those who experience them. In other words, if other university-level English teachers who may have experienced the Study Abroad Scholarship Programme, but in different contexts, read my findings and relate to them, 
they might say to themselves, "Yes that's what happened to me, I had a similar experience". As well the study might produce results that have direct relevance to everyday language classrooms. The combination of me wanting to achieve these insights in my readers, and the diverse views discussed above guided the present study in the direction of a qualitative approach.

Having decided that I would take the path of qualitative research and that I would base my research on interviewing university level English teachers, I was then faced with another challenge: deciding on which type of a qualitative procedures that would allow me to have a comprehensive awareness of university level English teachers perceptions' of graduate studies and its impact. After consulting Creswell's (1998) book: Qualitative inquirer and research design: choosing among five traditions, along with the advice of my supervising professor Fox, I decided to pursue a grounded theory study. Below, I discuss what has been understood about the grounded theory approach in the present literature in order to establish its appropriateness in addressing my research question.

I was attracted by the fact that the aim of grounded theory is to develop theory that is "grounded" in the data itself and that it steadily surfaces from the data in a natural way rather than it being forced from the outer circle. In this regard Chenitz and Swanson (1986) note that

Grounded theory is a highly systematic research approach for the collection and analysis of qualitative data for the purpose of developing explanatory theory that furthers the understanding of social and psychological phenomena. The objective of grounded 
theory is the development of theory that explains basic patterns common in social life (p. 3).

It can be also added that grounded theory research is a very satisfying enterprise for those who undertake it. Because it speeds up the pace of attaining a comprehensible contact and acquaintance on what is occurring in ones data without giving up the fine points of enacted events (Charmaz, 2006). Similar to a "camera with many lenses, first you view a broad sweep of the landscape. Subsequently, you change your lens several times to bring scenes closer and closer into view" (Charmaz, 2006, p. 14).

\section{Self Study}

Many researchers now recognise that they are not neutral but are profoundly invested in their studies on a more personal level. The common point that was documented within the educational literature more than four decades ago by Ross Mooney was "[r]esearch is a personal venture which, quite aside from its social benefits, is worth doing for its direct contribution to one's own self-realization" (1957, p.155). In addition, within the same domain Bullough and Pinnegar (2001) stressed that "[w]ho a researcher is, is central to what the researcher does" (p.15).

One of the goals of self-study research is to enhance teacher education practice, in particular the encouragement of reflective teaching. It is further added that self-study is an influential means that function in a number of roles in preparing teachers (Dinkelman, 2003). 
The present research consists of an element of self-study, as this research is focussing on reflections of teachers who have participated in the Libyan Study Abroad Scholarship Programme, and I myself am a teacher, who is currently participating in such programme. My reflection and evolvement in this study will not only add another dimension to it in terms of triangulation, but it will also enhance my own professional development as a teacher. I include myself amongst the participants (Teacher D), and present my own reflection in the discussion of the findings.

\section{The study}

In this section I discuss the participants: who they are and why they were chosen, and the similarities and differences amongst them. A table highlighting the backgrounds of each participant is presented. I then shed some light on the rationale and methods utilised to gather data.

\subsection{Participants}

The participants were three (two males and one female) university-level English teachers residing in Libya. I refer to the three teachers by their assigned pseudonyms: Teacher A, Teacher B, and Teacher C. All three teachers have experienced The Study Abroad Scholarship Programme in at least in one of their programmes, either their graduate or post-graduate programmes. The three teachers reside in three different cities: Tripoli, Benghazi and Misurata, the three biggest cities in Libya. Teacher A, B, and C come from Tripoli, Benghazi and Misurata respectively. I deliberately selected the participants from three different cities so that I have a 
sample that is representative of Libya from the far East to the far West of the nation. I had no former relationship with teacher A and B; however, both teachers are very close friends of my uncle (Mustafa), and Teacher B was my uncle's former professor in his undergraduate programme. Having talked to my uncle about my research and interest he gave me these two names and introduced me to them over the phone. Both teachers expressed their strong willingness to participate. As for Teacher $\mathrm{C}$ she was one my colleagues at the university of Misurata. She is also a close friend; our relationship assisted me in terms of not having to build a rapport with her; as well as, in data collection and scheduling.

The medium of communication with participants was mainly in Arabic (L1) when I was trying to obtain their verbal consent, and scheduling interview times. However, communication by e-mail always took place in English as were their written responses to the questionnaire. I deliberately started the interview with an English question and asked whether they would be comfortable in conducting the interview in English. The teachers expressed their comfort and keenness to do so.

The following summarizes some of the key commonalities and differences amongst the three participants:

They have all undergone at least one graduate study programme abroad.

They all have more than ten years of teaching experience

All three are currently teaching in university institutions in Libya and have been in the university teaching profession for at least five years. 
All three have taught a variety of courses in Libya that range from literature to applied linguistics and are proponents of the communicative and student-centred approach of teaching.

Two of them have taught in other contexts than the Libyan context.

They have undergone more than ten years of learning experience.

Two of them obtained their undergraduate degrees in Libya, one of them was fortunate enough to obtain his B.A from the UK.

They have a diverse age range (from around 30-60).

For the two teachers (Teacher A and B) with whom I had no former relationship, I tried to establish a rapport by respecting them as much as possible. As stressed by Charmaz (2006) if researchers do not establish a rapport with the informants, they may jeopardise having access to accomplish later interviews or observations. Charmaz further added that "our respect for our participants pervades how we collect data and shapes the content of our data" (p. 19). As recommended by Charmaz (2006) I tried to show my respect to my participants by making rigorous efforts to gain knowledge of their beliefs and behaviours and attempted to understand their lives from their "windows". Thus, "it means discovering what our research participants take for granted or do not state as well as what they say and do....we try to understand but do not necessarily adopt or reproduce their views as our own; rather we try to interpret them" (Charmaz, 2006, p.19). 
I deliberately selected teachers with varied backgrounds as this variance may contribute to a number of factors that can be explored in terms of the impact of the Libyan Study Abroad Scholarship Programme on returning university level English teachers. The table below provides a brief outline of the three teachers. 
Table 7

Participants' Demographic information

\begin{tabular}{|c|c|c|c|c|}
\hline & Teacher A & Teacher B & Teacher $C$ & Teacher D \\
\hline Gender & Male & Male & Female & Female \\
\hline Age Range & $45-55$ & $55-65$ & $25-35$ & $25-35$ \\
\hline Current Degree & $\mathrm{PhD}$ & $\mathrm{PhD}$ & $\mathrm{MA}$ & $\mathrm{BA}$ \\
\hline Current Position & $\begin{array}{l}\text { University Professor } \\
\text { and head of the English } \\
\text { and linguistics } \\
\text { department }\end{array}$ & University Professor & University Professor & $\begin{array}{l}\text { Graduate } \\
\text { Student }\end{array}$ \\
\hline $\begin{array}{l}\text { Where and when the } \\
\text { degree was obtained }\end{array}$ & $\begin{array}{l}\text { UK, } 2004 \text { and returned } \\
\text { to Libya in } 2009\end{array}$ & $\begin{array}{l}\text { UK, The MA in } 1981 \\
\text { and returned to } \\
\text { Libya, then left for } \\
\text { the PhD in } 1994 \text { and } \\
\text { obtained the PhD } \\
\text { degree in } 1999 .\end{array}$ & $\begin{array}{l}\text { Canada, } 2005 \text { and } \\
\text { returned to Libya in } \\
\text { the same year. }\end{array}$ & Libya, in 2004 \\
\hline $\begin{array}{l}\text { Years of English } \\
\text { teaching experience }\end{array}$ & 20 years and more & 20 years and more & 10 years & 5 years \\
\hline $\begin{array}{l}\text { Years of university } \\
\text { level teaching } \\
\text { experience }\end{array}$ & $\begin{array}{l}10-15 \text { years (started in } \\
1999 \text { ) }\end{array}$ & More than 20 years & 6 years & $\begin{array}{l}\text { a year and a } \\
\text { half }\end{array}$ \\
\hline
\end{tabular}




\begin{tabular}{|c|c|c|c|c|}
\hline $\begin{array}{l}\text { Years of learning } \\
\text { experience abroad }\end{array}$ & $10-15$ years & 8 years & 7 years & 3 years \\
\hline $\begin{array}{l}\text { Teaching experience } \\
\text { abroad }\end{array}$ & $\begin{array}{l}5 \text { years and UK, Saudi } \\
\text { Arabia and United Arab } \\
\text { Emirates. }\end{array}$ & $\mathrm{NA}$ & & $\mathrm{NA}$ \\
\hline Data Source & $\begin{array}{l}\text { Questionnaire and } \\
\text { interview }\end{array}$ & $\begin{array}{l}\text { Questionnaire and } \\
\text { interview }\end{array}$ & Questionnaire & NA \\
\hline
\end{tabular}




\subsection{Data Gathering Methods}

Prior to conducting the study ethics approval was obtained from the Carleton Research Ethics Board (REB). My certificate of ethics approval is appended (Appendix I). A variety of techniques were used to collect the data. The data were collected over three stages. With every participant Stage 1, I distributed a questionnaire which they completed along with their informed consent forms and returned to me. Stage 2 was a follow up of the previous stage; I followed up on the questionnaire with a semi-structured interview. The final stage, stage 3 , was a further clarification stage, where I used e-mails and phone calls to clarify, extend and validate my understanding. The following section provides a description of each of the three stages in more detail.

\section{Stage 1: Questionnaire}

Before I distributed the questionnaire, I contacted the three participants by both phone and e-mail to invite them to participate in my research. After I obtained a verbal consent, I sent them a letter of information that fully described the objective and scope of the research. It also informed the participants that this project would focus on their beliefs about their prior Study Abroad Scholarship Programme, their beliefs about teaching and learning and how it had impacted their instructional strategies and choices in their current classrooms. They were aware that their work would be made public (with identities hidden). I considered this understanding an important part of the research process as "beliefs and conceptions must be opened for debate and exchange; beliefs become of relevance for action only when they can be shared with other" (Tillema, 1997, p. 286). The letter was enclosed with a consent form. Upon their agreement I 
sent them the questionnaire (see Appendix II). Distributing the questionnaire at the start of the study proved to be useful, in a way it provided the participants with a framework for considering and reflecting upon concepts and views that could be the focal point of the subsequent stage. Not only was it a spring board for thinking for the participants, but it guided me in allowing me to lead the conversation in a path that helped to elicit answers to my main research question.

The questionnaire included questions with regards to their background information: their demographic information, educational degree (place and time), and current position. It also included questions with respect to their English learning experience and teaching experience. The questionnaire also touched on aspects of their own philosophy of teaching and employed classroom approaches and techniques. The final section of the questionnaire asked the teachers to reflect on issues of implementing their concepts and ideas of teaching in their classroom and educational reform. Space was allotted after each question to give the participants an idea of how much is expected of them and for some of the questions I gave multiple choice boxes. As I had employed a grounded theory approach for this study, I tried my best to assess the fit between my early research curiosity and awareness and my establishing data. I tried not to force my predetermined notions and hypotheses upon the data.

\section{Stage 2: Semi-structured Interview}

I conducted a one a half to two hours semi-structured interviews over Skype with two experienced English language teachers working in two different institutions and cities in Libya. It is very important to note that I was unable to conduct an interview with Teacher $C$ due to the 
February 2011 political situation that occurred in Libya. The type of interviews I employed in this study could be described as an intensive interview, because it "permits an in-depth exploration of a particular topic or experience and, thus, is a useful method for interpretive inquiry" (Charmaz, 2006, p. 25). Using my own notes from their answers to the questionnaire in stage 1, I encouraged the three teachers to reflect on how they felt their classroom practices had been informed by their former graduate studies abroad.

Overall these interviews were based on a series of pre-determined, open-ended questions (see Appendix III). The purpose of these interviews was to open up the topic, by encouraging each participant to talk extensively about their classroom experiences, while making sure that the interview did not "turn off track". I gave each participant ample flexibility to talk about whatever he or she wished to articulate. It is often the situation that one teacher has constructive insights into one particular component of being a language teacher and classroom practices, while a different teacher has similarly important insights into another component (Senior, 2006). As many teachers would do, the two teachers who participated in this study brought to the interviews not just insights gained from their current teaching practices in Libya, but insights from their language teaching experiences in other contexts and cultures, their personal experiences as language learners and as graduate students, and their personal life experiences as well.

The insights offered by one teacher produced further questions in my mind; questions that the next teacher could be asked to answer. This form of questioning is known as "theoretical sampling" within the grounded theory approach (Charmaz, 2006). This particular technique enables the researcher to discover and explore the implications of additional phenomena that 
may not have been regarded as important before undertaking the research. Furthermore, by "asking [a] subsequent teacher[s] to elaborate on insights and observations provided by previous teachers, [allow for the development of] a compromise picture of what all the teachers are collectively saying". Besides the "validity of the findings is also enhanced, since the researcher can check whether the insights provided by one teacher are unique or shared by others" (Senior, 2006, p. 21).

I employed the same interview techniques throughout this study putting teachers at ease by asking them about their past learning experience abroad, and then asking them for their personal insights with regards to how they felt graduate studies was important in guiding their practices. Regarding interview questioning, I ensured that I asked open questions instead of leading ones. I tried to carefully word my open-ended questions because as a novice researcher it would help me to "avoid blurting out loaded questions and to avert forcing responses into narrow categories" (Charmaz, 2006, p.18). My questions asked the participants to describe and reflect upon their experience in particular ways that rarely take place in everyday life. I also frequently pushed the participants to expand on each point they made; along with a questioning tone of voice to encourage the participants to further expand. This meant that they further explained a particular incident or presented an example of what they meant by a particular concept. I also used 'devil's advocate' style questions and hypothetical ones such as 'what if?' For example, one of the teachers said that he implemented communicative approaches in his classroom techniques. In order to understand what he actually meant by communicative approaches, I asked him to give an example of what he does in his classroom that he believed was communicative. 
In addition, I encouraged them to describe events and behaviours that they believed had helped or hindered the implementation of ideas and methodologies of teaching that they may have acquired or experienced from abroad. After their clarifications and responses to my questions, I would provide on-the-spot validity checks. This was achieved by repeating to each participant what they had said during the flow of the interview and to also ensure that I have understood them correctly.

As each interview progressed and themes in the data started to emerge, I considered secondary sources in any research areas that seemed to be relevant. Insights from these sources further informed and enhanced my analysis and understanding of the teachers' accounts of their current practices and their learning experience abroad.

\section{Stage 3:}

This section was a further clarification stage, where I used e-mails and phone calls to clarify, extend and validate my understanding of the two teachers' accounts and reflections that took place in stage 2. For example I asked: What other countries have taught at other than Libya? Do you only teach at the graduate level and only at the Academy of Graduate Studies, Janzour?

\subsection{Data Analysis}

The convention in research methodology is to collect all the data first, and then after the whole process of data collection is completed an analysis of the data would follow. Having employed a grounded theory approach in this study, a different procedure was followed. I interchanged between data collection and analysis in an ongoing manner. This required that the 
interviews were not conducted until I had all of the questionnaire responses, and the second interview was not conducted until the first interview was analysed. This procedure supports Stake's (1995) notion that "[t]here is no particular moment when data analysis begins. Analysis is a matter of giving meaning to first impression as well as to final compilations" (p.71).

The questionnaire responses were read several times and emerging themes were highlighted as I attempted to detect some of their beliefs with regards to graduate studies, classroom practices, innovation and change. When examining participants' responses either from the questionnaire or interviews I took these key points that Woods (1996) emphasised upon examining any data:

The importance of the issues to the teachers is signalled by the frequency of their occurrence, their centrality with regard to other issues, and by explicit mention, by tone of voice and other signals of highly loaded issues, and other means of evaluation. The relationships among themes are signalled and can be deduced by the way in which the themes are embedded in sentences and contexts which include mention of other themes. (p. 32)

The interviews were audio-recorded by using a programme called Pamela for Skype: The Professional Version 4.7. The interviews were later transcribed and coded. All of the interviews were transcribed in full (see Appendix IV). Although at the start of the research I decided that I would only fully transcribe the first interview, after reading the first transcription several times, I found underlying meanings imbedded between the lines. Despite the fact the process of fully transcribing the interviews was very time consuming, it proved to be a worthwhile activity. A 
number of likely important pieces of data may not have been identified if I had not undertaken to transcribe the entire interview. It can also be related to that fact that a researcher is unable to know until a much later stage of the research the significance of what has been articulated by the participants.

The data underwent coding, there were several coding procedures that took place so that it would open my mind to several ways of understanding and exploring the data. "Grounded theory coding requires us to stop and ask analytic questions of the data we have gathered. These questions not only further our understanding of studies of life but also help us direct subsequent data-gathering toward the analytic issues we are defining" (Charmaz, 2006, p. 24). The following sequence of coding practices was followed:

a) Open Coding: First opening up of the data.

b) Axial Coding: Positioning the data collectively in novel modes.

c) Selective Coding: Analytically unfolding categories to the essential trends that are surfacing.

The first stage of the analysis involved making notations all over the transcripts. This process included the:

1) Highlighting of words that were noticeable from the neighbouring texts.

2) Noting words that were very similar or even connected with other texts.

3) Drawing arrows representing potential relations between texts.

For validity checks I asked my supervisor and one of my colleagues to read my transcripts and to see whether or not we arrived at similar codings and emerging themes. In the 
next chapter, findings of the study are presented; this is followed in Chapter Six by a discussion of the findings in relation to the research literature and theory that informed the study, and the research question that guided this inquiry. 


\section{Chapter V}

\section{Results}

[Change] is not effected without some concomitant change in the teacher ... What the teacher thinks, what the teacher believes, what the teacher assumes all these things have powerful implications for the change process, for the ways in which curriculum policy is translated into curriculum practice (Hargreaves, 1989, p. 54).

This chapter describes the findings of this study that addressed the main research question, namely, what is the impact of the Libyan Study Abroad Scholarship Programme on returning university level English teachers? I present the three teachers' reactions to their prior learning experience in the study abroad graduate programme, the effect of these experiences on their beliefs about learning and teaching of English, and the effects of these beliefs on their choice of classroom practices and teaching behaviours in their current teaching. Here I draw on interviews with the teachers and questionnaires, through which I aim to understand the impact of the Graduate Study Abroad Programme on university-level English teachers' practices. Applying a constructivist, grounded theory approach (Mills, Bonner, and Francis, 2006), to the data, several themes emerged, which are relevant to understanding the impact of the Study Abroad Scholarship Programme. I consider each of these in turn below:

1. Teacher's characteristics 
- My perceptions

- Teaching experience

- The graduate programme and its value

2. Significant concepts within graduate studies and how they affected teachers' beliefs and current practices

3. The implementation of innovative practices, and obstacles that surfaced

4. Graduate studies and how it informed teaching practices

Before I proceed with presenting the findings, it is important to note that the findings are briefly discussed in this chapter. In The subsequent chapter I discuss the findings in relation to the literature review and research questions in greater depth.

\section{Teacher's characteristics}

\section{a) My perceptions}

From interviewing and establishing a rapport with the teachers, and in all my conversations with the teachers, I would describe the teachers as the following:

Teacher $A$ appeared to be what I would describe as a sound and insightful teacher, who has good social interaction abilities. From his accounts he appears to be modest, open-minded, motivated and enthusiastic. He claims that he considers all his students to be friends.

Whereas, in my conversations with Teacher $B$, appeared to be what I would describe as a father-like figure in the classroom, who appears to be mature, wise, tolerant, motivated and 
has a sense of humour. He acknowledges that he is a rebel inside the classroom and is always prepared to take risks for the sake of learning. Teacher $B$ loves the profession of teaching and considers teaching a part of him: "I love teaching. I mean the profession of teaching is something I really like very much; I can't imagine myself doing something else".

Both teachers seem to have faith in their students' abilities to accomplish and be successful individuals. It appears that they take their students seriously and allow their students to assume responsibility and control of their own education. They appeared to be dedicated to letting guiding principles and practices emerge from both their fundamental learning objectives and from a reciprocal respect and agreement between the students and themselves (Bain, 2004). Unfortunately, it was not possible to describe Teacher C's characteristics due to the lack of communication as a result of the political situation in Libya.

\section{b) Teaching Experience:}

Teacher $A$ has been teaching English for more than twenty years, and has been teaching at university level since 1999, (in all almost thirteen years). He is currently working at a private institution for graduate studies teaching courses in relation to applied linguistics, which include English for specific purpose (ESP), grammatical structures, comprehension, language testing, and technology in ELT, general linguistics, syntax, semantics, and second language acquisition (SLA). Prior to his current teaching position in Libya, he was a university professor in several other countries. These included UK, Saudi Arabia and the United Arab Emirates. 
Teacher $B$ has been teaching English for more than twenty years and his only teaching experience has been at university level. Teacher $B$ was in one of the first Libyan student contingents to study English in the United States in the early eighties. He started his university teaching career in 1981 and continued until 1994. After completing his $\mathrm{PhD}$ in 1997, he returned to his former teaching position at a public university in Benghazi. He is currently teaching courses related to literature, literary readings, literary criticism, and literature in ELT. Teacher $B$ teaches both graduate and undergraduate courses at the same university, and he has no interest in teaching abroad: "I want to teach here, I want to suffer here, to show my student a model of a different teacher. At least my students will say we knew one person like that one day. And for me that is success".

It is important to note that due to the political situation in Libya, I was unable to interview Teacher $C$ and record her accounts and reflections with regards to the research question; the only data that I was able to obtain was her questionnaire responses. In the upcoming sections, if Teacher C's responses are not represented, this is due to the fact that information with regards to this participant is missing because it was impossible to interview her as a follow up to the questionnaire.

Teacher $C$ has taught English for almost ten years, and has been teaching at university level since 2005, (in all almost six years). She is currently working at a public institution in Misurata teaching courses in relation to applied linguistics, which include language skills, oral practice, language question, academic writing and research methods. Prior to her current teaching position in Libya, she was a teacher assistant in several ESL language schools in Canada and undertook many practicum placements for her TESL teaching certificate. 
c) The Graduate programme and its value:

Teacher $A$ holds both a Master's and Doctoral degree in English language teaching and applied linguistics. He had spent more than ten years in the UK, where he obtained both degrees. His latest degree was completed in the year 2004, and he returned to Libya in 2009. His Master's degree was a thesis path (courses and thesis), and his doctoral degree was a dissertation-based degree. Teacher $A$ had approximately fifteen years of learning experience abroad as a student.

Along the same lines, Teacher $B$ also holds a Master's and Doctoral degree in literature. His Master's was obtained in the United States. It was course-based (along with a comprehensive exam) with a thesis path degree. He took more than twenty courses during that degree, which ranged from applied and theoretical linguistic to literature and education. He completed his doctoral degree in the UK. Like Teacher A, it was a dissertation based degree.

Teacher $C$, however, holds only a Master's degree that was obtained from Canada in English language teaching and applied linguistics. She had spent more than seven years in Canada, where she obtained her degree and other certificates such as floral arrangement. Her latest degree was completed in the year 2005, and she returned to Libya at the same time. Her Master's degree was a thesis path (courses and thesis), and she had seven years of learning experience abroad as a student. 
Teachers $A$ and $B$ explicitly acknowledged that they enjoyed their graduate programmes and their studies abroad. They described the learning environment as relaxing, enhancing, cooperative, motivating and supportive. They enjoyed the flexibility, and both admired and witnessed good-teacher rapport and mutual respect. They emphasized that it was a healthy learning community, and they were a part of it. They acknowledged that they had not experienced such a sound learning environment during their undergraduate programmes in Libya, for example Teacher A pointed out:

[What] I liked about it [study abroad] was the good atmosphere, the warm atmosphere, very motivating environment, obviously good teachers. ... It was a very warm equal relationship, a lot of respect encouragement... The encouragement, the fairness, their [professors] availability, their continuous presences and support, we like full time staff working there. That's how good and how flexible and how inclusive the environment was ...I can honestly say, I was very happy in the years I spent [there].

Teacher $B$ echoed a similar view:

It was a very good programme... I did enjoy the way you know coming from Libya and going to the States... I mean it was there in front of my eyes differences between the way I was taught here as an undergraduate in Libya... The atmosphere was open. $I$ enjoyed the the educational freedom... The environment itself as you said professors I enjoyed the kind of you know laissez faire attitude that was there you know coming from a very conservative educational atmosphere to a very kind open atmosphere. The relationship between teacher and student is not as conservative as or as restrictive as it was here [Libya]. 
Teacher $A$ further reported that it was not only the learning experience and the accumulated knowledge that made this whole experience enjoyable, but also the cultural experience that added to his personal experience:

It wasn't ...the education; it was the culture, living in the country. We learnt a lot of things that know I'm passing to my students in in Tripoli, where I am teaching at the academy of graduate studies. So it was really other skills I mean, interpersonal... it was not just the education, it was we learnt the personal skills from our professors, ...we acquired some life styles...it was much more than just the education programme.

\section{Significant concepts within graduate studies and how they affected teachers' beliefs and current practices}

As a result of asking the teachers to reflect on concepts; or theories related to teaching that had struck them and were significant during their Study Abroad Graduate Programmes, several themes emerged: the student-centred approach, the facilitating role of the teacher, communicative approaches to teaching, flexibility, good teacher-student rapport and an enhancing learning environment. Each of these themes is discussed below:

\section{a) Student-centred approach}

According to Dewey, this approach emphasizes the importance of learners' independence and responsibility for the learning process, and ascribes more importance to the learners' 
experience and knowledge in the classroom. In addition, the student is perceived as an investigator, rather than a passive receiver of information; in other words, the learning process can be seen as a "shared activity" in which "the teacher is a learner, and the learner is, without knowing it, a teacher" (Dewey, 1916, p. 160).

Both teachers commented that they had been surprised when they experienced and witnessed this both in theory and practice during their graduate programmes abroad. They emphasised the different role of the teacher, whereby, the teacher took on the role of a facilitator. Their strong emphasis on this concept as they discussed their experience with me may have stemmed from the fact that they had no prior experience with it during their educational years before graduate studies. As mentioned earlier in Chapter Two, the prevalent role of the teacher in Libyan educational system is teacher-centred:

Teacher A: I think the most striking theory or method of teaching was the learner centred-approach, where learning was given, the responsibility was given completely or thrown at the students... This for me this was something very new, because we I didn't have any experience. We before we relied on our teachers, whether we were at the university or at the high school or at the primary school.

Teacher B: in the States with reference to teaching I still use it and I use... A teacher is not a dictator in the classroom a teacher is a facilitator. In other words, I think one of the ideas I learnt over there, one of the concepts as a teacher, your job is to facilitate the process of learning for students it is not to dictate things. The whole concept of the teacher is not as a guru. 
When I asked Teacher $B$ about the rarity of student-centred learning in the Libyan educational system, he reported that students are reared from a very young age to memorise whatever is dictated by their teacher and what is printed in their textbooks. They are expected to reprint the "spoon-fed information" and nothing more, and thus the student-centred approach is conceived as a very rare approach in the Libyan context:

Yes, because we are forced to learn things off by heart. Teacher is the as I said the god like figure who does not make mistakes or hardly sleeps. Alright who kind of you know divulges the information and what you have to do imbibe it in and take it in and thank you for that.

The prominence of both the teacher-centred approach and memorisation in the Libyan educational system, and how it may impede educational reform is discussed in detail in the subsequent chapter.

\section{b) Communicative approaches:}

In stage 1 of the data collection (questionnaire), I asked the teachers about the approaches to teaching that they have experienced during their graduate programmes and of which they are currently proponents of. All the three Teachers $(A, B, C)$ stated they were proponents of the communicative approach. However, Teachers $B$ and $C$ contended that there should be an integration of both communicative and traditional approaches in language classrooms. Their views were as follows: 
Teacher A: I am a believer in the communicative language teaching approach and I think it is the best in all the approaches. It offers a real opportunity for all students to learn another language.

Teacher B: with reference to literature, it is necessary to use a combination of approaches that cater to the students' needs and takes into account their language level and literary competence.

Teacher C: Through many years of experience ....classes have always been comfortably teacher-centred. ...From experience using the communicative approach $I$ do believe that it is important for language learning and it is more successful. ... But, at the same time, I do not agree that we should be ignoring the old traditional approach because the integration of both approaches when needed is required.

It appears from Teacher $B$ and $C$ 's above accounts that in their opinion there should be a balance between the traditional and communicative approaches to teaching; no one approach can substitute for the other, as each has its own advantages.

c) The effects of these experienced concepts on the two teachers beliefs system

It was evident from the two teachers' questionnaire responses, reflections and accounts which took place in the interviews that the above teaching concepts and their graduate programme learning experience and learning environment had had an impact on their beliefs. Consequently, teachers' beliefs about student-centred learning, the teacher as a facilitator, and communicative approaches may have had a significant influence on their practices: 
Teacher A: I think that's what I am saying this I got this from Sulphide, Colchester and from Glasgow where I studied...So it's that kind of thing I got from the UK or my experience from the west.

Teacher B: So that [graduate studies abroad] helped me to build up a very good background in English literature and English language, linguistics and you know... the background I am proud of I actually accumulated in the United States through the MA programme I studied... I think that's my own philosophy here I think as a teacher is shaped by all of those concepts that we discussed before.

The notion of the teacher as an authority, passing on knowledge to students is no longer the two teachers' notion of teaching. Their belief now is for a more autonomous, student-centred approach, in which the teacher facilitates and assists communicative educational activities with students:

Teacher A: giving the responsibility of learning to the students makes them aware that learning is their business and they will obviously work on that and they will know that the results they get it is that it's their work and so my role in where I teach now, again mainly as a facilitator, a helper, a counsellor...

The teachers reported the importance of the cognitive powers of students to build up their own, autonomous understandings or structures of their world. Students are treated as selfdirected, independent and unique individuals who ought to be capable of assuming responsibility for their learning process within this supportive and co-operative mode of learning that they are implementing:

Teacher B:[ I tell my students you have to] extract your own meaning from the text, if you want to adapt the things I say that's fine. But I'd rather you say something completely different... You [talking about how he adopts his approach] do it in a way where [you] actually try to relate what you are talking about to their own experiences 
or you even, you start to prompt them with question here and there, right. You try to as I said kind of entice them to say things... If you want to have that kind of grade then you have to say things I haven't said, do things I haven't done, even if you're wrong.

The teachers further reported that their role is no longer the transmitter of information but rather the facilitator with the goal of raising students' awareness. The teachers followed a path of a more student-centred, autonomous style of learning and it was clear from their accounts that the previous associated concepts of teacher authority have diminished within their current practices. They implemented these new concepts (for the Libyan educational system), by having classroom discussion, presentations, encouraging students to express their opinions, promoting opportunities for critical thinking activities and so on:

Teacher A: I make students give lectures with me in the course. I make them give presentations... I said really I tell the students from day one of any course that it is their business to learn and study. I am just there to advise them to add from my experience whatever is in the books... the students participated in discussions they gave presentations they even brought outside topics and discussed them, for example we looked at the TOFEL test in terms of reliability, validity and their... particularly that kind of depth...

Teacher B: The idea of a the facilitator ... I always make clear in the class that there is no monopoly, for example, when we talk about literature when we have a literary text, there is no monopoly on meaning. There is no monopoly on the way it is interpreted. I always make that point very clear. What I say is just one meaning. Or a meaning for example and that meaning is shaped by my own personal opinion, background, ideas, etc etc...

How graduate studies have changed the two teachers' roles in their current classrooms are discussed further in the subsequent chapter. 
When the teachers discussed the underlying principles behind their instruction, they revealed ideas about the roles of teachers which are not in line with those of the Libyan educational culture and context. Their perceptions and beliefs of learning were no longer in line with the traditional educational Libyan culture that perceives education as a process of conveying information.

Teacher $A$ further emphasised that it was always possible to apply the student-centred approach in the Libyan context. He explained that this practice is possible as his students (who are mostly practicing teachers) reported that they will be replicating Teacher A's approach in their own classrooms. He also mentioned that not only can a teacher implement a student-centred approach within the Libyan educational context, but in fact any other approach from abroad:

Teacher A: Yeah I think I would like to emphasize the the point that the ...it is possible to make students responsible for their learning and encouraged to work on their own. When they are not in the the class, they become more forthcoming for asking for help and guidance from me. ... the other point I didn't mention that the students say yeah we will also apply this when we go back to our teaching, to our schools to our classes....And yeah there are ways where you can bring something from anywhere in the world and apply them in Libya.

However, Teacher $B$ implemented a mix of both student-centred and teacher-centred approaches, which he referred to as an 'eclectic approach'. He believed there was a need to implement a teacher-centred approach to help ease the cognitive load of an activity, and thus promote and mediate learning:

Teacher B: you have to start the class with a traditional approach by providing information for example or by providing information of text or whatever. Then you move on to the the other approaches the student the student-oriented or student-centred where you ask students question OK what 
do you think [about] this? What do you think of that? ...then you start to move from different approaches.

When he applies a teacher-centred approach he claims that he does not take on the role of the teacher in authority, but instead takes on the role of a mediator, working to integrate both teacher-centred and student-centred approaches and to reduce the cognitive demands of the tasks to accommodate the students:

Teacher B: sometimes you resort to the traditional way of teaching, but only to help, only help and to go back to the main task which is students-centred. You have to do it. a) you have to do it to meet the students needs, b) to to encourage them ... In other words, when I lecture I don't stand at podium and giving a lecture and sometimes I come across agonising, shake them out of their places you need to do that.

Furthermore, it is clear from the teachers' accounts that they seem to be oriented towards communicative approaches to teaching; they felt that the majority of students' characteristics such as motivation and openness to not resist made it a possible and practical instructional technique:

Teacher A: Students were most of them I would say were really motivated... and I think the students are so happy... They were so much motivated...

An example of the communicative approach in the teachers' comments on teaching is their use of group work. The implementation of group work can be viewed as a change or innovation, as discussed earlier (Chapter Two) the educational learning setting within a Libyan classroom is a competitive type rather than cooperative (as from Chapter Two). The implementation of group work may help this philosophy of competition to fade away: 
Teacher A: I always try to get students to work in groups whether it is a, for example if we have a problem to look at for example testing. ... I would obviously change the set up of the classroom the way the students sit. So they would sit in groups or in a in a circle or a semi circle. And the students start discussing the issue in a group and then they come up with some group answer. ... So it's all done like in a small community kind of work. Students give group presentation. For example we had one presentation where it was given by three or four students not just one.

Teacher B: each group will study the text separately from other groups in the class. We have different groups and then we come together and then we start discussing things how we come up with ideas together we designate... And I've become a mediator by the way, I don't even say anything, I don't even talk... just can guide what the other groups think. And sometimes when we have conflicting ideas, I say alright, why did you say that?

Although they used group work in their classroom practices, they did acknowledge that they were sensitive to the cultural and Islamic norms of Libyan culture, such as the convention where males and females who are not from the same family tree are prohibited from having close relationships (Orafi, 2008). They encouraged group work and mixed groups, but did not intervene and assign groups. Instead, they allowed the students to choose their own groups, as they were aware some students who were not comfortable working in mixed groups. Their main concern was rather the product of that activity, and how the whole activity promotes a co-operative learning environment, and thus enhances learning. They reported that group work happens very smoothly and naturally. They stated they would have groups of single sex and mixed groups during group work activities:

Teacher A: Yeah I mean I'm sensitive to this. If people would like to sit with each other whether males or females, I would definitely, go with the situations. In some classes you find females are sitting in own groups and males in their own groups. In some classes they were mixed. So I just really let go by the 
circumstances or situation. I don't force people to sit in a particular set up. It works smoothly... If they're happy to sit with each other I don't really mind.

Teacher B: I say lets break down the class into groups of five or six alright. Naturally speaking some of the groups will be all females and some of the groups will be males, and then you will have most of the groups. But then you will have most of the groups will be mixed you will have two males with four females or whatever. And I don't I don't interfere and I don't intervene and I don't say why or whatever. ...And you know as you said tradition is of course is there.... I am sensitive to the, because I am part of the culture. I am sensitive to the culture itself, being based on religion mostly, it is a religious culture.

Touching on the issue of sensitivity, Teacher $B$ further reported that whenever he chooses a piece of literature that he wishes to present to the students, he takes into account the Libyan cultural norms. He never chooses a text that would violate the cultural aspect of the Libyan society, regardless of the quality of the text. Thus, in accordance with Cortazzi and Jin (1997), this establishes that the sensitivity to the culture is a crucial factor when the teachers implement innovative practices in their Libyan classrooms:

I'm mostly sensitive to the extent that the text I choose, should not in any way infringe on that culture ... I do admit to others that I sometime I practice it on myself. I censorship... I do my own censorship, I don't choose texts for example that are full of curse words or whatever, I don't do that. Because there are texts that I would like to teach, but I don't teach simply because I have I have got the alternative.

As discussed above, the teachers reported that they were inspired by and enjoyed the enhanced learning environment of their graduate programme, which had the qualities of flexibility, good teacher-student rapport, respect and support. It must be noted that a positive 
teacher-student relationship leads to: higher academic motivation and academic success (Roeser Midgley and Urdan, 1996; Wentzel, 1997); increased student social emotional skills, such as caring, empathy, and social responsibility (Buote and Schonert-Reichl, 2004). Having experienced all of these attributes as students, they stated that they are attempting to replicate the same democratic learning environment within Libyan classrooms. From their accounts, they believe there is an environment of support, respect, good teacher-student rapport and flexibility in their current classroom practices:

Teacher A: I am so flexible now where I work at the academy. My office when I arrive students just pop in and come in stay or talk, bring their problems or whatever. It's the the they told me that they said we have not really experienced this in many other teachers... I can treat them like friends more than students. And the and again I practiced things that flexibility -that I experienced in the UK. ... again flexibility, it's the input is open to the students to bring in whatever they want to the course.... give; I always give the students priority to talk. If if I just feel that a student is trying something I just stop straight away immediately and let them talk or whatever they want.

Teacher B: I think it kind of influenced my experience or that experience influenced my practice as a teacher here in Libya at the moment. It is reflected in the way [I] treat my students or the way I deal with my students at the moment... I am teacher who is approachable; my students have no problem whatsoever to come to me not only with their academic affairs or problems or what over, they come to me with their most intimate personal problems, and they talk to me and they feel very free. And they tell to my face they feel very free to talk to you than other people or whatever. I think it is reflected the way I deal with my students whether academically or on a personal level. 
Not only did their reflections establish such issues within their practices, but also their responses to the questionnaire. The questionnaire focused on eliciting their beliefs about the essential components of an enhancing learning environment, and these were their responses:

Teacher A: A supportive learning environment

Teacher B: Motivation, Interest

Teacher C: Effective teaching techniques are essential for language learning, but teachers need to be familiar with the level and background of students.

Teacher $C$ did not touch on the issues of motivation and support, instead, she focussed on factors (attending to students' levels and backgrounds), which are seen as fundamental factors in teacher education. By Teacher $C$ focusing on the recognition of students' individuality and levels, her goal can be seen as creating an environment that is conducive to the learning for all students, because the more students believe that their school community cares about them and meets their needs, the more likely they are to feel attached to that community, to thrive academically, socially and emotionally (Schonert-Reichl, 2005). It can be also argued that " [Teacher $C]$ view[s] education not as a mass production effort, but as a personal and individual experience" (Boyd-Zaharias and Pate-Bain, 2000). 


\section{d) How they perceive their own practices}

With the implementation of their innovative approaches to teaching English, both teachers reported that their students acknowledged that what they were doing was not the norm for the Libyan educational context. It was therefore categorised and referred to as change:

Teacher A: I remember my first class here in Tripoli. This was a class of an MA I think it was general linguistics and the students told me that this class we felt that this class is running outside Libya it is not in Libya. Wow, I was really flattered and surprised and said no we really felt like in the UK or America... I mean along on the way there are things that I do that that students said we we've never experienced this we've never known this.... And said wow we've never we can never imagine this would happen anywhere in Libya. But I did it in my class.

Teacher B: they look at me alright this is not what other people say, other people want us kind of [to] regurgitate whatever's being given to them, and I said well each scholar has their own way alright. This is how I do things.

When the teachers reported that students had referred to their current practices as a change, I further asked the teachers whether they believed what they were doing was change and innovation. They responded that within their current teaching context it was change, and it was innovative to be teaching in this particular manner, although in other educational context such as the West this would be the norm. As explained in Chapter Two innovation, change is considered from the perspective of implementing established and sound approaches and concepts of teaching that are conventional in the Western classrooms, and which are alien and/or new to the Libyan educational system and culture. When asked whether he considered these practices a 
"change", Teacher A remarked, "It was we're doing what have never been done before... Yeah absolutely yeah". The response of Teacher $B$ was remarkably similar:

Within the context I am in at the moment, yeah I will probably the most of the things I do are innovative, within the context I' $m$ in within the circumstance I have. I sometimes even call myself. I sometimes tell them that don't worry I might be crazy. So I wanted to resort to the idea even if you don't like it or whatever just think of me as a someone who's lost his marbles.

Both teachers saw students developing academic skills as a result of this change that were missing within the Libyan educational culture, such as ones mentioned earlier on in Chapter Two, namely, students being active, autonomous learners, and critical thinkers. For Teacher $A$, he saw students developing multimedia projects, significant improvement in students' collaborative skills, engagement in their work, and becoming more independent compared to traditional methods. In the case of Teacher B, he saw improvements in students' learning autonomy and analytical thinking:

Teacher A: the students participated in discussions. They gave presentations. They even brought outside topics and discussed them... They were so much motivated and they worked hard [with] a few extra technological skills ... In this particular course every week I had a few students [who] would have had learnt something new ... And they say look doctor... now I want to show you and the students what I have learnt in the past few days before coming to class, I would like to show you and would like to teach the other students

Teacher B:[As a result, I know have students] who actually enjoy learning and enjoy my teaching and enjoy the process of learning and to them the idea is not only that we're going to pass the test or whatever... they talk to you and are very good. 
As discussed in Chapter Three, that teacher development is a very complex phenomena (Harris et al., 1998). In order for it to be successful and have an impact it depends to a great extent on a positive and encouraging context for learning and practical, appealing activities. In addition, the accessibility of resources, the presence of flexibility, support, and respect are all key factors in teacher development (Guskey, 2002). Having all these factors present within a teacher enhancement programme (like the Libyan Study Abroad Programme) can promote and mediate teachers' aspirations to improve or change their practice (Loucks-Horsley et al., 1987). Upon examining the teachers accounts of their graduate programmes and how it had affected their current practices, it can be argued that Loucks-Horsley et al attributes, which characterise an effective context to promote change were replicated in Teacher A's and B's graduate programmes. Therefore, change and refinement in their classroom practices can be seen in their accounts, as the by-products of those programmes.

Not only did the positive qualities of the learning context of their graduate programmes play a fundamental role in promoting change in their classroom practices, but it can be further argued that the two teachers made changes in their approaches, because they recognised the existence of a gap or inconsistency between both their objectives and principles, and the current practices within the Libyan university context (Atkin, 1992; Whitehead, 1989). Furthermore, as reported by the teachers, they experienced accommodative ${ }^{25}$ change because they appeared to possessed the following qualities. They were: 
1. internally motivated to learn, and to change.

Teacher B: I was highly motivated and enjoyed as you said the enjoyment I think the enjoyment that's where it came from.

2. fascinated when they saw satisfactory things happening and progress in their graduate programmes.

Teacher A: ...this for me this was something very new because we I didn't have any experience....So I think that was the most striking concept.

Teacher B: I didn't have any problem kind of getting into the spirit of that system. It was not like a shock to me, you know, it was something new. I was pleasantly shocked you can say

3. became aware of their implicit ideas and practices and critically examined them; consequently, constructed alternative knowledge, beliefs, and practices (Hashweh, 2003).

\section{Implementing innovative practices and obstacles that surfaced}

During stage 1 of the data collection, I asked the teachers about how difficult they found the implementation of new ideas in their classrooms. Teacher $A$ explained that he found the implementation process to be fairly easy, despite the fact there was evidence of a clash between his perception of learning and that of the students in his current classrooms. Teacher B, however, indicated that he found the implementation of new approaches to be moderately difficult. In 
accordance with Cortazzi and Jin (1997), and Orafi (2008) (as mentioned in Chapter Three), both teachers reported in their responses that the culture of learning was a stumbling block during the implementation of new approaches. Why the culture of learning was impeding their innovative approaches is discussed further in the subsequent chapter.

Similar to Wang (2006) and $\mathrm{Hu}$ (2002), lack of facilities was an external factor that hindered and in extreme cases even prevented the implementation of innovative approaches in Teacher $B$ 's classrooms. Following up on their questionnaire responses, the interview further elaborated on the issue of implementation and what factors affected their innovative approaches in their classrooms. From their accounts the following factors emerged as common themes (Charmaz, 2006):

\section{Student Culture}

- Student resistance

- Student levels

- Students disinterest in the whole learning concept

2. The dominating Libyan educational culture

3. Lack of facilities

\section{Student Culture}

- Student Resistance:

As discussed in Chapter Two, both Teachers and students function within a socio-cultural setting, bringing with them to any classroom a fixed set of beliefs and expectations about the 
classroom etiquettes, what is to be taught and how it should be taught (Senior, 2006). While the two teachers brought with them from their graduate study programmes and learning experiences set beliefs about how learning should take place, so too, their students also brought their own expectations and beliefs.

Teachers $A$ and $B$ both noted that in every class there was a minority amongst the students who resisted their new approaches to teaching. They remarked that they try to educate the students and show them how advantageous their new approach might be. Teacher $B$ pointed out that he uses humour in his classroom to acknowledge that what he does may seem "insane" to some students, but that as the years pass, they will appreciate it, because they are acquiring lifelong learning skills:

Teacher A: a minority did definitely resist... it's you know they they were a minority in each class, I find in each class. And I think these... this minority believes that it's their right is to get information from the teacher and and and that's it really. Here, there is of course resistance... The other part is to educate them, to show them how this new technique... approach works.

Teacher B: There were a few times where students resisted sometimes even openly, but not so much... we [one student talking on behalf of the students]actually had a meeting and [they said] we don't like the way you teach etc. So I said alright so we discussed dramatically.. I make jokes about myself being a kind of an outlaw, a kind of teacher who is actually on the wrong page who should be should be incarcerated, who should be imprisoned. And it works by the way. I express the idea, that you may hate me, but you'll love me thirty years from now.

- Students' levels:

Teacher $A$ remarked that the low levels of linguistic competence that students generally have constituted a problem in dealing with his students; he was even surprised that they were in a 
graduate programme. He further emphasised that a prevailing characteristics amongst the Libyan students was they had high expectations of themselves, despite the fact they were not fully competent in English. They continuously argued about their grades, and would do anything to improve them, which was challenging for the teacher:

One of the challenges is that the, many students have higher expectations in terms of the grade they get....I remember I had one of the students, really kept disrupting the class, talking about this day that she got very poor; I think she got a very poor grade, but her English was not really up to the standards of an MA student. I don't know how she got into the programme. .... This is most of the challenges I have Yeah I mean it's it's in probably in all classes

Teacher $B$ complained that students often lacked literary competence and literary analysis skills such as critical thinking skills, rather than insufficient linguistic competence. He reported that while his students were fully competent in English and spoke fluent English with native-like accents, the lack of literary competence amongst his students was challenging his ability to implement his innovative techniques to teaching, (which would in the long run promote studentstudent learning). Despite this challenge, he stressed that he enjoys the way he tackles this issue, and his attempts to develop critical thinking and analytical skills within his students. His account was as follows:

Teacher B: It is very challenging in that it deals with critical theories and you know. . And I think that is where the problem lies in the literary competence, they do lack that kind of that strata or system by which they can actually look at a literary text and you ...I enjoy that kind of challenge. 


\section{- Students disinterest in the whole learning concept:}

Another characteristic that concerns student culture and which challenged the teachers', (in particular Teacher B), implementation process and classroom practices is students resistance and disinterest in to the idea of the whole learning process. This resistance according to the teachers, stemmed from students' lack of interest in the whole idea of learning, as their main concern was the material that they would be tested on, as evidenced in Teacher B's that:

...you're talking about concepts, you're talking about ideas you're talking about philosophies sometimes. Then someone, not someone but a group of students might raise their hands, excuses sir could you tell us exactly what part of the curricula [this is]? In the test which are not include and what type of test will it be? An essay or MCQ?... I am only here as you said I am only here to pass to I am here to get a degree.

It can be argued that interest is an inner characteristic that elicits attention, and that volitional attention is conducive to better learning (Hidi, 1990), where it necessitates assimilation and interest. Creating interest in learning is one of the main roles of the teacher because interest constructs the principal basis of learning. It is generally accepted that one does not learn material if he/she has not developed the interest to learn. In addition, interest encourages better attention, and thus better observation and insights. Interest should also be stimulated before learning starts, and for reasonable results, it should be sustained throughout the learning process (Hidi, 1990).

To sum up, factors such as students' resistance, students' levels and students disinterest in the whole learning concept brought about student culture that was a stumbling block when these teachers implemented their innovative approaches. Suggestions on how to deal with the 
prevalent dynamics of the Libyan culture of learning, which may hinder any educational reform policy, are offered in Chapter Six.

\section{The dominant Libyan educational/learning culture}

From the teachers' accounts it can be surmised that the underlying principle behind students' resistance was the dominant Libyan educational culture. The teachers emphasised that the attributes (for example, students being passive learners, classroom pedagogy is test driven, rote learning, and prominence of memorisation as discussed in Chapter Two), had a significant effect not only on what takes place in their classrooms but also on the whole educational system. They reported that their students are generally accustomed to the dynamics of being passive learners rather than the teachers' innovative student-centred approach. The students expect the teacher to teach, to fully prepare students for exams, and to only teach what will be on the exam; this contradicts the teachers' notion of students taking responsibility for their own learning. In addition, students are not used to the idea of arguing about the validity of any given information from the teacher, as this is seen as impolite within Libyan customs.

Furthermore, the teachers' accounts reflected that memorisation of facts and information continues to be prominent within the Libyan educational culture. Students may just want to memorise and in turn mirror the sustained belief that anybody can accomplish success in language learning and acquire it, in either French or English, just by conscientious work. Nevertheless, the interpretation of hard work is generally established by memorization and practice, even at university level: 
Teacher A: it's probably cultural... I think it's cultural, I think in this part of the world people expect much more than they should get I think... Yes I mean yeah the culture of the institution and the culture of the the society definitely affect sorry affect the system, the teaching the assessment and so on.

Teacher B: I think it is the whole culture as I said before we were reared up this way, this is what you learn, you learn off by heart and you are going to be tested on. I don't blame them by the way...I know that's very difficult, they are trapped the students and teachers by the way. They are trapped into a culture that still cannot escape from these constraints that it has on itself....it's the general culture as well. It is not only the students' culture, it is part of the overall culture as well. ...It is in the whole system, it is not just my class, or somebody else's class. It is not my faculty or my university. it is all over the place.

With regards to the prominence of memorization, both teachers had much to say:

Teacher A: a minority did definitely resist the idea and obviously I understood the situation because of their long experience in rote learning and memorisation and the teacher is the authority, the source of information and all this stuff... And I think these this minority believes that it's their right is to get information from the teacher...

Teacher B: We are forced to learn things off by heart. Teacher is the, as I said, the god like figure who does not make mistakes or hardly sleeps. Alright who, kind of you...know, divulges the information and what you have to do imbibe it in and take it in and thank you for that. I think is one of the major problems we face today. 
They also agreed that the educational system does not rear students to think critically or

reflect:

Teacher B: I don't blame them by the way. It is the system itself, they were never encouraged, they were never told, never encouraged to think on their own. They were never encouraged to express themselves you know. And talk about what they think or whatever, that is the problem. ...they have to learn things off by heart the things the professors or teacher says. That is from day one they were never told to think critically. So and the problem is compound in the university that's all.

Teacher $B$ further reported that students do not express their views forthrightly in the class. Instead, they would come to his office later (privately) and express their ideas and interpretations of the texts. This touches on one of the dominating factors customary in the Libyan culture, where it is seen as impolite to disagree with someone's point of view. It is more respected to save face in a conversation than to argue:

[t] hey'll come up to my office. I really liked what you said, and I think do and they talk to you and are very good. And I say why didn't you say that in class. And they say well, I would rather. They don't like to talk in public in groups for example. So there is that kind of behaviour.

\section{Lack of facilities:}

Pergrum \& Anderson (1999), claim that the use of educational technology is viewed as a move towards school reform. Teacher $A$ did not identify any shortage or lack of resources and technology facilities at his current institution, instead there was reasonable satisfaction. There was internet access in all classrooms (this was very abnormal within a Libyan context at the time 
of the interview) and availability or resources such as data shows. The availability of resources can be related to the fact his institution was private, and has private funding. The government did not offer any form of support to these privately run institutions. Thus, Teacher A's institution may have introduced technology as part of school development or reform-"a systematic, sustained effort aimed at change in learning conditions and other related internal conditions ..." (Van Velzen, Miles, Eckholm, Hameyer, \& Robin, 1985, p. 48). This may be considered as evidence of one of the private institutions in Libya reform agenda that has taken practical steps towards educational reform.

However, Teacher $B$, who is currently teaching at a public institution in Benghazi, complained about the lack of facilities both within his classroom, and in most institutions. These facilities had no internet access, data projectors, or screens; no tape recording equipment, gadgets to plug a tape recorder, and in extreme cases, no electricity within the whole institution. Teacher $B$ emphasised that absence of basic equipment and facilities in the classroom impeded and sometimes prevented him from implementing some of his teaching approaches in his classroom:

Instead of teaching I would like to show the students a movie, a film, instead of teaching a play for example. I do like to do that because that play or that novel, ...And you can't simply because you don't have the facilities. Sometimes you have the... I do have tapes for example, poetry .... you know you don't have facilities available all the time to have your students listen to it. Even if you have the tape recorder or whatever, you don't have the plug where you can actually you know... we sometimes even teach in the dark sometimes [electricity being cut off in the winter as this is very common in Libya during the winter season]. 


\section{- Reform and the Libyan educational context}

The notion of reform was touched upon during stage 1 and 2 of data collection. In the interviews the teachers argued that the Libyan educational system needs to be subject to reform in order to boost the quality of the Libyan educational system:

Teacher A: I mean reform is definitely required I think the education, the education programme that are at schools, they should they should always be subject to some kind of reform. I think reform is good in education, Because of the development in the world, and the technology. So definitely we should I think the reform should be ongoing and continuous and in terms of time it should be carried out.

Teacher $A$ mentioned that the Libyan educational system needs to create good management, increase resources, increase training for teachers, raise standards and improve facilities. In order to support teachers the Libyan educational system needs to introduce the teaching assistant system, lower teaching loads, provide enough faculties, encourage research and create the right environment for research, raise teachers' salaries, and prepare qualified teachers. During the interview Teacher $A$ further elaborated on reform and added that technological reform at all levels is needed in their institution:

we probably we need more technology at least in this part of the world. We do have technology, I have internet in the office where I teach; most classrooms have data shows and so it's... but it's we still need some kind of technological reform if you like so to boost the system, the whole system whether it is registration, or access to electronic libraries, on line databases and that kind of stuff. We still lack these things.

Along the same lines, Teacher $B$ stressed that his institution needs to be subject to numerous reform, including: better facilities and resources, teacher-student relations and institutional 
dynamics. But from his perspective, change and reform in terms of the way people think and behave is of most importance:

I think basically you know as well as I do, we need reforms from $A$ to $Z$ whether it is the institution itself, whether it's the facilities, whether it is the relations between students and teachers, leadership in the institutions, in higher institutions. We need people who are open minded, intelligent enough, probably crazy enough. There are ways and ways in doing things and that, the more we kind of open up the better we become, that kind of thing. On all levels, demonstrative, academic you name it.

It can be argued from analysing the teachers' accounts that they are aware of these factors which can be seen as both external (cultural norms, facilities) and internal (students' beliefs and levels; Wang, 2006), and how they impede or prevent the implementation of their innovative approaches. Despite the existence of these factors, the teachers reported and expressed reasonable satisfaction with their classroom approaches and student uptake:

Teacher A: They say, look doctor, now I want to show you and the students what I have learnt in the past few days before coming to, I would like to show you and would like to teach the other students.... So you can't have better than this.

Teacher B: if I have only five or ten, who actually enjoy learning and enjoy my teaching and enjoy the process of learning and to them the idea is not only that we're going to pass the test or whatever. ... I am here in the university because the university [is] where [I] actually can develop as an individual... if I can find and I do find most of the times and even the minority of the students and I think that makes my day.

The teachers were enthusiastic about their approaches to teaching and classroom practices. They had taken ownership of them, and wanted to continue with their approaches and 
developing teaching materials, despite the student resistance and the gap between the Libyan classroom educational norms and the lack of facilities in particular for Teacher $B$ :

Teacher A: The way I designed the course is completely practical the assessment is based on the idea of portfolio. ... We had no exams no tests. It was just the students have the course outline, they have things called can do lists, kind of objectives, kind of criteria and they would apply these can do list on the computer they produce the evidence for me they would put the evidence in a portfolio and by the end of the course they show to me and say look doctor we can do this this this. It is evident.

It appears from their accounts that their imported practices from their graduate programmes have become so embedded and entrenched into their beliefs system that they continued to teach in this manner even without funding, or institutional and educational support.

\section{Graduate studies and how it informed teaching practices}

The teachers who were the focus of this study both strongly and explicitly acknowledged that their graduate studies abroad and their learning experiences had a great impact on what and how they practice in their English university-level classrooms today:

Teacher A: Yes my graduate studies gave me me the knowledge and theoretical background and also I have acquired some skills from my professors and some other students. When I was in my graduate studies and obviously now I am passing the knowledge and the skills to my students, so I think if you question is whether the graduate or post graduate are useful or not. Definitely, they are useful ... Graduate studies, my graduate courses and programmes are I think very useful in terms of informing current practices in teaching. 
Teacher B: Mostly it is my MA studies in the States that inform the way I teach at the moment mostly, ... The things I do mostly in practice were informed by my studies in the United States... I emulated the teachers who taught me in the States and I emulated the context in which I was a student. And I enjoyed being a student and I think I tried as much as I can to recreate that kind of context here in Libya in my classes. This is what I meant when I said they were informed by the, the things that were practiced either by teachers who were teaching, my interaction with other students, or taking courses with, with the activities, academic activities I was involved in that sort of thing

However, from observing and examining their responses it can be further argued that graduate studies have not only affected what they do in their classrooms, but also how they behave and think on a personal level (Fox, 2008). Teacher $A$ has started to view the whole world from a global perspective, where the world is one small village where everyone has to integrate:

Teacher A: we should think global whether we are in Libya or Canada or it's the the developments that are happening in the world, the technology, ... this is what we should consider in education and actually indeed I always try to make my students think international, and I told [them] they should think of getting jobs outside Libya and have the experience. ... And this is what I try to bring to my classroom as well.

Teacher $B$ can be seen as a tolerant person who seeks to develop broad-mindedness and tolerance amongst people:

Teacher B: We need people who are open-minded, intelligent enough, probably crazy enough. There are ways and ways in doing things and that, the more we kind of open up the better we become, that kind of thing. 
From the above accounts, it can be argued that graduate studies has had a positive impact on teachers both professional and personally. Teacher $A$ expressed that he strongly recommends all graduates, and in particular his students, to take part in the study abroad graduate programme, as it will be a fruitful experience "I recommend my students to go on to do PhD programme ... at least one of the yeah one of the yeah degrees...either an MA or PhD".

Nevertheless, no matter how comprehensive and thorough a teacher enhancement programme may be there are always skills and practices that a person cannot develop and acquire without experience. The teachers who are the main focus of this study put forth this notion very strongly. Teacher $A$ mentioned that he learnt from his teaching experience how to deal with human nature, which was not brought up during his graduate programme.

Teacher A: It's it's the human nature that a students would do anything to get more grades and that's again obviously, you I didn't learn anything like this in in in in a course in in in testing. So obviously, of course there are always things you learn by experience, by teaching that you wouldn't learn in the in an academic course at a university. Or even at a graduate or post graduate course in a university. So I think one element that I would probably say now that I am learning through experience of teaching is how to deal with this I think a new characteristic of a human being.

Teacher $B$ reported that he is still learning how to improvise that is how to take advantage of the teachable moment- (1) how to recognise a need for an alternative approach; (2) how to change plans when things are not working in accordance to lesson plans. He explained that he improvises in order to reduce the cognitive load, or boost confidence, or re-explain unclear 
terms. He stressed that he has to be awake and alert to change an approach, when things are not working according to plans. He further stressed that teaching is a continuous lesson that will never have an end, and every lesson provides an opportunity to learn something new:

It is not exactly the same no matter how you learn, no matter how you study, no matter how we read, no matter whatever. In practice there are so many things, as I said you have to improvise. I think this is what I learnt from teaching you how to improvise; you have to be ready all the time on the look out to improvise. And you have to update yourself; you have to keep yourself ready all the time. To be on your toes as it were. And you like, that's what I learnt from my teaching experience.

To sum up, the participants reported that the Libya Study Abroad Scholarship Programme was advantageous and of great value for the teachers; it had changed the teachers' perspectives of both learning and teaching; and, consequently, their classroom practices. The two teachers considered in this study implemented innovative practices in their current practices, despite the presence of existing road blocks which included student culture, the prevalent Libyan educational culture, and the lack of facilities. Overall, their graduate studies abroad and their learning experiences had a great impact on what and how teachers practiced in their English university-levels classrooms. In the subsequent chapter, I further discuss these findings in relation to the research literature that framed and informed the study, namely, curricular reform, teachers' beliefs and teacher development or enhancement programmes. 


\section{Chapter VI}

\section{Discussion}

Teachers possess the power to create conditions that can help students to learn a great deal - or keep them from learning much at all. Teaching is the intentional act of creating those conditions, and good teaching requires that we understand the inner sources of both the intent and the act. (Palmer, 1998 p. 6)

Having presented the study's findings in Chapter Five, this chapter discusses the findings in detail and in relation to the research literature that framed this study, and the research questions that guided the inquiry. In addressing the question: What is the impact of the Libyan Study Abroad Scholarship Programme on returning university level English teachers? This chapter discusses the key findings in terms of:

1. Evidence of Innovation

2. Obstacles to Innovation

3. Sustaining Innovation

Teachers $A$ and $B$, who attended different universities and lived in different cities, expressed very similar accounts of what has shaped and continues to shape their work. Their autonomous accounts were in the form of a retrospective consideration of their study abroad 
graduate programmes. Their accounts suggest that not only was the Libyan Study Abroad Scholarship Programme an enjoyable learning experience, it had a meaningful and substantive impact on their current university-level classroom practices.

\section{Evidence of Innovation}

Looking at the findings and taking into account that "real improvement is achieved by modifying classroom practice" (Hopkins, 2002, p. 2), it may be argued that what has taken place (and is continuing) in these teachers' classrooms is evidence of change. However, the Teachers $(A, B)$ who reported innovative approaches to teaching within the Libyan context may also have been motivated to change because they were dissatisfied with the prevalent teaching practices, as their comments on the typical Libyan educational experience suggest:

Teacher A: [the problem is the students'] long experience in rote learning and memorisation and the teacher is the authority, the source of information and all this stuff...

Teacher B: we were reared up this way, this is what you learn, you learn off by heart and you are going be tested on[it]... We are forced to learn things off by heart. Teacher is the, as I said, the god like figure who does not make mistakes or hardly sleeps. Alright, who kind of, you know, divulges the information and what you have to do is imbibe it in and take it in and thank you for that. I think this is one of the major problems we face today

It is possible that they have questioned the trustworthiness of the current situation, and realised that the existing system is not generating the necessary results, and thus experienced dissatisfaction. If they were dissatisfied, the dissatisfaction could be also seen as a by-product of 
their Libyan Study Abroad Scholarship Programme. Their determination to implement these novel approaches mirrors what Stoller (1992) had stressed; the more disappointed stakeholders are (in this study Teachers $A$ and $B$ ), the more likely they will implement innovations, and proposed innovations would be positively supported. We may relate this to what happened to Teachers $A$ and $B$ during their graduate study abroad experience in that they came across situations where they made hypotheses, tested them, and then formed their own personal constructs. The constructs are their theories and beliefs, which were changed and adapted with experience.

The point I wish to emphasize here is that these teachers believed that their innovation was of value. Whether there is credible evidence to support their beliefs is a different issue. It can be further argued that Teacher $A$ 's and $B$ 's ideologies became more deep-rooted and well established with more experiences. Here, experience is viewed as both their learning experience abroad, where they witnessed these concepts and theories of learning and teaching, as well as their own teaching experience. As noted by Breen et al. (2001): "[the r] lationship between practices and principles is likely to be interactive; each will influence the other as the teacher works from day to day" (p. 472).

It would appear that these teachers' beliefs encouraged them to continue with innovative approaches after they began testing them out. Ultimately, this belief notion appears to be an essential factor in teachers who sustain innovation and persist in their attempts to introduce change, as argued by Woods (1996), Markee (1997) and Hargreaves, (1989, 1993). For an innovation to be implemented, teachers need to gain knowledge of new skills, and likewise they 
may well need to modify beliefs about their students or instruction that have prevailed throughout their professional careers (Darling-Hammond \& McLaughlin, 1996). Having established that beliefs are fundamental in initiating and sustaining innovative classroom practices, it would seem that Teachers $A$ and $B$ current belief systems, in accordance with Kindsvatter, Wilen, and Ishler (1988), may have stemmed from:

1. Their own learning experiences as language learners. This is the notion that teachers teach they way they are taught. i.e. in this particular study, they teach in the ways they were taught in their graduate and post-graduate programmes.

2. Experiences of what brings about success. This may be related to experiencing an enhancing learning environment in their study abroad programme that brought about success for them.

3. Educational based principles. Such principles are rooted in teachers' reading of research and/or in the case of these participants, in their own research.

4. Principles derived from an approach or method. Teachers $A$ and $B$ have regarded the student-centred approach or teaching method as the most effective, and employed it in their own classroom practices.

It was also evident from the two teachers' reflections and accounts of their current practices that there was a major change in the teachers' approaches to teaching. In essence, their approaches changed from a "transmission style" to a more problem-solving or "interpretative" style of learning that involves collaboration between students and teachers (Barnes, 1974). The teacher was no longer the only source of information; instead students' own experiences were 
seen as instructive learning resources. Their accounts also reflected that the teachers focused intensively on engaging students (in, for example, groups) to solve difficult, real-life problems, rather than on increasing the acquisition of facts related to the subject matter (as is the case in the traditional educational culture of the Libyan context). Rather than dispensing knowledge, these teachers set up projects, and created the established arrangements and support that can assist students in succeeding. This approach, which I would view as innovation in these teachers' classroom practices, shifts the conception of learning beyond rote memorisation of facts and measures to learning as a procedure of knowledge formation.

Teachers $A$ 's and $B$ 's implementation of innovative approaches can be seen as a combination of a top-down and a strong bottom-up process for implementation - a requirement, according to Fox (2005), for sustentative and sustained curricular reform. In this process of innovation the Ministry of Education provided funding for the Study Abroad Scholarship Programmes (topdown). And the teachers functioned according to their standards and attitudes, which were rooted in deep-seated beliefs and manners (bottom-up). Therefore, in this process Teachers $A$ and $B$, from the bottom up perspective, are those who identified the need for the change, and performed an essential role because they acted as both originators of and collaborators on innovation (Markee, 1997). Teachers $A$ and $B$ 's successful implementation of innovative approaches may be due to the following positive conditions:

The existence of a powerful, top-down educational change agent (The Ministry of Education),

A comprehensible classification of educational goals, 
A conscientious identification of the problem within the educational zone, by both the Ministry of Education and the teachers (Fox 2005).

In accordance with Fox (2005), the combination of top-down and bottom-up processes are fundamentally required for an effective innovation to occur at classroom levels, because it is perceived to be the most effective and sustaining form of implementation within the educational literature.

Moreover, from the teachers' accounts, it appears that major changes took place in their classroom practices after their return from the Study Abroad Scholarship Programme. The changes that Teachers $A$ and $B$ implemented in the Libyan educational context were not simple changes because simple changes are unlikely to be accepted and implemented successfully (Clark et al., 1984). This is mostly because that they are not considered as very important (Clark et al., 1984). Although innovation implemented by the teachers was original and novel within the Libyan educational context, it was not so original as to lie "outside the realm of acceptable norms, conventions, and expectations" of the Libyan cultural norms or educational context (Stroller, 1992, p. 150). I would also argue that the teachers were able to implement change because they had created conditions in their classroom such as cooperation, trust, reflection and thoughtfulness ${ }^{26}$.

26 Similar to those attributes stated by Hashweh (2007). 
It would seem reasonable at this stage of the research to stress that teachers have to believe that what they are doing in the classroom has value, before they give it any form of enthusiastic support. I found that the teachers believed that they engaged in valuable and meaningful tasks and had the motivation and willpower to sustain them. The innovation was sustained despite the anticipated impediments and difficulties of implementing innovations in the fact of the prevailing culture of learning, student resistance and lack of facilities. The teachers' were willing to accept and apply innovation more quickly, because it was seen by them as superior to what it replaced (Rogers, 1995).

Also it matched with the existing values, past experiences, and needs of Teachers $A$ and $B$. The teachers' innovation was applied taking into account students' expectations of the Libyan educational culture; although clash and conflict had occurred with a minority of students. The implementation of innovative approaches in Teachers $A$ and $B$ 's classrooms was sensitive to the Islamic-Libyan cultural norms (considered as a crucial factor throughout their practices). Clashes between students' and teachers' perceptions of learning, which raised resistance on behalf of some of the students, may have arisen because the teachers' innovations necessitated new behaviours and responsibilities on the part of the students. These new behaviours challenged and opposed the behaviours and responsibilities that were usual, normal and embedded in the target society and culture. Therefore, the "[1]ack of 'fit' between the 'users' (learners) and the assumptions of the innovative methodology was [a] result of 'value conflict', [and] learners' beliefs and assumptions about the norms of appropriate classroom behaviours, which were entrenched in the culture of the community, clashed with the assumptions of the innovative methodology" (Shamim, 1996, p. 119). 
Although the teachers innovations required large changes in the "core of educational practice," namely, how teachers "understand the nature of knowledge and the student's role in learning" (Elmore, 1996, p. 2), it was sustained in the teachers' university classrooms. These innovative practices, as reported by the teachers, were sustained despite the fact they were far from the Libyan educational classroom norms. These findings contradict Elmore's view that the further an innovation is from the standard practices in a school, the less likely it will be sustained over time.

From interviewing Teachers $A$ and $B$, I was able to get a visual sense of their philosophy of what constitutes 'success' in the profession of teaching. The following concept map represents Teachers $A$ and $B$ 's notions of success - which were very similar to one another: 
Figure 4

The concept map of Teachers $A$ and $B$

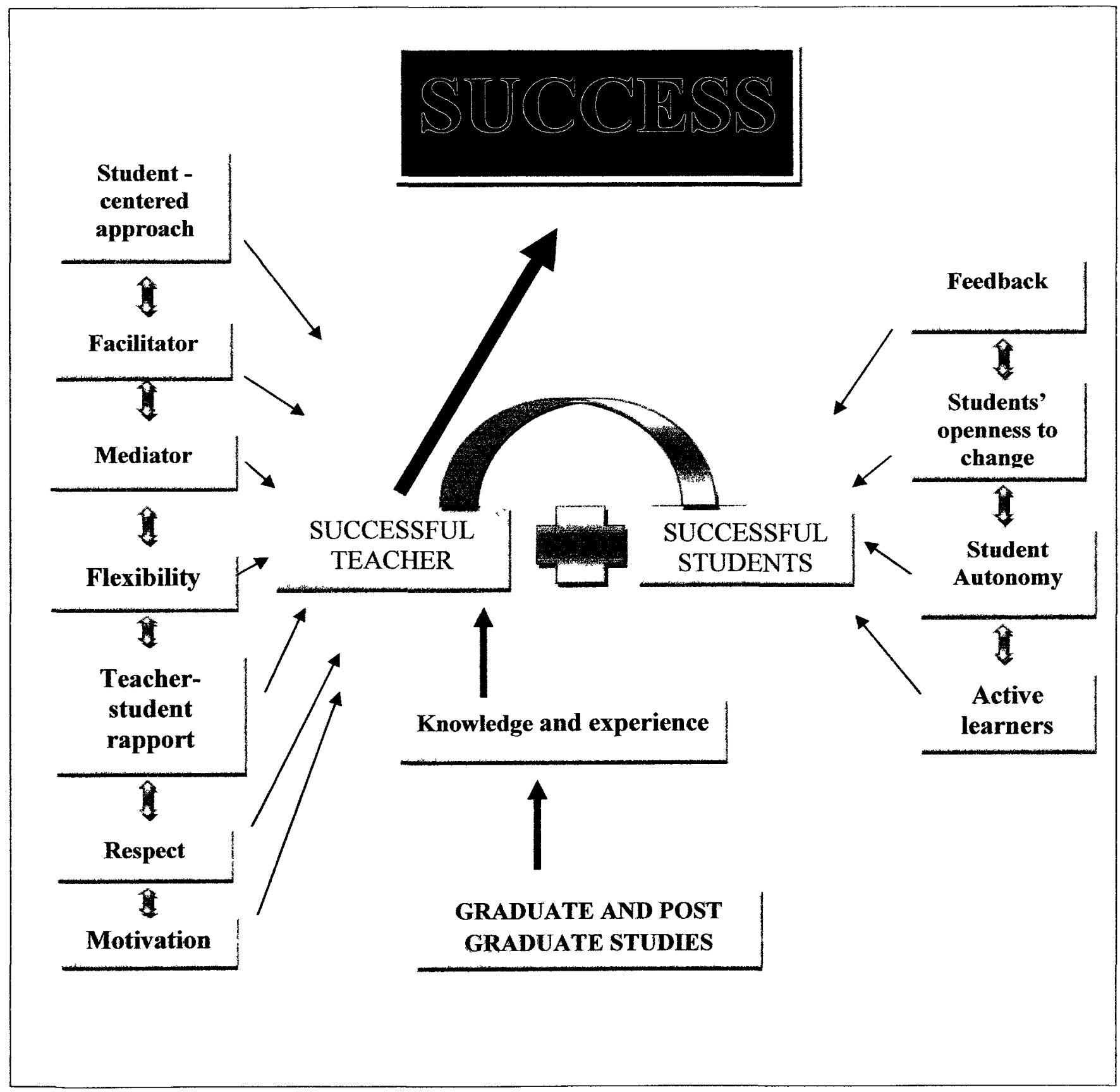




\section{Obstacles to Innovation}

It is important to note that both Teachers $A$ and $B$ indicated that the prevalent Libyan “culture of learning' (an internal factor as identified by Wang, 2006) had in one way or another impeded their implementation of innovative approaches in their university classrooms. It can be stressed that the characteristics of the Libyan culture of learning as discussed in Chapter Two had a substantial influence not only on what takes place in their classrooms, but also on the whole educational system. They reported that their students are accustomed to the dynamics of passive learning, rather than the active-learning required for teachers' innovative student-centred approach. The students were accustomed to teachers who transmit information, prepare students for exams, and cover only the material the students would be tested on, which in essence contradicts the teachers' notion of students taking responsibility of their own learning. The teachers further argued that Libyan students have been educationally reared to not take responsibility of their own learning, or to become analytical, critical, or autonomous learners:

Teacher B: I don't blame them by the way. It is the system itself, they were never encouraged; they were never told, never encouraged to think on their own. They were never encouraged to express themselves you know. And talk about what they think or whatever, that is the problem. ...they have to learn things off by heart the things the professors or teacher says. That is from day one they were never told to think critically. So and the problem is compound in the university... 
Furthermore, Teachers $A$ and $B$ reported that memorisation of facts and information continues to hold prominence within their classrooms in particular and in the overall Libyan educational culture. Students may just want to memorise and this in turn mirrors the widespread belief that academic achievement is defined by memorisation and rote learning, even at university level; and education is a process of conveying information.

What I would like to argue here, in accordance with Cortazzi and Jin (1997), is that the "culture of learning" may be a strong influential factor with regards to what happens inside a language classroom, in particular the type of pedagogical approach to be implemented and the definition of what is determined to be a successful language learning environment; beliefs about how teachers ought to teach and how students learn are deep-rooted and entrenched by the time a person goes into university, and at that stage they are more or less at the stages of anti-change. These beliefs are rooted in the whole educational system; they begin on the day we first walk into a classroom as young innocent learners, and to continue to develop until the moment we graduate. Therefore, beliefs are not just rooted in learners, but in the whole educational context, and these have existed for decades within the Libyan context.

Knowing that the Ministry of Education is aiming to develop the quality of the education system by sending Libyan students to study abroad, it seems that it is putting the graduates of such programmes in a challenging situation. They are expected to implement innovative approaches in their classrooms, and to promote and enhance a more productive learning environment for their students, according to the Ministry's objectives for the study abroad programme. However, upon returning, teachers have to deal with the prevalent culture of 
learning that challenges and may impede educational reform and innovation. Consequently, the teachers either have to challenge this culture of learning and continue with their innovative approaches, or revert to traditional educational approaches. It is clear that the participants in this study chose to challenge the existing culture of learning. However, it is also clear that inevitably some who return, perhaps without noticing, find themselves teaching in the same way they always have, employing some of the innovative materials, they acquired from abroad, but altering them to suit traditional patterns.

If the Ministry of Education is aiming to initiate a reform policy at university level, it ought to deal with some of the problems of the culture of learning, such as the prominence of memorization, as early as grade one. As reported by the Ministry of Education in 2004 (see page 28), the prominence of memorisation skills within the Libyan education system affects and impede innovation, and reform. It also deters students from becoming reflective, critical, analytic learners, and students "are left with very limited opportunities for creative expression in the classroom" (O'Dwyer, 2006, p.3).

Acknowledging that the "culture of learning" may be perceived as "part of a hidden curriculum" (Cortazzi and Jin, 1997, p.169), it can be argued here that having memorization as part of the Libyan culture of learning may have a great influence or even shape how the curriculum is delivered. Therefore, the Ministry of Education's reform policy ought to reconsider future Libyan classroom pedagogy (from grade one to university-level education), so that rote learning and memorisation have less prominence in classroom practices and tests. Instead, it should promote opportunities for students to become analytical, critical, or 
autonomous learners, because a "teacher who is attempting to teach without inspiring the pupil with a desire to learn, is hammering on cold iron" (Horace Mann, 1796-1859, cited in Pychyl, 2011). In addition, as mentioned earlier on in Chapter Three that when initiating an educational innovation, the need for a change is not only restricted to teachers, but also ought to include students and in fact the whole community (Shamim,1996). Consequently, teachers returning to their classrooms in Libya upon the completion of their degrees should be prepared and set to employ innovative practices, novel curriculum material and new subject matter knowledge in unique ways with fewer challenges. In this way, change in materials and methods would not simply operate at surface level, but represent a deep and enriching increase in understanding and knowledge which encourage life-long learning.

Another internal (Wang, 2006) factor that Teachers $A$ and $B$ made reference to, but which they did not consider important in hindering innovation, was the culture of individualism. However, from my perspective, and based on my teaching experience at one Libyan university, I argue that the culture of individualism, which prevails in the teaching culture, is an essential factor in impeding change. In accordance with Lortie (1975), the teachers at Libyan universities are separated into a series of 'egg crate-like compartments'; they are removed and cut off from each others' work. In a university context it is believed that there is less curriculum control over students and teachers (Fox, 2009; Wang and Cheng, 2005).

Within the domain of teacher isolation, Teachers $A$ and $B$ reported that they had developed the custom of working alone with their own students 'in their respective classrooms under the "one-teacher-package" (Wang and Cheng, 2005, p.22). They had no knowledge of 
what took place in neighbouring classes or how their colleagues managed and orchestrated their language classes: "I am talking about myself and don't know what is happening with the other teachers" (Teacher A). I would argue that teacher isolation can be disadvantageous, as it prevents teachers from developing professionally. It may also establish a possible obstacle for implementing innovation (Flinders, 1988; Hargreaves, 1993).

In order to find a fit between teachers' culture of isolation and the implementation of innovation and reform, I stress that teachers do need to exchange instructional ideas and to learn from one another for the purposes of professional development. I know it is difficult to achieve collaboration within the Libyan university due to the heavy work load, but certainly the concept of cooperation would be possible. As mentioned earlier on in Chapter Two, the culture of teaching and learning in Libya is highly competitive, rather than cooperative, where teachers (as well as learners) compete for recognition of excellence and promotion. This competitive working environment can frighten teachers and place them under enormous pressure. Therefore, attempts ought to be made by institutional administrators in order to "promote and nurture an environment where it is safe and unthreatening for teachers to observe each other without losing face or confidence" (Wang and Cheng, 2005, p.22).

In accordance with Wang and Cheng (2005), to promote collaboration, I suggest that teachers engage in professional group discussions and activities. For example, teachers should observe each other's classroom pedagogy and then write a reflection on the observations and outline plans for their own individual development. Classroom observations and reflections 
could then be followed up by activities, where teachers meet in smaller groups of their choice to express their standpoints about teaching and learning.

Accordingly, teachers returning to their classrooms in Libya upon the completion of their degrees abroad will be more positive in implementing innovative practices, having observed other teachers' classroom practices and how they deal with the challenges of the "culture of learning". Teachers who were fortunate enough to study abroad and those who were not may benefit from interacting and sharing ideas with their colleagues. The process of cooperation and reflection amongst teachers may open a window for educational reform and teacher enhancement; "[t]eacher education, which encourages reflective practices, can foster the clarification of teachers' developing pedagogical theories and goals, which in turn will guide their navigation through new instructional environments" (Sakui, 2004, p. 160).

It is evident from the Teachers $A$ 's and B's accounts' (and my own observations) that sending teachers abroad is not enough to promote substantial change within the Libyan education system. There is a strong need for institutional reform. Based on the Teachers $A$ and $B$ 's accounts and my experience it can be argued that the proposed reform for public higher institutions ought to include:

Creating good management;

Increasing resources and facilities;

Improving technology

Increasing training for teachers; 
Raising expectations (for example, evidence of critical thinking, autonomous learning and so on);

Introducing the teaching assistant system;

Lowering teaching load;

Encouraging research and creating the right environment for research.

Human, material, and financial resource support is essential for successful implementation of an innovation ( $\mathrm{Li}, 1998)$. By considering this and the above suggested elements for reform, the Ministry of Education could take steps towards filling in the gaps within the Libyan educational system. It could establish reform from the inner circle and work simultaneously with the Study Abroad Scholarship Programme reform policy to boost the educational system and create better opportunities for the younger generations. Hence, with the availability of resources and facilities and a developed educational system, teachers returning to their classrooms in Libya upon the completion of their degrees abroad may be equipped to implement innovative approaches without having to deal with external factors that may hinder their classroom practices.

\section{Sustaining Innovation}

Within the domain of sustaining innovation, my research results demonstrate the important role that students play in inspiring teachers to sustain their innovation. From examining their comments, the majority of Teacher A's and B's students were interested and enthusiastic about 
their innovations and the continuous positive feedback they got. In fact, the adjective "happy" was used frequently by the teachers. For example, Teacher $A$ reported that from introducing his innovative approaches, students wanted to attend class more than before: "So it is these kinds of things that makes students would like to come to my classes try to register on my courses whenever they can". They reported that students were keen, passionate, and want to implement these approaches in their own classrooms.

When they believed that students were benefiting from and were encouraging their innovative practices, they dedicated more time and effort necessary to increase the advantages of the innovation. In this regard, sustainability of Teacher $A$ 's and $B$ 's new practices can also be seen as a product of the teachers' intrinsic reward from implementing their innovative practices. It is argued in the educational literature that the most important source of intrinsic reward comes from student collaboration and success (Metz, 1993). Therefore, teachers are likely to devote both time and effort to tasks that lead to student achievement.

With regards to the concept of sustainability of practices, I would further argue that the teachers were mainly able to sustain their innovative practices in their classrooms because of their professional and personal satisfaction. This satisfaction stemmed from being able to teach in the manner they deemed to be important and potentially more successful, in addition to witnessing the positive effects of their practices on their students' learning and development. It ought to be noted that the teachers sustained their innovative practices despite the lack of facilities (a key external factor according to Wang, 2006; Hu, 2002) that may have impeded their practices. 
In summary, on the whole, teachers reported that innovative classroom practices were sustained in their Libyan university classrooms because:

1. they corresponded with the objectives of the teachers (needs);

2. they were achieved within the constraints of the universities in terms of the facilities (practicality);

3. teachers were happy with the pedagogical approaches employed in the innovation (compatibility);

4. they understood that students were benefiting more from the innovation than the Libyan educational practices (relative advantage); and

5. the credit and acknowledgements they received from both students and colleagues in implementing practices considered to be innovative tended to stimulate teachers to sustain them (observability).

In addition, teachers' sustainability of innovation began with moral purpose. The teachers were not only committed to enhancing and developing their own classrooms, but were also keen and devoted to changing the larger organization, i.e. the whole educational policy.

The findings of this research contradict much of the research cited earlier in Chapters One and Three, which argues that teacher development programmes have little or no impact on classroom practices or teachers' pedagogical beliefs (Kennedy, 2005, Briscoe, 1999). The findings have challenged the view that those who participate in teacher development and enhancement programmes will not be capable of implementing innovations in their classroom, or will only implement them if they have precisely the same beliefs and theories as the instructors 
(Breen et al., 2001). In addition, these accounts of these teachers challenge the view that "real change in practice will not arise from programs of instruction, especially when those programs take place in a centre removed from the teacher's own classroom" (Hewitt's, 2004, p. 156).

The present findings suggest that teacher enhancement programmes (such as the Study Abroad Scholarship Programme), which took place far from the Libyan context, promoted changes in beliefs, and thus classroom practices. Consequently, teacher professional development is at the heart of initiating and sustaining an innovation. My analysis supports this view and classifies professional development ${ }^{27}$ as an essential factor in institutional change. The following model $^{28}$ (Figure 5) attempts to visually demonstrate potential factors that contribute to both implementing and sustaining innovative practices in the Libyan university level context. It consists of two sets of conditions underlying implementing and sustaining innovative practices: one set is categorised essential, the other contributing. These are represented by "E" and "C", respectively. Certain factors are labelled essential, because without them, implementing and sustaining innovative approaches in the classroom would not be possible. The factors that were labelled contributing are seen as mediating tools that support the implementation process.

27 The manner in which teachers acquire their knowledge and skills, being it through education courses, learning in informal groups with colleagues or self-study is not distinguished in here. I use the term professional development in the very broadest sense to indicate that teachers have to or acquire pedagogical competencies and other associated knowledge and skills to implement sustainable innovations in university-level classrooms.

28 This model was adapted from Owston's (2007) model of sustainability of innovation. 
Figure 5

Cycle for implementing and sustaining innovation

\section{TOP-DOWN}

\section{Support from the Libyan Ministry of Education}

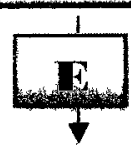

Supportive Plans and policies

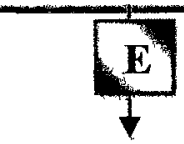

Funding

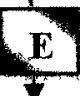

Teacher Professional Development

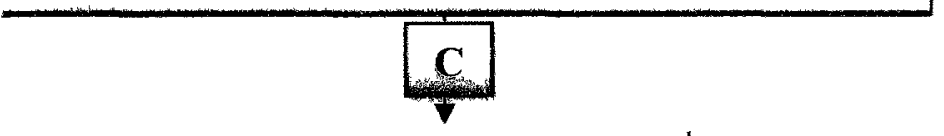

Support waithin waiversity

TMIDLIEMIENTING AND SUSTAINING TINNOVATIVE PRACTICIS

$\hat{\imath}$

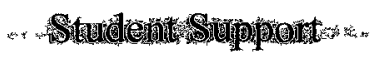

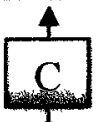

Perceived value of innovation

E

To

Teacher's BAK

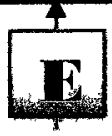

Teacher Professional Development Programmes 


\section{Self - Reflection}

At the outset of this study I had a strong belief that all teachers who returned to their Libyan classrooms after the completion of their degrees abroad would teach in the same way they always had: employing some of the innovative materials, but altering them to suit traditional patterns. However, this belief was disproved by the findings of this study. I was pleasantly surprised to discover that the graduate Study Abroad Scholarship Programme did have an impact on the teachers' beliefs and thus their classroom pedagogy.

As a new graduate, I started my teaching profession at high school. My first subject to teach was phonetics. The classroom pedagogy was test oriented, although this was against my BAK at that time. I believed that respect, teacher-student rapport and motivation were important factors for providing an enhancing learning environment. I tried my best to have this philosophy woven in my classroom practices. Above all, I always had this sense that transmission, or 'spoon-feeding' information was not an adequate means of learning. Students ought to have a

role in the learning process and contribute to it. However, the context I was working in at that time forced my classroom instruction to be test-driven because the final year exams were approaching and the students had been without a teacher for a couple of months.

My second position was a teacher assistant at Misurata University. Within this educational context I had more freedom as there was less curriculum control over students and teachers. In my university level classrooms, my practices could be described not as studentcentred per se, but I did strive towards more student involvement and urged my students to take more responsibility for their own learning. I created conditions for classroom discussions, 
encouraged students to express themselves, had a more democratic learning environment, and asked students to search for information. I never gave notes to students to memorise, as was the traditional way of learning, instead I asked the students to take their own notes whilst I was lecturing, and to do their own research. In particular, I repeatedly acknowledged to the students that it was their responsibility to get their own notes, I was not going to spoon-feed them the information. I also tried my best to reduce the prominence of memorisation amongst my practices. I encouraged students to answer questions in their own words, and not just parrot what they had memorised from the material. In order to encourage them, I gave students extra marks and high pass grades for those who did so. However, even with these small steps towards a student-centred approach, I was met with strong student resistance. The majority of my students explicitly acknowledged that they did not like this approach to teaching and said that I ought to only teach to the exams. The following concept map summarises my BAK prior to enrolling into the Carleton graduate programme. 
Figure 6

My concept map of professional success prior to graduate studies

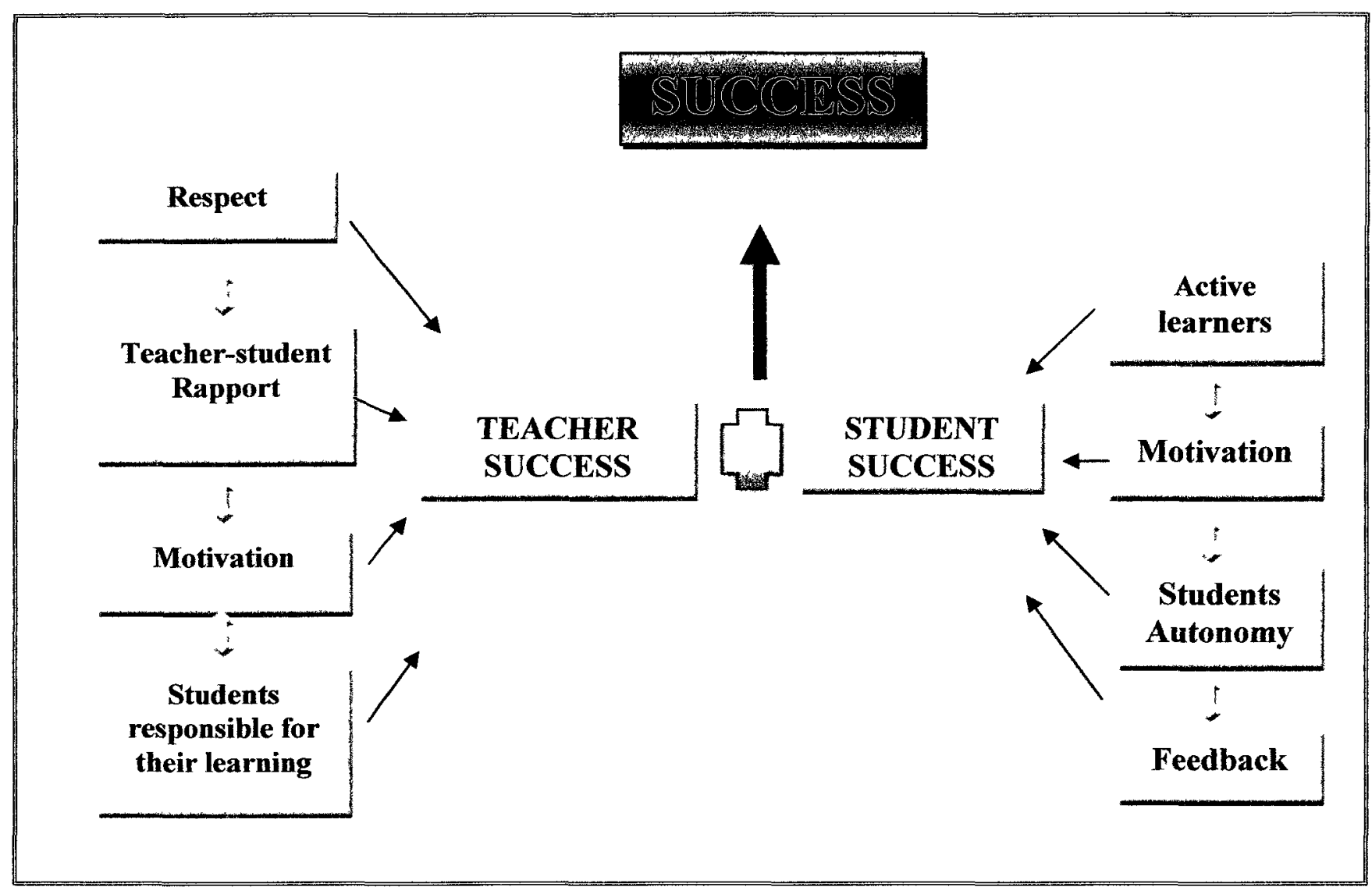

Upon interviewing the two participants and analysing their accounts of the study abroad programme, I found that there were many things that I could relate to, as I am an English teacher who is currently participating in the same scholarship programme. These findings can be summarised as the following: 
1. Like the participants, I really enjoyed my graduate programme and the study abroad learning experience. The learning environment was an enhancing, cooperative, motivating and supportive one. In particular, I enjoyed the flexibility of the professors, (for example in terms of meeting deadlines), and the good-teacher rapport; as well as, the mutual respect. I have to admit that such an enhancing learning environment stood in stark contrast to my undergraduate programme in Libya.

2. Upon arriving in Canada and beginning a graduate programme I was pleasantly shocked by theories related to teaching which include: the student-centred approach, the facilitating role of the teacher, communicative approaches to teaching and task-based teaching. At the start, it was very challenging to adapt myself to such concepts that were well established here in North America, but novel to me. Like Teachers $A$ and $B$, the surprise and challenge may have stemmed from the fact that I had no prior experience with these concepts during my educational years before graduate studies.

From reading relevant research and experiencing the positives outcomes of employing the above concepts in a classroom, I have become a supporter of such classroom pedagogies and consider them to be sound approaches for teaching. As a result, my belief in the importance of teacher respect, teacher-student rapport, and motivation has become more ingrained in my value system. Conducting this research has increased my motivation in that it encourages me to believe that like my teacher participants, I can implement innovative approaches to teaching within my Libyan classroom after my return from abroad. At the same time it allowed me to see the external and internal factors that may challenge how I employ my future innovative approaches. 
The following is my concept map that I constructed for myself after participating in the study abroad graduate programme:

Figure 7

My current concept map of professional success after graduate studies ${ }^{29}$

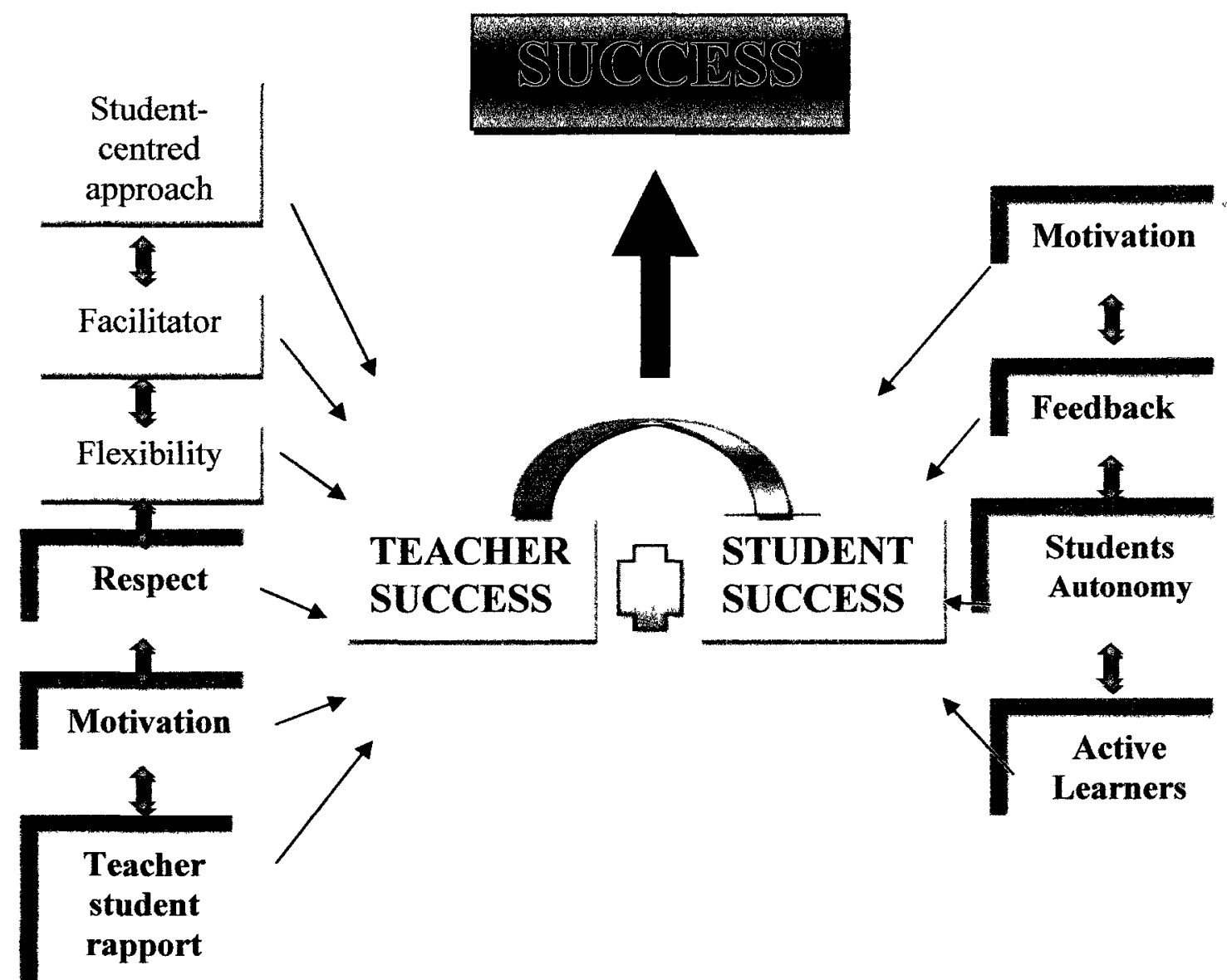

29 The concepts that are in bold are the concepts that characterised my BAK prior to the graduate programme, but have now become more ingrained in my value system after the programme. And the combination of teacher success and student success leads to professional success. 
After discussing evidence of Teachers $A$ and $B$ 's innovation, obstacles to their innovation, and how they sustained innovation in terms of the research literature, the final and concluding chapter considers the overall findings of the study, its limitations, implications, and future directions for research. 


\section{CHAPTER VII}

\section{CONCLUSION}

[To teach is to create a space]...these are revolutionary words, because most of us think in terms of filling a space: filling the number of minutes between the beginning and end of class, filling the student's notebook, filling the student's head. . . What if we did the opposite? Instead of feeding, we were to honor the hunger with which our students come to school?... How can we make a space ... in our classroom? Mindfulness helps...Simply being there, with a very precise focused attention, listening, watching. Not being somewhere else, answering some question that hasn't been asked (O'Reilley, 1998, pp. 1-3).

This chapter provides a summary of the main findings of this study that resulted from attempting to address the main question of this research, identifies the limitations of the study, and highlights its educational implications and some suggestions for further research.

This study examined the impact of the Libyan Study Abroad Scholarship Programme on returning university level English teachers: two teachers who were interviewed for the study and whose commentary contributed in large measure to its findings, and one teacher participant who only completed the questionnaire. In particular the study explored the reflections upon their prior graduate learning experiences, the effect of these experiences on their beliefs about effective 
teaching and learning of English, and the effect of these beliefs on their choice of instructional approaches and teaching behaviours in their current English university-level classrooms.

In order to explore such phenomena, I had teachers respond to questionnaires and semistructured interviews. The study revealed that the Study Abroad Scholarship Programme did have a significant impact on changing returning university level English teachers' beliefs about teaching and learning, and thus on what and how they practice in their English university-level classrooms. Consequently, Teacher A's and B's beliefs changed; they no longer hold the notion of the teacher as an authority, passing on knowledge to students was no longer the two teachers' notion of teaching. Their new roles were complementary to a more constructivist ${ }^{30}$ notion of the learning process and rejected the realist model of learning as a method of knowledge transfer (Barnes, 1974).

They spoke of the importance of the learners participating in the process of learning, discovering things out for themselves, solving problems, activating prior knowledge and experience, connecting novel information with existing information and making sense of it. They implemented these innovative concepts (for the Libyan educational system), by having classroom discussion, presentations, group work, encouraging students to express their opinions, promoting opportunities for critical thinking activities and so on. It was evident from the teachers' accounts of their classroom practices, which reflected strongly held beliefs about

30 Constructivist learning theory is based on the notion that knowledge is actively constructed by the leaner. This notion has dramatically shifted the focus away from the traditional transmission form of learning to a type that is much more complex and interactive (Prawatt, Floden, 1994). 
language teaching and learning, that they were no longer in line with the endorsed principles of traditional educational Libyan culture that perceives education as a process of conveying information, facts and received knowledge. Although these teachers implemented innovative approaches in their current classrooms after their return from the Study Abroad Scholarship Programme, they are not typical of university English teachers in Libya. It must be noted that there may be teachers, who after their return from completing their degrees abroad, teach in the same way they always had: employing some of the innovative materials, but altering them to suit traditional patterns.

The study extended beyond the teachers' beliefs to a consideration of external and internal factors that may have been stumbling blocks for Teacher $A$ 's and $B$ 's implementation of innovative pedagogical approaches in their Libyan university-level classrooms. The teachers' accounts suggested an external factor that had impeded their implementation process such as lack of supporting resources, and as of internal factors which included: student resistance, student levels of proficiency, no interest in the whole learning concept, and the prevalent Libyan educational culture.

This study adds support to the research which suggests that teacher enhancement programmes such as the Study Abroad Scholarship Programme, do in fact have a significant effect on classroom practices. The teachers in this study used images of typical classrooms which they had constructed from the learning experience abroad as a basis for developing their own practices. In general terms, this study stresses that educational innovation is a complex social 
phenomenon because of the social, economical, political and cultural factors that are embedded in the teaching and learning process.

It supports the idea that for teachers to learn and teach successfully they have to be able to reflect on their own learning and to internalise new knowledge. Therefore, change at classroom level necessitates more than acquiring new skills or knowledge; in essence, it requires change in the way of thinking, beliefs and personal constructs for teachers to reform a personal approach to teaching. This cannot be accomplished without opportunities for teachers to reflect upon their practice and practices of others. Teachers must also examine their beliefs, perspectives, and thoughts concerning what they do and how they do it and teachers need time to reflect on their own practices, allocate language to their actions (Briscoe, 1991).

Furthermore, they need support in the reflection process to focus on the cognitive features of why they do what they do, and opportunities to collaborate. Teachers also must have time to tryout new approaches in their classrooms and build knowledge about teaching without having to feel threatened from administrators' traditional evaluations. Teachers must be given the chance to develop help groups for change, where teachers observe each other and consider what works and what does not (Wang and Cheng, 2005). As "[i]mages of classrooms which teachers have constructed from years of experience in schools, both as students and teachers, cannot be changed with words alone" (Briscoe,1991, p. 198).

Regarding the Libyan educational context, in particular, this study argues that the Ministry of Education reform policy ought to provide resources in human, material, and financial for 
teachers returning to their classrooms in Libya upon the completion of their degrees abroad. Changes require a great deal of learning on the part of the teachers and will be greatly impeded without support and guidance (Wang, 2006; Li 1998; Fox, 2004). in addition, resource support has been deemed to be necessary in determining the successful implementation of any form of educational innovation ( $\mathrm{Li}, 1998$ ), as well as; working on improving and developing "the culture of learning" that has been prevalent within the Libyan educational system for many decades. This may include decreasing the prominence of rote learning and memorisation in classroom practices and tests, and promoting opportunities for students to become analytical, critical, or autonomous learners. This in turn, with Study Abroad Scholarship Programme, may help to boost the educational system in Libya, and thus create a better future for the younger generations.

To sum up, it would seem that the success of any school improvement programme depends upon the degree to which it initiates the circumstances for change in teachers' pedagogies to take place and the way in which it develops the capability for shared learning (Wenger, 1998). In addition, to attain educational reform at all levels of an educational system (such as the one in Libya) is not an easy job, because it requires the joint efforts of all those who participate. 


\section{Limitations}

Although I tried to elicit as much rigorous data as possible and triangulated the analysis, there were twelve factors that limited my study:

1. The political outbreak in Libya (The February $17^{\text {th }}$ Revolution) affected the data gathering and no further contacts with participants was possible, due to line cuts and no internet access.

2. My approach of evaluation was based primarily on teacher self-report data. Given the time frame and the level of resources available for the evaluations of professional development programme, there was little opportunity to gather first-hand data evidence through observation in class about changes in teacher knowledge, practices, efficacy and students' learning outcomes.

3. The complexity of eliciting beliefs is evident because personal philosophies may be largely intuitive and subconscious; teachers may even be unable to explain or put them into words. In addition, associated with this is the concern of self-worth and self-esteem; either subconsciously or not, "teachers may wish to promote a particular image of themselves". Additionally, "there is often a difference between espoused theory (theory claimed by a participant) and theory in action (what a participant does in the classroom)" (Breen et al, 2001, p. 345). This quality of knowledge renders it to be awkward to obtain, comment on, and or even expand on. 
4. The only form of recording that took place was auditory. Having both visual and audio may have helped me to observe the body language of the participants, when expressing feeling of frustration, happiness or disappointment.

5. This study only focused on two participants in two different cities; therefore, the results of this study cannot be generalised beyond the two teachers that I had interviewed. In order to draw more rigorous conclusions, the impact of the programme would need to be evaluated over several years, and across a representative sample of scholarship participants and returnees.

6. There were many stakeholders I was unable to get access to, such as university administers and policy makers.

7. The participants of this study were not randomly chosen.

8. I took what the participants said for granted and accepted it to be true, especially when they were reflecting on their L2 classroom pedagogy in Libya. Whether this was the reality or not would be the question. Not having a window into the actual L2 classroom pedagogy that took place in Libya other than the participants' perspectives may have skewed the validity of my results.

9. I had no prior relationship with the participants. This may have triggered a level of formality amongst us that made the environment tenser, and consequently, skewed the validity of the results.

10. The employment of a grounded theory approach in this study, allowed me to assert that the Libyan-Study Abroad Scholarship Programme did have an impact on returning university-level English teachers, however; the policy makers of the new government 
need evidence that can only be provided through quantitative findings. If it had been both a longitudinal and cross-sectional case study, this may have provided me with more fertile data, and thus rigorous results.

\section{Implications and future research}

The results of this study suggest that it would be advantageous to extend this research to different parts of Libya and establish findings that can be generalised for the whole Libyan nation. It would be interesting to conduct a longitudinal study that examines the implementation of innovative approaches by returning university level teachers of different disciplines, to see whether or not the objectives of the programme were achieved. It would be also interesting to study through classroom observations, changes in teacher knowledge, practices, efficacy and students' learning outcomes. It will also be useful to research subsequent steps for graduates and post-graduates returning home after completion of their degrees that the Ministry of Education had planned as part of the reform policy. Further research will be needed in distributing a survey or funding research, with regards to the types of careers the Libyan graduates from abroad take on after they come home and how they reintegrate into the Libyan society.

To conclude, this study provided evidence that professional development can lead to improvement in instructional practices and student learning. We are only starting to learn about what and how teachers learn from professional development, or about the impact of teacher change on students learning. There is a full research agenda ahead in order to gather the information necessary to guide professional development policy, as well as, practice. 
I would like to end this work on a personal note. The composition of this thesis was one of the most demanding and challenging tasks within the past four months of my life. Being away from home whilst my beloved country was bleeding every day, and my dearest home town Misurata, being surrounded and attacked by the brutal regime had left me in a state of ongoing panic and restless sleep. I wake up every morning with tears soaking my pillow; afraid of opening my laptop and to find out whether or not I had lost a member of my family. As the days passed I started to build up my courage and the strong love for my country that was like a volcano inside me, pushed and encouraged me to accomplish this thesis. I wanted to do something for my people, the people who have given up everything for the sake of a free Libya. I wanted to contribute in one way or another in helping to build the nation that the brutal, Gaddafi dictatorship had pulled back by four decades. Despite the hardship I experienced while composing this work, I came to acknowledge that nothing in this world is impossible, with the motivation and strong determination to succeed, anything can be possible. I hope this work may help in some small way in building a better future and better life for the new Libyan nation. 


\section{REFERENCES}

Abou Jaafar A E (2003) The EFA 2000 Assessment: Country Reports, Libyan Jamahiriya. Retrieved from http://www2.unesco.org/wef/countryreports/libya/rapport_1.html

Adey, P., Hewitt, G., Hewitt, J., \& Landau, N. (2004). The professional development of teachers: Practice and theory. Dordrecht: Kluwer Academic.

Adler, J. (2000). Social practice theory and mathematics teacher education: A conversation between theory and practice. Nordic Mathematics Education Journal, 8(3), 31-53.

Al-Buseffi, A. (2003). Difficulties in learning vocabulary with reference to Libyan secondary school students. (Unpublished MA Thesis). Academy of Graduate Studies, Tripoli-Libya.

Aldabbus, S. (2008). An investigation into the impact of language games on classroom interaction and pupil learning in Libyan EFL primary classrooms. (Unpublished Doctoral dissertation). Newcastle University, United Kingdom.

Alderson, J.C. and Wall, D. (1993). Does Wash-back exist? Applied Linguistics, 14, 115-129.

Alrnarza, O. (1996). Student foreign language teachers' knowledge growth. In D. Freeman \& J. Richards (Eds.), Teacher Learning in Language Teaching (pp. 50- 78). Cambridge: Cambridge University Press. 
Andrews, S. Cheng, L., Watanabe, Y. and Curtis, A. (Eds.). (2004). Washback and curriculum innovation. Washback in Language testing: research contexts and methods pp. 37-50. NJ and London, Lawrence Erlbaum Associates, Mahwah.

Anning, A. (1988). 'Teachers' theories about children's learning in J. Calderhead, (ed.): Teachers' Professional Learning. East Sussex: Falmer.

Artemeva, N., Fox, J. (2010). Awareness vs. production: Probing students' antecedent genre knowledge. Journal of Business and Technical Communication, 24(4), 476-515.

Atkin, J. M. (1992). Teaching as research: An essay. Teaching and Teacher Education, 8(4), $381-390$.

Bain, K. (2004). What the best college teachers do. Cambridge, Mass: Harvard University Press.

Bax, S. (2004). The end of CLT: a context approach to language teaching. ELT Journal 57(3): $278-87$.

Beer, M. (1980). Organization Development and Change: A Systems View. Santa Monica, CA: Goodyear.

Blackwell, S. (2003) Saving the King: Anglo-American strategy and British counter supervision operations in Libya, 1953-59. Middle Eastern Studies, 39, 1-18.

Borg, M. (2001). Teachers' beliefs. ELT Journal, 55(2), 186-188.

Borg, S. (2003). Teacher cognition in language teaching: A review of research on what language teachers think, believe, and do. Language Teaching, 36(2), 8 1-109. 
Borko, H. (2004). Professional Development and Teacher Learning: Mapping the Terrain. Educational Researcher, 33(8), 3-15.

Boyd-Zaharias, J., \& Pate-Bain, H. (2000). The continuing impact of elementary small classes. Paper presented at the annual meeting of the American Educational Research Association. New Orleans, Louisiana.

Breen, M.,Hird, B.,Milton, Oliver, R., \& Thwaite, A. (2001). Making sense of language teaching: Teachers! Principles and classroom practices. Applied Linguistics, 22(4), 470-501.

Brindley, G., \& Hood, S. (1990). Curriculum innovation in adult ESL. In G. Brindley (Ed.), The second language curriculum in action (pp. 232-248). Sydney, Australia: National Center for English Language Teaching and Research.

Briscoe, C. (1991). The dynamic interactions among beliefs, role metaphors, and teaching practices: A case study of teacher change. Science Education, 75(2), 185- 199.

Brookfield, S.D. (1990). The Skilful Teacher: On technique, trust and responsiveness in the classroom. San Francisco: Jossey-Bass.

Brookfield, S.D. (1995). "What it means to be a critically reflective teacher" in S.D. Brookfield., Becoming a Critically Reflective Teacher. San Francisco: Jossey-Bass, 1-27.

Bullough, R. V. Jr. \& Pinnegar, S. (2001) Guidelines for quality in autobiographical forms of self-study research, Educational Researcher, 30(3), 13-21.

Buote, D. B., \& Schonert-Reichl, K. A. (2004, March). Significant school-based adults: 
Impact on pre-adolescent's social-emotional and academic well-being. Poster session presented at the biennial meeting of the Society for Research on Adolescence, Baltimore, Maryland.

Calderhead, J (1988) (ed.): Teachers' Professional Learning. East Sussex: Falmer.

Carless, D. (1998). A case study of curriculum implementation in Hong Kong. System, 26(3), $353-368$.

Chan, F. (2002). The cognitive element of curriculum change. In V. Crew, C. Davison \& B. Mak (Eds.), Reflecting on Language in Education. Hong Kong: Hong Kong Institute of Education.

Charamaz, K. (2006). Constructing grounded theory: A practical Guide through qualitative research analysis. London: Sage.

Cheng, L., \& Wang, H. (2004). Understanding professional challenges faced by Chinese teachers of English. TESL-EJ, 7(4), A-2 (1-14).

Chenitiz, C. And Swanson, J. M. (eds.). (1986). From practice to grounded theory: Qualtative research in nursing. Menlo Park, CA: Addison Wesley.

Chin, R., \& Benne, K. (1976), General strategies for effecting changes in human systems. In W. Bennis, K. Bennis \& R. Chin (Eds.). The Planning of Change. (pp. 22-45). New York: Rinehart and Winston.

Clandinin, D. J., \& Connelly, F. M. (1992). Teacher as curriculum maker. In P. Jackson (Ed.), Handbook of research on curriculum (pp. 363-401). New York: Macmillan. 
Clark, C., and Peterson, P. (1986). 'Teachers thought processes' in M. Whiterock (ed.): Handbook of research on Teaching $3^{\text {rd }}$. New York: Macmillan.

Clark, D. L., Lotto, L. S., \& Astuto, T. A. (1984). Effective schools and school improvement: A comparative analysis of two lines of inquiry. Educational Administration Quarterly, 20(3), $41-68$.

Cobb, P. (1994). Where is the mind? Constructivist and socio-cultural perspectives on mathematical development. Educational Researcher, 23(7), 13-20.

Coleman, H. (1996). Society and the Language Classroom. Cambridge: Cambridge.

Connelly, M., \& Clandinin, J. (1988). Recovery of curriculum meaning. In Teachers as Curriculum Planners, pp. 81-97. Toronto: OISE Press.

Cortazzi, M. \& Jin, L. (1997). Culture of learning: Language classrooms in China. In H. Coleman (Ed.), Society and the language classroom, pp. 169-206. Cambridge: Cambridge University Press.

Country Profile (2005) Libya [online]. Library of Congress Studies, Federal Research Division. Retrieved from http://lcweb2.loc.gov/frd/cs/profiles/Libya.pdf.

Country Studies (1987) Libya: The Fourth Shore [online]. Library of Congress. Retrieved from http://lcweb2.loc.gov/cgi-bin/query/r?frd/cstdy:@field(DOCID+ly0031

Covey, S. R. 1989. The 7 habits of highly effective people: Powerful lessons in personal change. New York: Simon \& Schuster. 
Cresswell, J. W. (1998). Qualitative inquiry and research design: Choosing among five traditions. Thousand Oaks, CA: Sage.

Crookes, G.,Riley, L., \& Delano, L. (1994). The meaning of educational change. Journal of Teacher Education, 39(6), 3 3-39.

Darling-Hammond, L. (2000). How teacher education matters. Journal of Teacher Education, $51,166-173$.

Day, C. (1999). Developing Teachers: The Challenges of Lifelong Learning. London: Falmer Press.

De Lano, L., Riley, L., Crookes, G. (1994). The meaning of innovation for ESL teachers. System 22 (4), 487-496.

Deeb, K., M., \& Deeb, I., M. (1982). Libya since the Revolution: Aspects of Social and Political Development. New York: Praeger Publishers,

Dewey, J. (1916). Democracy and education. New York: The Free Press.

Dewey, J. (1938). Education and Experience. New York: Collier Macmillan.

Dinkelman, T. (2003). Self-study in teacher education: A means and ends tool for promoting reflective teaching. Journal of Teacher Education, 54(1), 6-18.

Dughri, M. (1980). Human Resources Development and Educational Policy in Libya. Doctoral Dissertation. Retrieved from ProQuest Dissertations And Theses 1980. (AAT 8018296) 
Elmabruk, R. (2008). Using the Internet to Support Libyan In-service EFL Teachers'

Professional Development. Doctoral Dissertation. University of Nottingham, United Kingdom. Retrieved from http://etheses.nottingham.ac.uk/1038/1/Elmabruk_(2008)_PhD_Thesis.pdf

Elmore, R. F. (1996). Getting to scale with good educational practice. Harvard Educational Review, $66(1), 1-26$.

Flinders, D. (1988). Teacher isolation and the new reform. Journal of Curriculum and Supervision, 4(1), 17-29.

Fox, J. (2004). Curriculum design: does it make a difference? Contact, 30(2), 1-4.

Fox, J. (2005). Revisiting the storied landscape of language policy impact over time: A case of successful educational reform. Curriculum Inquiry, 35(3), 261-293.

Fox, J. (2008). How important is the text book? The case of the Enriched English Curriculum in Taiwan. Paper presented in the Symposium: EFL teacher education and professional development in China, ALLA, Essen Germany.

Fox, J. (2009). Moderating top-down policy impact and supporting EAP curricular renewal: Exploring the potential of diagnostic assessment. Journal of English for Academic Purposes, $8,26-42$.

Fox, J., Hartwick, P. (2011). Taking a diagnostic turn: Reinventing the portfolio in EAP (with P. Hartwick), In D. Tsagari \& I Csepes (Eds.), Classroom-based language assessment. Frankfurt: Peter Lang (in press) 
Freeman, D., \& Richards, 1. (1996). Teacher Learning in Language Teaching. Cambridge: Cambridge University Press.

Fullan, M. (2001). The New Meaning of Educational Change (3rd ed.). London: Teachers College Press.

Fullan, M., \& Miles, M. (1992). Getting reforms right: What works and what doesn't. Phi Delta Kappan, 73(10), 745-752.

Fullan, M., \& Park, p. (1981). Curriculum Implementation. Toronto: Ontario Institute for Studies in Education.

Fullan, M., \& Stiegelbauer, S. (1991). The new meaning of educational change (2nd Ed.). New York, NY: Teachers College Press.

Gao, Y., Li, L. \& Lu, J. (2001). Trends in research methods in applied linguistics: China and the West. English for Specific Purpose, 20, 1-14.

Gorsuch, G.J. 2000: EFL educational policies and educational cultures: influences on teachers' approval of communicative activities. TESOL Quarterly, 34(4), 675-710.

Gusbi, M. 1966. English for Libya. University of London Press Ltd.

Guskey, T. R. (2002). Professional development and teacher change. Teachers and Teaching: Theory and Practice, 8(3), 381-391.

Halliday, J.S. (2001) Critical thinking and the academic vocational divide, The Curriculum Journal, 11, 159-175. 
Hargreaves, A. (1989). Curriculum and assessment reform. Toronto: OISE Press.

Hargreaves, A. (1993). Individualism and individuality: Reinterpreting the teacher culture. In L. W. Little \& M.W. McLaughlin (Eds.), Teachers' work: Individuals, colleagues, and contexts (pp. 51-76). New York: Teachers College Press.

Harmer, J. (1991). The practice of English language teaching. London: Longman.

Harris, A. \& Hopkins, D. (2000). Alternative perspectives on school improvement. School Leadership and Management 20(1), 9-15.

Harris, A. (2003). Behind the classroom door: The challenge of organizational and pedagogical change. Journal of Educational Change, 4(4), 369-382.

Hashim, S. (1997). Review of Teaching English in Libya-Textbooks Used In Preparatory And Secondary Levels. In ESP in the Arab World: Reality Check and Prospects Proceedings of the XVIIth MATE Annual Conference Erfoud.

Hashweh, M. (2003). Teacher accommodative change. Teaching and Teacher Education, 19(4), 421-434.

Hidi, S. (1990). Interest and its contribution as a mental resource for learning. Review of Educational Research, 60, 549-571.

Holden, G. (2002). Towards a Learning Community: The Role of Teacher-Led Development in School Improvement. Paper presented at the CELSI British Council Leadership in Learning Conference, London. 
Holliday, A. (1994). Appropriate Methodology and Social Context. Cambridge/New York: Cambridge University Press.

Holliday, W. G. (2004). A Balanced Approach to Science Inquiry Teaching. In L. Flick \& N. G. Lederman (Eds.) Scientific inquiry and nature of science implications for teaching, learning, and teacher Education (volume 25, pp. 201 - 218). Series: Science \& Technology Education Library. Dordrecht: Kluwer.

Hopkins, D. (2002). School Improvement for Real. London: Falmer Press.

Hord, S., Rutherford, W., Huling-Austin, L, and Hall, G. (1987). You are in this book. In: S.H. Hord et al.Taking Charge of Change, pp. 3-25. Alexandria VA: Association for Supervision and Curriculum Development.

Hu, G. W. (2005). English language education in China: Policies, progress, and problems. Language Policy, 4(1), 5-24.

Hu, G.W. (2002). Potential cultural resistance to pedagogical imports: The case of communicative language teaching in China. Language, Culture and Curriculum 15, 93 - 105.

Huberman, M. and Miles, M. (1984). Innovation up Close: How School Improvement Works. New York: Plenum Press.

Johnson, D. W., Johnson, R. T., \& Stanne, M. E. (2000). Cooperative learning methods: A metaanalysis. Minneapolis, MN: University of Minnesota Press. 
Johnson, S., Monk, M., \& Swain, J. (2000). Constraints on development and change to Science teachers' practices in Egyptian classrooms. Journal of Education for Teaching, 26(1), 9-24.

Joyce, B. \& Showers, B. (1988). Student achievement through staff development. New York: Longman.

Joyce, B. (1990). Changing school culture through staff development. Alexandria, VA: Association for Supervision and Curriculum Development.

Kelly, G. A. (1969). Clinical psychology and personality. In B. Maher (ed.), The selected papers of George Kelly. New York: John Wiley \& Sons.

Kennedy, A. (2005). Models of continuing professional development: A framework for analysis. Journal of In-Service Education, 31(2), 235 - 250.

Kennedy, C. (1987). Innovating for change: Teacher development and innovation. ELT Journal, 41(3), 163-170.

Kindsvatter, R.,Wilen, W., \& Ishler, M. (1988). Dynamics of Effective Teaching. New York: Longman.

Kolb, D. (1984). Experiential learning: Experience as the source of learning and development. Englewood Cliffs, NJ: Prentice Hall.

Lamb, M. (1996). The consequences of INSET. In T. Hedge \& N. Whitney (Eds.). Power Pedagogy and Practice.(pp. 139-149), Oxford: Oxford University Press. 
Li, D. (1998). "It's always more difficult than you plan and imagine": Teachers' perceived difficulties in introducing the communicative approach in South Korea. TESOL Quarterly, $32,677-703$.

Libyan Ministry of Higher Education (2005)

Literacy Trust. (2005). Retrieved from www.literacytrust.org.uk

Lortie, D. (1975). Schoolteacher: A sociological study. Chicago: University of Chicago Press.

Loucks-Horsley, S., Harding, C. K., Arbuckle, M. A., Murray, L. B., Dubea, C., \& Williams, M. K. (1987). Continuing to learn: A guidebook for teacher development. Andover, MA: Regional Laboratory for Educational Improvement of the Northeast \& Islands.

Maghur, A. (2010). Highly-skilled Migration (Libya): Legal aspects. CARIM Analytic and Synthetic Notes 2010/31, Highly-Skilled Migration Series. Retrieved from http://cadmus.eui.eu/dspace/handle/1814/13685

Markee, N. (1997). Managing curricular innovation. Cambridge: Cambridge University Press.

Marshall, H. (1988). Work or learning: Implications of classroom metaphors. Educational Researcher, 17, 9-16.

Metz, M. H. (1993). “Teachers' ultimate dependence on their students”. In J. W. Little, \& M. W. McLaughlin (Eds.), Teacher's work: Individuals, colleagues, and contexts. (pp. 104-136). New York: Teachers College Press. 
Mills, J., Bonner, A., \& Francis K. (2006) Adopting a constructivist approach to grounded theory: implications for research design. International Journal of Nursing Practice, 12, 813.

Mohamed, S. (1987). The Communicative Approach in Language Teaching and its Implications for Syllabus Design in Libya. Doctoral Dissertation. University of East Anglia, United States.

Mooney, R. (1957). Research for curriculum improvement, association of supervision and curriculum development. Washington, DC: Association of Curriculum Development.

Munby, H. (1982). The place of teachers' beliefs in research on teacher thinking and decision making, and an alternative methodology. Instructional Science, 11, 201-225.

Murphy, J. (1993). Restructuring: In search of a movement. In J. Murphy \& P. Hallinger (eds.), Restructuring Schools: Learning from Ongoing Efforts (pp. 1-31). Newbury Park, CA: Corwin.

O'Dwyer, S. (2006) The English teacher as facilitator and authority. TESL-EJ, Retrieved from http://www-writing.berkeley.edu/TESL-EJ/ej36/a2.html

Olson, J. (1982). Innovation in the science curriculum. London: Croom Helm.

Orafi, S. (2008). Investigating teachers' practices and beliefs in relation to curriculum innovation in English language teaching in Libya. (Unpublished Doctoral dissertation). Leeds University, United Kingdom. 
Orafi, S. M. S. and Borg, S. (2009) Intentions and realities in implementing communicative curriculum reform. System 37(2). 243-253.

O'Reilley, M.R. (1998). Radical Presence: Teaching as contemplative practice. Portsmouth, NH: Boynton/Cook.

Otman, W., \& Karlberg, E. (2007).The Libyan economy: economic diversification and international repositioning. Springer Berlin Heidelberg: NewYork.

Owston, R. (2007). Contextual factors that sustain innovative pedagogical practice using technology: An international study. Journal of Educational Change, 8(1),61-77.

Pajares, M. (1992). Teachers' beliefs and educational research: Cleaning up a messy construct. Review of Educational Research, 62(3), 307-332.

Palmer, P. (1998). The courage to teach. San Francisco: Jossey-Bass.

Pennington, M. (1996). The cognitive affective filter in teacher development. System, 24(3), 337 350.

Pergrum, W., \& Anderson, R. (1999). ICT and the emerging paradigm for lifelong learning. Amsterdam: International Association for the Advancement of Educational Achievement.

Prawat, R. S. (1992). Teachers' beliefs about teaching and learning: A constructivist perspective. American Journal of Education, 100(3), 354-395.

Prawatt, R.S. \& Floden, R.E. (1994). Philosophical perspectives on constructivist views of learning. Educational Psychology, 29, 37-48. 
Prodromou, L. (1995). The backwash effect: From testing to teaching. ELT Journal, 49(1), 1325.

Pychyl, T. (2011). A focus on students learning styles and students motivation. [PowerPoint slides for ALDS5204W:PSYC6104W [16567:16501] Seminar in University Teaching (SEM) Winter 2011]. Retrieved from Lecture notes online website: http://lms.carleton.ca/webct/cobaltMainFrame.dowebct

Richards, C. (1998). The primary school curriculum: changes, challenges, questions. In: C. Richards \& P.H. Taylor. (Eds), How ShallWe School Our Children? Primary education and its future. London: Falmer Press.

Richardson, V. (1996). The role of attitudes and beliefs in learning to teach. In I. Silcula (Ed.), Handbook of Educational Research (pp. 102-119). New York: MacMiffian.

Rogers, E. M. 1995. Diffusion of innovations. New York: Free Press.

Roeser, R., Midgley, C , \& Urdan, T. C. (1996). Perceptions of the school psychological environment and early adolescents' psychological and behavioral functioning in school: The mediating role of goals and belonging. Journal of Educational Psychology, 88,408-422.

Salcui, K. (2004), Wearing two pairs of shoes: Language teaching in Japan. ELT Journal, 58(2), 155-163.

Savignon, S. (2002). Interpreting Communicative Language Teaching: Contexts and Concerns in Teacher Education. London: Yale University Press. 
Schonert-Reichl, K. (2006). Pedagogical caring and students' social-emotional and academic success: The importance of teachers. [PowerPoint slides in pdf]. Retrieved from http://bctf.ca/uploadedFiles/News_and_events/Public_Ed_Conference/Every_kid_counts/Sc honert-ReichlPresentation.pdf

Schostack, J. (2002) Understanding, Designing, and Conducting Qualitative Research in Education: Framing the project. Buckingham: Open University Press.

Schulz, R. A. (2001). Cultural differences in student and teacher perceptions concerning the role of grammar and corrective feedback: USA-Colombia. Modern Language Journal, 85(2), 343-358.

Schwartz, A. (2002). National standards and the diffusion of innovation: Language teaching in the United States. In S. Savignon (Ed.), Interpreting Communicative Language Teaching (pp. 112-130). London: Yale University Press.

Scileppi, J. (1988). A Systems View of Education: a Model for Change. Lanham: University Press of America.

Senior, R. (2006). The experience of language teaching. Cambridge: Cambridge

Shamim, F. (1996). Learner resistance to innovation in classroom methodology. In H. Coleman (Ed.), Society and the Language Classroom (pp. 105-121). Cambridge: Cambridge University Press. 
Smith, D. (1996). Teacher decision making in the adult ESL classroom. In D. Freeman \& J. Richards (Eds.), Teacher Learning in Language Teaching (pp. 197-216). Cambridge: Cambridge University Press.

Smith, L., \& Southerland, S. (2007). Reforming practice or modifying reforms? Elementary teachers' response to tools of reform. Journal of Research in Science Teaching, 44(3), 396423.

Smylie, M. \& Perry, G. (1998). Restructuring schools for improving teaching. In A. Hargreaves et al. (eds.), International Handbook of Educational Change (pp. 976-1005). GB: Kluwer Publications.

Spillane, J.,Reiser, B., \& Reimer, T. (2002). Policy implementation and cognition: Reframing and refocusing implementation research. Review of Educational Research, 72(3), 378-431.

Stake, R. (1995). The art of case research. Thousand Oaks, CA: Sage Publications.

Stenhouse, L. (1975). An introduction to curriculum research and development. London: Heinemann.

Stoller, F.L. 1992 Analysis of Innovations in Selected Higher Education Intensive English Programs: a Focus on Administrators' Perceptions. (Unpublished Doctoral Dissertation). North Arizona University.

The Libyan National Commission for Education. (2004). The Development of Education in the Great Jamahiriya: A National Report Presented to the International Conference on Education. Geneva. 
Tikunoff, W.J., \& Ward, B.A. (1983). Collaborative research on teaching. Elementary School Journal, 83, 453-468.

Tillema, H. (1997) Reflective Dialogue in Teams: a vehicle to support belief change in student teachers, European Journal of Teacher Education, 20, 283-296.

Tillema, H. (2000). Belief change towards self-directed learning in student teachers: Immersion in practice or reflection on action. Teaching and Teacher Education, 16(5), 575-591.

Tudor, I. (2001). The Dynamics of the Language Classroom. Cambridge: Cambridge University Press.

Tyack, D., \& Cuban, L. (1995). Tinkering toward utopia: A century of public school reform. Cambridge, MA: Harvard University Press.

Van Velzen, W., Miles, M., Eckholm, M., Hameyer, U., \& Robin, D. (1985). Making school improvement work. Leuven, Belgium: ACCO.

UK Embassy (2005) The UK and Libya: Our Shared Tradition [online]. Retrieved from http://www.britishembassy.gov.uk/servlet/Front?pagename=OpenMarket/Xcelerate/ShowPa ge\&c=Page $\&$ cid $=1064572031651$

Wall, D. (2000). The impact of high-stakes testing on teaching and learning: can this be predicted or controlled? System, 28, 499-509.

Wang, H. (2006). An Implementation of the English as a Foreign Language Curriculum Policies in the Chinese Tertiary Context. (Doctoral Dissertation). Queen's University, Canada. 
Wang, H., \& Cheng, L. (2005). The impact of curriculum innovation on the cultures of teaching. Asian EFL Journal, 7(4), 7-32.

Wenger, E. (1998). Communities of Practice: Learning, Meaning and Identity. Cambridge: Cambridge University Press.

Wentzel, K. R. (1997). Student motivation in middle school: The role of perceived pedagogical caring. Journal of Educational Psychology, 89, 411-419.

White, R. (1993). Innovation in curriculum planning and program development. Annual Review of Applied Linguistics. 13, 244-259.

Whitehead, A. J. (1989). Creating a living educational theory from questions of the kind, "How do I improve my practice? Cambridge Journal of Education, 19(1), 41-51.

William, M., \& Burden, N. (1997). Psychology for Language Teachers: A Social Constructivist Approach. Cambridge: Cambridge University Press

Woods, D. (1996). Teacher Cognition in Language Teaching. Cambridge: Cambridge University Press. 


\section{APPENDICES}

\section{Appendix I: Ethics Approval Form}




\section{Carleton}

UNVYERSITY

Canada's Gaptal University
Carleton University Research Office

Sth Floor Tory Building

1125 Colonel By Drive

Ottawa ON K1S 5B6 Canada

Tel: $613-520-2516$

Fax: 613-520-2521

waw carleton ca/cu/research/curol

\section{Ethics Clearance Form}

This is to certify that the Carleton University Research Ethics Board has examined the application for ethical clearance. The REB found the research project to meet appropriate ethical standards as outlined in the Tri-Council Policy Statement: Ethical Conduct for Research Involving Humans and, the Carleton University Policies and Procedures for the Ethical Conduct of Research.

¿ New clearance

$X$ Renewal of original clearance

Original date of clearance: 8 December 2010

Date of renewal

Student researcher

Status

Department

Faculty supervisor

Funding status

Project number

Title of project
18 April 2011

Nwara Abdulhamid

M.A. student

School of Linguistics and Language Studies

Professor Janna Fox, School of Linguistics and Language Studies Not funded

11-1496

What is the impact of the Libyan study abroad scholarship programme on returning university level English teachers?

Clearance expires: 31 May 2012

\section{All researchers are governed by the following conditions:}

Annual Status Report: You are required to submit an Annual Status Report to either renew clearance or close the file. Failure to submit the Annual Status Report will result in the immediate suspension of the project. Funded projects will have accounts suspended until the report is submitted and approved.

Changes to the project: Any changes to the project must be submitted to the Carleton University Research Ethics Board for approval. All changes must be approved prior to the continuance of the research.

Adverse events: Should any participant suffer adversely from their participation in the project you are required to report the matter to the Carleton University Research Ethics Board. You must submit a written record of the event and indicate what steps you have taken to resolve the situation.

Suspension or termination of clearance: Failure to conduct the research in accordance with the principles of the Tri-Council Policy Statement: Ethical Conduct for Research Involving Humans and the Carleton University Policies and Procedures for the Ethical Conduct of Research may result in the suspension or termination of the research project.

Lestie 1. Mäbonald-Hicks

Research Ethics Board Coordinator

For the Chair of the Carleton University Research Ethics Board

Prof. Antonio Gualtieri 


\section{Appendix II}

\section{Questionnaire}

Personal information:

1. Name

2. Gender :

male

female

3. What is your age range?

25-35

,35-45

, 45-55 , $55-65$

4. What degree do you hold?

Master's

PhD

5. At what faculties are you teaching? Faculty of Arts $\square$, Faculty of Education $\square$ Both $\square$ Other $\square$ if other please specify....

6. What is your specialisation within your faculty? 
7. For how long have you been teaching English? 9 yrs or less $\square$ 10-15 yrs , 15-20 yrs $\square, 20 y r s+\square$

8. For how long have you been in the teaching profession? 1-5yrs $\square \square \mathbf{5 - 1 0}$ , 10-15 yrs $\square$ 15-20 yrs $\square 20$ yrs +

9. When did your teaching profession at the university start?

10.For the past year or so what courses have you been teaching at the university? 
11. When did you complete your last degree and in what year did you return to Libya?

12.From where did you obtain your degree?

UK $\square$, Canada $\square$ USA $\square$ or other $\square$ lease specify

\section{Information related to the profession}

13. What do you believe is essential for language learning? 
14.If you were asked to identify what language teaching approach you are a proponent of? Would you say:

The traditional grammar-based $\square$, Audio lingual method $\square$, Communicative $\square$ or Task-Based teaching $\square$, other $\square$, please specify

In the box below, please explain why you answered question 14 in the way you did? 


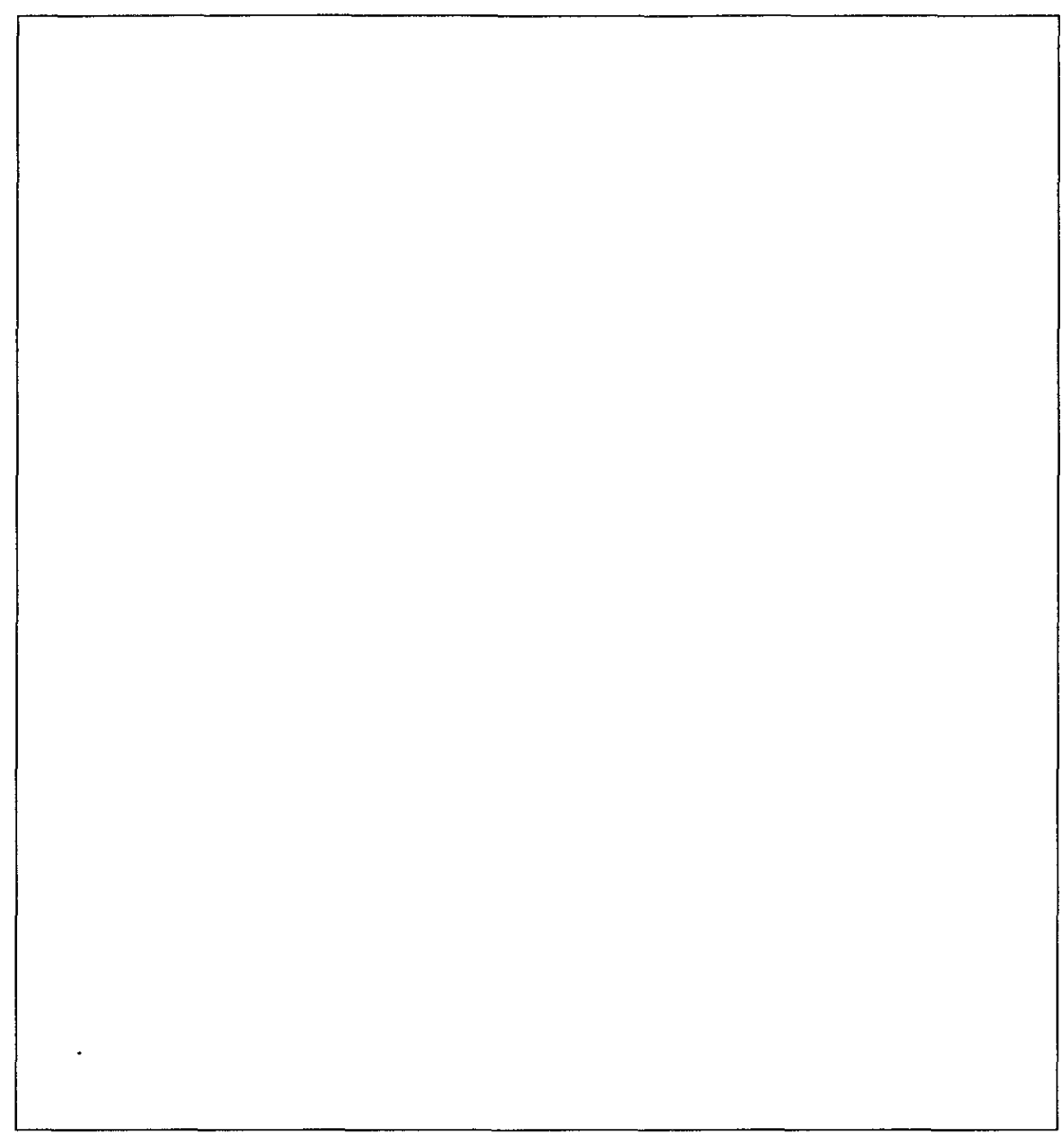

15. Is your classroom?

Teacher-centered $\square$, Student- centered $\square$

16. Do you use a textbook in the courses that you are delivering?

Yes $\square$ No $\square$, if not, what do you use? 
17. How do you find the implementation of new ideas in your classroom?

\section{Easy Moderately Difficult $\square$ Very Difficult $\square$ mpossible}

18. What obstacles have you encountered in implementing new ideas? (You can tick more than one if you wish).

$\square$ Culture, Students' attitudes $\square$ Classroom norms $\square$

\section{Lack of facilities, Institutional regulations}

other $\square$

If you would like to further clarify. Please feel free to do so in the box below: 
19. Do you find there is a clash between teacher-student perceptions of learning within the courses you are currently delivering?

$\square$ Strongly Agree, $\quad$ Agree $\square$ Disagree $\square$

Strongly disagree $\square$

20. Based on your experience are there any important aspects in your institution that seem to be missing? 


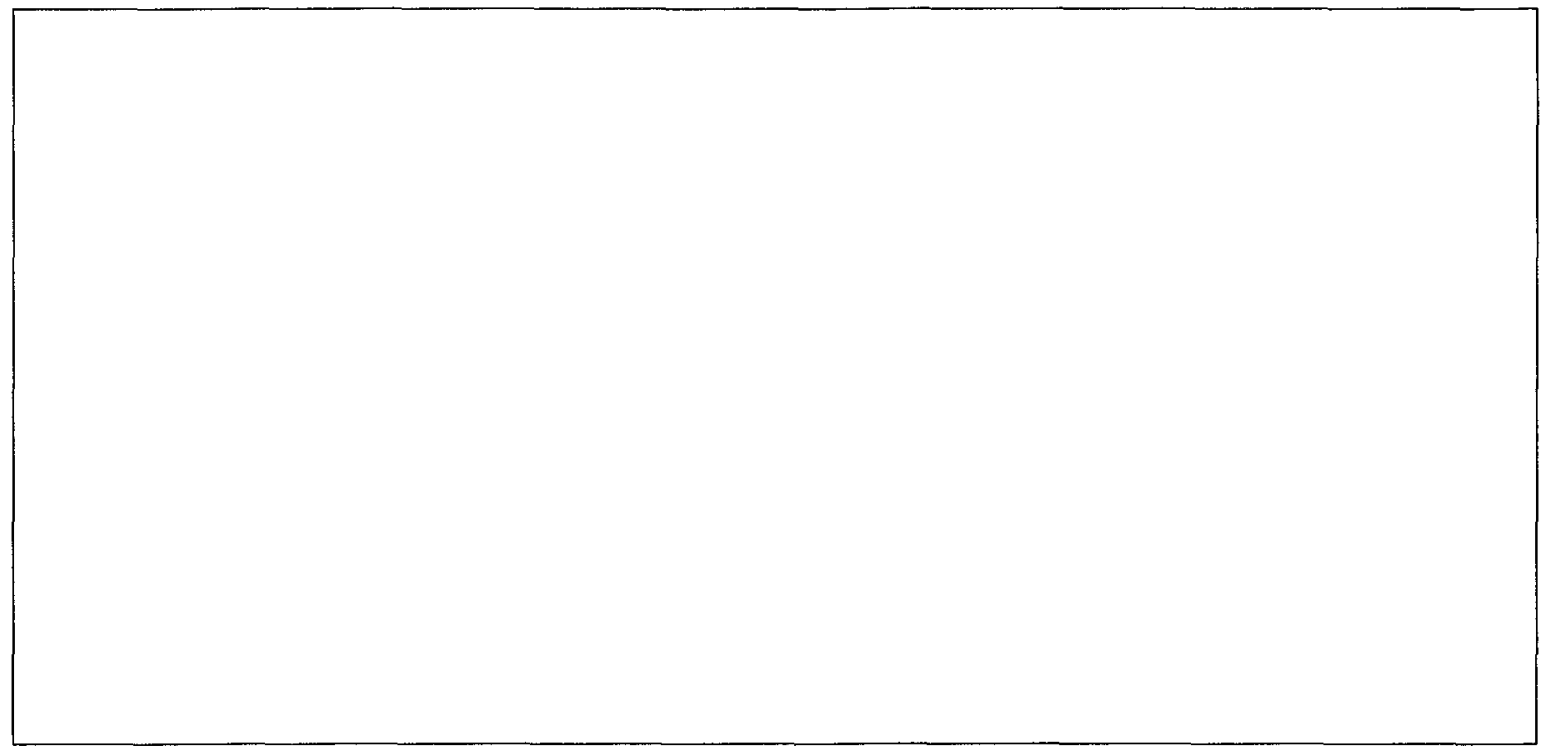

21.If you had the option to improve your institution, or educational system, what aspect(s) would you focus on? Please be as explicit as possible.

Thank you for your participation it is most appreciated 


\section{Appendix III}

\section{Interview Questions}

1. What was your formal graduate studies programme like?

- What did you like about it? And why?

- What didn't you like and why?

- Would you recommend study abroad to other teachers? And why

2. Which ideas, concepts, theories about teaching really struck you and were significant when you were studying abroad? And why? And which didn't and why?

Note that I will be switching to a totally different topic!

Your current experiences teaching a course

Think about a course you are currently teaching:

1. How is it going? What is good and bad about how it is progressing? Are you finding any difficulties, challenges or "hotspots"

Think about a recent lesson/class: 
1. What were the objectives?

2. How did it go? What was good or bad about how it went? Were there any difficulties, challenges or hotspots?

Now we are going to go back to the concepts and ideas from graduate studies that were significant to you

1. You mentioned that such......and such.......concepts had an impact on you. Have any of these ideas or concepts influenced the way you think or act as a teacher? Which ones and why? And which ones didn't? Could you please give me an example of such idea in your classroom practice and what things you do in your classroom?

2. What have you learned by actually teaching that is different from what you learned in your graduate programme?

3. Is there anything in particular that you do in your classroom today that you would label or categorise as innovation or change?

4. In general terms, from what we have just talked about could you synthesise and explain how your graduate studies have informed what you do today as a teacher?

5. Do you feel there is any teaching reform from which your institution might profit?

6. Elaborating on their responses to the questionnaire. 


\section{Appendix IV}

\section{Interview Transcripts}

\section{Teacher A}

Me: What was your formal graduate study like? What did you like about it and why?

Teacher A: Could you repeat the question, could you repeat there was a little a bit of cut, there was one word missing.

Ok. I will tell you what, is it ok like this.

Yeah

Ok. What was your graduate study like? What did you like about it? and why?

Teacher A: Well the MA was a half taught course, there were some courses, and there was a small dissertation of 60 pages or 70 pages and emmm. I think what I liked about it was theeee the the good atmosphere, the emm warm atmosphere, very motivating environment, obviously good teachers. This was in the UK emm this is what I mainly liked about it it it was it was it was just good I meant it. I enjoyed the period where I was doing my MA in Sulphide in Manchester and $\mathrm{my} \mathrm{PhD}$ at Glasgow University in Scotland.

Me: Ok yahhh, what did you like about it most?

Teacher A: I think it was the attitude of the teachers the professors towards the students; it was a very warm ahh equal relationship, ahh a lot of respect ehhh encouragement. So, I think this was it was the the the the rapport if you like of the students or as I was one of students and the teachers, the relationship, the the flexibility the motivating attitude the respect that we had. The encouragement, the fairness. Yah I mean this is As far as I can remember this is was like 30yrs ago, yes it was the atmosphere the relationship with the teachers.

Me: Yes and did that apply emm for as well to the $\mathrm{PhD}$ programme as well, because I believe that your $\mathrm{PhD}$ programme was only about as much about five or six years ago? Right

Teacher A: Yeah about six years ago, yes it was the same really, it was the same. I mean the same. I think it applies to both courses, the MA and the $\mathrm{PhD}$.

Me: Ok but Is there anything you did not like about your $\mathrm{PhD}$ ? 
Teacher A: Emm No I don't think so really, it is aaah. I enjoyed I really, I can honestly say, I was very happy in the years I spent, when I was doing the $\mathrm{PhD}$ programme, it was very good, there was nothing really to complain about.

Me: And you

Teacher A: And I Yeah

Me: Sorry

Yeah I just enjoyed the whole, and again the flexibility of the teachers, and their their availability, their continuous presences and support ... I remember, I was even given an office in the department you know hah, like any other professor, it was so good really, it was so so good.

Me: And did you feel like it was like a healthy learning community, and you didn't have that feeling that were just a learner there or just a student. You were part of the learning community?

Teacher A: Absolutely, Absolutely, no we we were not excluded from anything or from any kind of activities. I as I told many I had an office in the department, I don't know about, I don't if happens know, but in those years we I had an office in the department, because only because, I was given only because I was ahh I was ah $\mathrm{PhD}$ student, so I was treated like any teaching professor in that department. Obviously we were about six or seven students at that time. We were all given a places and desks to sit and ahhh you know, we go there every day sit and study. Met the other professors not just our supervisors. We attended seminars; we gave presentations and seminars ourselves. So we were one of the I mean, we were like full time staff working there. That's how good and how flexible and how inclusive the environment was.

Me: Right Ok. So you would recommend the study abroad programme to other teachers?

Teacher A: Absolutely, absolutely, at least part of the time, at least one of the yeah one of the yeah degrees...either an MA or PhD yeah definitely.

You could yeah I could hear a strong sense of confirmation there and emm and especially and quote your words absolutely there, So why did you say absolutely? You seem very certain there. Is it because of the learning experience, is it because of other emm aaah things that a learning teacher, a student teacher might learn from studying aboard!, or is it apart from acquiring the knowledge or learning the knowledge, that is conveyed over there in that educational programme or institutional programme over there. Is there other learning experiences that you would benefit you would advise? Benefit from?

Yeah 
Me: That you would advise?

Teacher A: Yeah. No form was not just the programme the study, it was the culture it was ehh . obviously I spent a lot of time in the UK I did my I did a certificate, then an diploma, then an MA then a PhD. so I spent a lot of time in the UK, over ten years or so over there. So it wasn't.. Apart from that the $\mathrm{PhD}$ or the MA it wasn't just the education, it was the culture living in the country. We learnt a lot of things that know I am passing to my students in in Tripoli, where I am teaching at the academy of graduate studies. So ahh it was really other skills I mean ahhh, interpersonal ahhh emmm skills ahhh it was ahh I remember at one of the courses we had a doctor a professor who had a PhD. We started to call him Doctor John or Peter or smoothening. He said no no don't call me that just call me John or peter. And I think that's one example, of a very good learning experience, emm and so yeah definitely it was not just the education, it was we learnt the personal skills from our professors, Ahh we acquired some life styles which we have know even in Tripoli so yeah it was much more than just the education programme .

Me: Ok. So you said emmm doctor that your emm that yeah some concepts that you acquired from abroad you're passing them on to your students, can you mention some of them, can you show, can you give me an example ? So do your students call you by your first name or do they call you by your last name? Do they have the.. Is there some aaah register between you?

Teacher A: Yeah I mean ahh I I am so flexible now where I work at the academy. My office when I arrive students just pop in and come in stay or talk, bring their problems or whatever. Its the the they told me that they said we have not really experienced this in many other teachers. And the yeah they yeah. I can of treat them like friends more than students. We are talking about; these are all post graduate students. And the emm and again I practiced things that flexibility -that I experienced in the UK. I aaah give the students a lot of respect and aaah a lot of again I am trying to be human and students quoted that I am fair and you know. So it is these kinds of things that makes students would like to come to my classes try to register on my courses whenever they can and so it's yeah.

Me: Yeah so it's the continuous feedback you're getting form the students that aah emm emphasizes that you are emm ehh passing on what you learnt from this study abroad experience. Right

Teacher A: Yeah absolutely, absolutely. And I I told them .. and I remember my first class here in Tripoli. This was a class of an MA I think it was general linguistics and the students told me that this class we felt that this class is running outside Libya it is not in Libya. Wow, ahh I was really flattered and surprised and said no we really felt like in the UK or America. So it's that kind of thing I got from the UK or my experience from the west. 
Teacher A: I am really happy to hear this, really happy that is good. ... So the second question is during the so I don't want you really to think back to the MA programme... during that $\mathrm{PhD}$ programme you obviously went through and heard a lot of ideas and concepts and theories about teaching.

Yeah

Me: Ok, so what which of these ideas and concepts and theories really stuck you and were significant when you were studying abroad and why? So shall I repeat it? Or

Yeah

Me: So which concepts, which ideas, concepts or theories about teaching really struck you and were significant to you when you were studying abroad. So which really touched and significant to you as a students? And why?

Teacher A: Yeah. I think the most striking aaah theory or method of teaching was the emm the aah the learner centred approach, where learning was given aaah, the responsibility was given completely or thrown at the students. Ahhh and this this for me this was aaah something very new because we I didn't have any experience. We before we relied on our teachers whether we were at the university or at the high school or at the primary school. So I think that was the most striking concept. And emmm I know try whenever can to apply this theory to the students here in the MA. So I make students give lectures with me in the course. I make them give presentation.

\section{The line cut off}

Me: So you were telling me about the emm aah you talked about the learner cantered approach and how it struck and that your emm (sorry) and that your students, your tried to implement this in your classroom practices emm by asking your students to participate in the teaching aah of the course give classroom presentations and emm because you feel that this process will facilitate and mediate their their learning process. Right?

Teacher A: Absolutely yeah

Me: OK. So could you further elaborate and just give me aaah emmm aaah another example for instance?

Teacher A: Yeah I mean as I said it's it's. aaah giving the responsibility of learning to the students makes them aware that learning is there business and emmm they will obviously work on that and they will aaah know aah that the results they get it is that it's their work and emmm so my role in in where I teach know, again mainly as a facilitator, a helper, a counsellor emmm 
and as I said really I tell the students from day one of any course that it is their business to learn and study I am just there to advise them to add aaah from my experience whatever is in the books. So That's that's really the kind of thing we are do here now.

$\mathrm{Ok} \ldots$

Teacher A: And I think students are enjoying it as well very very much and they kept telling me this is good this what we want, we didn't have this experience before. And I think that's what I am saying this I got this from Sulphide, Colchester and from Glasgow where I studied. .

Me: Aaah . Right so you said that you are a facilitator, you are a counsellor. I can see all these adjectives

Teacher A: Yes Yes

Me: Yes emmm eeeh which are very make me very enthusiastic and interested in like going into your classroom and seeing these activities.

Teacher A: Laughs

Me: can you help me to visualise them, like in the way that in, for example emmm give just one activity emmm that you do that you do that you ahh facilitate, counsel your students, the way you say you do?

Teach A: Yeah yeah yes aah for example ahhh $(2 \mathrm{sec})$ I would give the students a course plane and the course desorption and...

Me: Is that the course outline, is that the course outline?

Teacher A: A course outline yes a course outline. And then aaah emmm aaah I would definitely ammm aah elicit throughout the course this is ongoing I mean in the plan everything mentioned the objectives, the description, the schedule, the aaah midterm the final exam, the projects, the submission date and all the stuff that you are familiar with. And then obviously we have the sources the textbooks the main ones the secondary one and the websites,. And then as we go along I would for example elicit, and I will ask the students if we have aaah a point where I ask can someone of you or a few of you ahh will go and find something on the internet. A week later, wow hay this is a website address and it's fantastic. I've just remember eeem this is my last course, in we've just finished the semester now where, and aaah we've just finished the final exams for the fourth semester, we are actually, and one Turkish we're actually aaah a multinational college and classes., so I've a Turkish student and He brought for us a website and 
in this web site there are like tens of books, e-books, free e-books where students managed to get into this website and they got so many sources where they can download and study. so this is for an example where I actually encourage students to find sources aaah you know raise their own learning and aaah again another student brought another website address and there is another one and so on. This is an example of really where I just aaaah facilitate in terms of like asking or suggesting eliciting students to get me to get, for the class websites address which will give us several sources, or books, journal or whatever on , particular points in linguistics for example.

Me: Right, Right ok. So emm aaah obviously many things we study. As a current MA student I went through this process as well. There are some ideas that come across you and you think, oh no, you seem very wary of them, oh you think oh no no no, this is ahh ahh this will never hit me. Stay away from me. I don't want to hear this theory or concept. Was there a concept or theory during your PhD programme that did not struck you, strike you and was not significant to you?

Teacher A: Aaah let me think, and in our filed there is a lot of overlap between theories and one of the things we, I and my students found that we are trying to to grasp the idea of linguistics. I mean it's it's a very as I have always kept telling my students it's fuzzy and this fuzziness of language in linguistics it's it's and again it's it's one of the reason we cannot experiment these ideas that in these theories and there are so we take them as some explanations ahhh of ahhhh problems of linguistics rather than ahh they are at least in some of them, rather to be applied. So far they they ahhh they ahh, we we, I and my students find that these theories obviously they are very hard to apply particularly in language learning and second language acquisition and the things to do with the the what is going through the brain when a child is learning his emm first language or second language. Ahhh we I think we aaah we it's it's it's not just the we are kind of puzzled with this theorizes really, because as I said because it is they are there. They are theories, you can not prove or refute them taht is what I would like to say.

Me: Right so basically you're saying that there is no way to say that emmm the concepts or theorise within our field cannot contradicted. Right? Unless they are experimented in or carried out classroom, then we can decide whether they are valuable or not right?

Yeah I mean I think it's the problem with linguistics, if I can say here are are real theories, we cannot as I and my students were talking, we cannot open somebody's brain and find how they process language or verbs, or how they process meaning. Or I mean We know that now that in the there are very strange experiments in America where they collect injured people in very bad accidents with brains. It's but We still doubt that, we say that these are theories, there are overlap. and We think it's the complexity of our human language that makes these theories aaah 
inapplicable, particularly things to do with sociolinguistics, the new linguistic. 0The other parts of linguistics, the phonology, the syntax, the morphology, the paralinguistic are a bit obvious; we can say we can apply them in translation and teaching and so.

Me: Yes so you, it it's basically the matter of abstract and concert ideas right?

Teacher A: Yes yes.

Me: Can you think of a course you are currently teaching now?, what is the name of the course? and what and what are objectives, how is it going?

Ok let me... I am actually teaching several courses now, but one course came to mind is the of is language testing. ( $3 \mathrm{sec}$ ) and the objective is really to make these students who are mostly aaah emm English language teachers in high schools and private language colleges in Tripoli and other cities around Tripoli and make them aware of aah testing and the testing principles ahhh and emmmm how to really be ahhh write better test and know more about student evaluations in English.

Yes

Teacher A: And the course has gone very well, we've just had the final exam last week and the it was good in in a ways students said we had really didn't have input on this topic in our undergraduate course in our university. Students were most of them I would say were really motivated. Its a kind of, we did it together if you like we the the students participated in discussions they gave presentations they even brought outside emmm aaah topics and discussed them, for example we looked at the TOFL test in terms of reliability, validity and their particularly that kind of depth. The principles of language testing. We looked at IELTS the British Australian test. We looked at international tests like the Cambridge proficiency. So we didn't stick to the course outline. So we had one student taught Arabic as foreign language in America he actually brought the ahh video files of the course he had as to bring in what they had done how actually assessed students in America American University. And this is the kind of thing about I am talking the course. emmm the course although it was well structured, but again flexibility, it's the input is open to the students to bring in whatever they want to the course.

So

Emm

Me: Sorry ago ahead sorry 
Teacher A: So ahhha emmm ahhh students were very happy I think as I can gather from what they were saying about the course aaah they wrote papers ahh they wrote papers, they gave presentations, ahh emmm and they brought problems because as I said most of them teach in schools and some of them in vocational training colleges and they brought problems they face to the class to this class to solve them and aah to bring them to the attention to the other members of the class. Aaah so yeah I think its its, the the calss went went ah went well.

Me: So, the I don't want to put words in your mouth. I don't like the idea saying things and then. Out of interest from you said there that your course followed was like following a progressive syllabus in a way that things change and progress depending on the circumstances of the class and depending on so the flow and structure of, you might have a certain idea how the course would evolve but you would change depending on what the students, depending on the students needs. Right?

Teacher A: Yeah as I said, I few of them, two or three a real problem of a language testing in their own places and like they threw these problems to the class and the class tried to give them some suggestions or solutions or how to go about these problems. So oh although as we have we have we have a plan that we follow a course outline, but again I allowed anything extra to come, either from myself or from the students to add on to whatever is is on the plan.

Me: Right. So did you have any challenges, did you, did you like, were you confronted with any challenges? Were there any difficulties, that you faced, were there like was there one day, or one class or even one particular activity that you felt challenged by the students? For example, they might be emmm the culture concept; they might be ahh for example classroom norms, restrictions, management, administration problems. So did you have any challenges during this language and assessment course?

Teacher A: Ahhh yeah of course there were challenges aaah. One of the challenges is that the, many students have higher expectations in terms of the grade they get. I think its is this is one thing that aaah is that emm or at least some of them won't be satisfied with the grade they get because they should get a higher grade than they normally get. I remember I had one of the students, really kept disrupting the class, talking about this day that she got very poor; I think she got a very poor grade, but her English was not really up to the standards of an MA student. I don't know how she got into the programme. But emmm you will get ahhh ahhh some group probably a minority each class who will have very high expectations of themselves, they think they could much better and obviously when they get their grades of a project or an exam or test, they find that their grade is very low. So this is this is the ahhh it's probably cultural, they think it's it's their right to get a higher grade. This is most of the challenges I have

Me: Do face it in most of your classes Doctor? 
Teacher A: Yeah I mean it's it's in probably in all classes, you always say oh I got a C how come you know,. so, although they their level is obviously is is not that good. But they still expect to get a very a very high high grade. I don't know how how they actually, how how this came came about. This is common in all classes.

Me: Don't you think it's the human ego?

Teacher A: Its

Me: We always expect higher than we actually are. Isn't that the human ego?

Teacher A: Yeah not in. This is not in all cultures not with all people I think.

Me: Yes you're right

Teacher A: I think it's cultural, I think in this part of the world people expect emmm much more than they should get I think. After this experience I have in teaching, where I teach now. I would definitely, this would not happen in Japan for example, where people would say no I think you gave more than I should deserve in grade. This is the experience that I got from a colleague who use to teach in Japan. So Yeah I think it's cultural.

Me: So we can call this that this is part of the educational culture within Libya, Right?

Teacher A: Yes Yeah definitely, definitely.

Me: Part of the. So the educational culture and the classroom norms and the is emmm influencing and affecting what you do, sorry it can either positively or negatively affect what you do in your classrooms right?

Teacher A: Obviously, it can more pressure on or to give more. But I for example would ask to repeat a test for example. Or give a week or more over the deadline. I actually resisted this completely. And said no. And emm know because I am ahead of the department, so I even told other professors please don't accept any reasons or excuses for any delay of work or any repetition of tests or anything like that emmm.

Me: Ok

Teacher A: So far it is working.

Me: So you mentioned that emm the emphasis on the importance of learner, student-centred learning. 
Me : And you said, I believe form what you explained to me it did have an impact on you as a student and then in the long run it did have an impact on you as aah as a teacher. So emm basically my question was so Have any of these ideas or concepts influenced the way you think or act as a teacher? And which ones did? And which ones didn't? And could you please give me an example of such idea in your classroom practices or and what things you do in your classroom that are student centered? Do have anything to add to your previous?

Teaceher A: Yeah I think I would like to emphasize the the point that the ahh emm it is possible to make students responsible for their learning and the get encouraged to the aaaah work on their own. When they are not in the the class, aaah emm they become more forthcoming for asking for help and guidance from me. So emm I think it it's definitely. And I think the other thing, the other point I didn't mention that the students say yeah we will also apply this when we go back to our teaching, to our school to our classes, which is obviously, another good positive point.

Me: Ok. Emm $(5 \mathrm{sec})$.... having the mixture of two educational setting is forcing to me ask you this question. When you were graduate students you were hit by the idea of student learning, you were not used to the idea of being an independent learner you were used to the idea of the teacher being the spoon feeder of the information, if we can metaphorically say. The teacher gives the information, the teacher tests you on the information and that's it.

Yes absolutely.

Me: Didn't you., whether it is acquired or not. Weren't you faced with resistance from your students? Were all, did all of the students accept your philosophy or your notion of student centred learning?

Teacher A: Oh no. A few, a minority did definitely resist the idea and obviously I understood the situation because of their long experience in rote learning and memorisation and the teacher is the authority, the source of information and all this stuff. So But, I think I think it's you know they they were a minority in each class, I find in each class. And I think these this minority believes that it's their right is to get information from the teacher and and and that's it really. Here, there is of course resistance.

Me: How did you overcome?

Emmm 
Me: What did you do to overcome? What did you do to change their views? Or did you just ignore them? Then a short laugh

Teacher A: Emm I mean it is definitely partly, partly ignoring them. The other part is to educate them, to show them how this new technique approach works. Obviously the students who were emmm forthcoming I gave them the chance to give presentations. Or and I think the the way I teach is actually. I give; I always give the students priority to talk. If if I just feel that a student is trying something I just stop straight away immediately and let them talk or whatever they want. I think it is the education and the taking any opportunities of this kind of learning. so For example, as soon as I feel from facial expression, or a wave or whatever I just from any student I just immediately stop of in the middle of a sentence or whatever I was talking about. I think this is how it works.

Me: Right. Since we are dealing with teaching and classroom practices, and what you do in the classroom, going back to the first questionnaire I sent you. You said you were a strong believer of the communicative approach and you think it is the most sound approach that can enhance and mediate and promote language acquisition or the acquisition of another language. I really interested in you, in knowing emm what things you do in your classroom are communicative?

\section{5 sec silence}

Teacher A: I think for example, I always try to get students to work in groups whether it is a, for example aaah aaah, i f we have a problem to look at for example testing. I would throw at the students. They Normally I wouldd obviously change the set up of the classroom the way the students sit. So they would sit in groups or in a in a circle or a semi circle. And the students start discussing the issue in a group and then they come up with some group answer. And then elect a reporter. So it's all done like in a small community kind of work. This is really a kind of example of communicative teaching I use just one example. Students give group presentation. For example we had one presentation where it was given by three or four students not just one. Ahh so that is the kind of aaah application of communicative approach.

Me: Ok right. Didn't, how did you being emm, both of us being Muslims we know very well the regulations and obligations of the Islamic culture, as well as the obligations and cultural norms of the Libyan culture. How do you deal with this in terms of group work?

Teacher A: Emm Yeah I mean I'm sensitive to this. If people would like to sit with each other whether males or females, I would definitely, go with with the with the situations. In some classes you find females are sitting in own groups and males in their own groups. In some classes they were mixed. So I just really let go by the circumstances or situation. I don't force 
people to sit in aaah a particular set up. It it it it works emm smoothly. I mean these are MA students and these are don't forget these are all mature students all have jobs have families. It's, it's it's a kind of adult thing really. People organise themselves by themselves. If they're happy to sit with each other I don't really mind.

It's it's fine.

Me: It works smoothly and you don't interfere as long as the student

Teacher A: Yeah absolutely.

Me: As long as the students are happy you're happy

Teacher A: Yes yes yes.

Me: Because the product is what you're looking for right?

Teacher A: Absolutely yeah.

Me: And you are not looking for the dynamics of that activity right?

Teacher A: Yeah yeah.

Me: Ok then, now we've jsut got a couple more questions. My questions is what have you learnt by actually teaching that is different from what you learnt in graduate programme? (5sec)

Teacher A: Learning from teaching

Me: Yes. What have you learnt from teaching that is actually totally different from what you learnt in your graduate programme? $\mathrm{O}$

Teacher A: Ok

Me: I can give a very small example aaah in terms of assessment, there is certain things, if you've taken the language testing course in graduate programme, and then when you come to apply the theories and concepts in that course, do your practical, do your evaluation and assessment, in assessing your students. For example there might be there might be totally different concepts from what you learnt, and the concepts you learnt from teaching.

Teacher A: Yeah I think, the the yeah. What you don't examine, if we relate this to testing it's it's the human nature aaah of where.. And I think it's it's because of the today's times and today's work. It's it's the human nature that a students would do anything to get more grades and that's again obviously, you I didn't learn anything like this in in in in a course in in in testing. So obviously, of course there are always things you learn by experience, by teaching that you 
wouldn't learn in the in an academic course at a university. Or Even at a graduate or post graduate course in a university. So I think One element that I would probably say now that I am learning through experience of teaching is how to deal with aah this I think a new aaah characteristic of a human being, or in particular student as we are talking about students. Students would do emm probably the majority of them at least in this part of the world where I am teaching. They would do everything to get aaah a higher grade. Even if it is two or one mark. It is amazing in my experience in this regard.

Me: And emm excepte from grades except from, emmm sorry, so your main that you find that you are learning from your teaching experience is how to deal with the students right?

Teacher A: Yeah, no no this is just an example.

Me: Yes an example

Teacher A: The the concept is definitely there. That you will definitely learn things through experience that you would not learn from books, from courses.

Aaah

Teacher A: And obviously it's because of the environment the context wherever you are. Whether you I am sure if I I I I move to teach in Australia or America, it would obviously be a different experience from where I teach now.

Me: Right It's context dependent right?

Yes yes.

Me: Context dependent . So depending

Teacher A: can tell you if I go in teach in Japan next semester, I wouldn't have this problem.

Me: Oh really

Teacher A: Yes yes, I've been told by a friend as I said before, aaah who taught in Japan, students came to him to complain, not about getting low marks or having low scores. They were complaining that the teacher marks more than they deserve. Which is very very interesting, very interesting.

Me: Is it emmm is this because of the cultural norms of the of the jaaa Japanese culture, in that they prefer to save face rather than argue and 
Teacher A: No I think no it's it's it's it's this particular friend this teacher friend

Me: Can you justify this?

Teacher A: I was amazed I was was ahhh (laught), I was was wow. Actually I would hope one day to go and teach in Japan. I would probably do one day.

Me: And so can you, can you interpret why the Japanese students say that they would like, they should get a lower mark? Do you know why right?

Teacher A: It wasn't, I think it shows you that they are so modest and so humble and that that ahhhh that's what I think and again it's cultural. The way they are I am just interpreting know I really have no experience in Japan, or a Japanese classroom. I think it's the way they are brought up, the culture, the education system makes people even say, you have given me more than I deserve, you should give me less than that. But It's it's it's amazing.

Me: So can we say that the cultural norms and the cultural norm and the educational culture, the institutional culture, the shape and influence what we do as teachers?

Teacher A: Yes yes I mean yeah the culture of the institution and the culture of the, the society definitely affect sorry affect the system the teaching the assessment and so on.

And what we do in our classrooms right?

Yes yes

Me: Is there anything in particular that you do in your classroom today ok that you would label or categorise as innovation or change?

Teacher A: Aaah I mean I yeah I mean along on the way there are things that I do that that students said we we've never experienced this we've never known this. Another example I am teaching another course which is called the technology in English language teaching,

Me :Ahah

Teacher A: Which is basically looking at the technology that we can use to support English teaching in a classroom. The standard the computer applications the word, excel and that kind of stuff. And then we go further into call software, the computer assessing language learning, we go to all the soft ware things like that. Make and add more to interest to the classroom and so on. So The way I designed the course is completely practical the assessment is based on the idea of portfolio. So they're actually in this course which again we finished just last week. We had no exams no tests. It was just the students have the course outline, they have things called can do 
lists, kind of objectives, kind of criteria and they would apply these can do list on the computer they produce the evidence for me they would put the evidence in a portfolio and by the end of the course they show to me and say look doctor we can do this this this. it is evident. And said wow we've never we can never imagine this would happen anywhere in Libya. But I did it in my class. And yeah there are ways where you can bring something from anywhere in the world and apply them in Libya. And yeah, they can be and I think the students are so happy, because taking off the pressure of tests and exams midterms and finals and that stuff. They were so much motivated and they worked hard a few extra technological skills and yeah this is this is one thing we can re -demonetarise the system.

Me And you would consider at change right?

Teacher A: Yeah absolutely yeah

Change Reform development in you what you do in your classroom. As compared as you to what you might have done by ten years ago.

Yes emmm

Teacher A: And again this is just one example it was we're doing that have never been done before. I am talking about myself and don't know what is happening with the other teachers.

Yes I could see

Teacher A: In this particular course every week I had a few students would have had learnt something new obviously we have data show and some other aaah gadgets in their classroom. And They say look doctor now I want to show you and the students what I have learnt in the past few days before coming to, I would like to show you and would like to teach the other students.

Me: Excellent

Teacher A: So you can't have better than this. (satisfaction)

Me: I can see it is very cooperative learning environment although in the BA and undergraduate studying environment it is very competitive. Whereas

Teacher A: Yes yes.

Me: Whereas I can see from your examples, I can see a very aaah enhancing aaah cooperative, collaborative learning.

Teacher A: Yes 
Me: Yes ok.

Me: Yes doctor, in general terms, in general terms from what we've just talked about, could you synthesise and explain how your graduate studies have informed what you do today as a teacher.

Teacher A: Yes my graduate studies gave me me the knowledge and theoretical background and also I have acquired some skills from my professors and some other students. When I was in my graduate studies and obviously now I am passing the knowledge and the skills to my students, so emmm ahhh I think if you question is whether the graduate or post graduate are useful or not. Definitely, they are useful; now I I emm, for example, I mean just for an example. I read a lot of research of students, every single day now I read tens of pages correcting them and editing for the master students. So these skills I learnt through doing research when I was at Glasgow university in the UK and Salford in Manchester..... so definitely. Graduate studies, my graduate courses and programmes aaah are I think very useful in terms of informing current practices in teaching.

Me: Right so you aaah you don't regret the postgraduate programme right it's very fruitful, it was very very fruitful

Teacher A: I mean definitely. I recommend my students to go on to do $\mathrm{PhD}$ programme which we are hoping to start next semester. So we are working on the $\mathrm{PhD}$.

Me: Do you feel that any teaching reform, from which your institution might profit?

$10 \mathrm{sec}$ silence

Teacher A: I mean

Me: I can give you time to think about this question. If you want time to think I can give you a couple of minutes to think?

\section{0 secs of salience}

Teacher A: I mean reform is definitely required I think the education, the education programme that are at schools, they should they should always be subject to some kind of reform. I think reform is good in education. Because of the development in the world, and the technology. So definitely we should I think the reform should be ongoing and continuous and in terms of time it should be carried out. 
Me: What particular reform do you think should be carried out in your institution? Emmm feel that I am asking for sensitive information, if you feel I am asking for sensitive information you have the right to not answer the question?

Teacher A:No no the the aaah the yeah I think reform in terms of we probably we need more technology at least in this part of the world. We do have technology, I have internet in the office where I teach the emmm most classrooms have data shows and aaaah so it's but it's we still need some kind of aaah technological reform if you like so to boost the system, the whole system whether it is registration, or access to electronic libraries, on line aaah databases and that kind of stuff. We still lack these things.

Me: You mentioned that in the first questionnaire that good management, increase resources, improve facilities, the teacher our loads, preparing qualified, would you consider the things I have just mentioned there, would you consider that fall under the category of the need for reform?

Teacher A: Yes yeah yes. These I mentioned that they can come under reform. We had I think two years ago we had a conference we had some guest from Holland I think as far as I can remember. We have the best education in the world. Holland

Yes

And then they were asked by the audience in the conference how did you do this. we they said we aaah recruited the best teachers as an example they gave, I don't whether this was in Amsterdam or the whole of Holland. They had aaah 7000 applicants to applying to become teachers and recruited 700 only out of the 7000 .

Wow

Teacher A; And they said also, they kind of abolished any kind of exams of assessment. Third thing they reduced the the the hours the teaching hours, and teaching load for the students and for the teachers. And they said that is how they made their education system is as as very very good. I mean yeah I think in this part of the world ought to be thinking in the same way, I think we need to improve the system radically..

Teacher A: I think the institution you're working is fortunate enough and lucky to have internet access. Is there anything would like to add, is their an idea that you would like to emphasises on anything?

Teacher A: No no, I think I've said what I would like to say and I think it's it's now we should think global whether we are in Libya or Canada or it's the the developments that are 
happening in the world, the technology, the aaaah globalization whether it's right or wrong, but it's affecting people all over the world and this is what we should consider in education and actually indeed I always try to make my students think international, and I told they should think of getting jobs outside Libya and have the experience. Because had I worked in several countries. I taught in the UK, I taught in Saudi Arabia, I taught in Dubai for ten years. I think this is another thing we should add to our students to our classrooms and our education system. we should think globally. So that We're not getting trained for just the local job market but I think, we should make ourselves to think international or globally. and this is what I try to bring to my classroom as well. 


\section{Teacher B}

Me: What was your formal graduate studies like what did you like about it and why?

Teacher B; The MA programme is still as vivid in my mind as as the $\mathrm{PhD}$ programme in the UK. So I don't think I will have a problem talking about either.

Me: So you can talk about both of them then.

Teacher B; All right the the the eeh what I remember most of course is of course, the most important thing I think I should make that common before I start, which is that I was lucky enough to ahhh aaah to study in both the US and the UK. Simply because As an MA programme I think I was aah I was fortunate enough to study in the United States because it was kind of the the core system, you know like they have courses, and then you have the comprehensive exam, and then you have the the the research, or thesis or the independent study. You know. So I was actually, I spent about three and a half years and I took more than twenty courses. So that helped me to build up a a a very good back ground in English literature and English language, linguistics and you know. Aaah and ehn I went to finish my $\mathrm{PhD}$ course in the uk it was a research programme, we did not have any course we just have you know. You you write a proposal and then it gets accepted and then you start writing you know and assigned a supervisor and start writing you research. Sp specifically I think. I was fortunate to do my MA in the US and my $\mathrm{PhD}$ in UK. Because As I was was not as young when I started the $\mathrm{PhD}$ programme and that helped me a lot. I was more experienced and you know more faithful and probably wiser. When I started my PhD I was 45 years old. Just about $45 y$ rs old so I was a little a bit wiser. But the background I am proud of I actually accumulated in the united states through the MA programme I studied in state university. So I studied more than as I said I studied more than twenty courses. aaah in different departments, department of English, department of adult education, department of education and I you know, a collection of courses has to do with pedagogy teaching of foreign language. As I said teaching aids and teaching methodology in the department of education, I think know, it was a very good programme as far as I can remember and it helped me a lot in teaching here in Libya because most of the times I was not teaching literature, which was the main focus of my studies. I taught so many different skills like writing reading and translation as well. so it is a collection of so many things and I think in the UK the MA programme they do have what is called modules where you have to study there modules three or four or five modules. But basically not as comprehensive as in the United States.

Me: As I understood from what you were saying the wide range of courses that you enrolled you gave you an option to see and study different components within our field. You expressed 
that they were very useful and comprehensive as well as they had opened a window on many aspects that are related to our field. in what way were you inspired?

Teacher B: I think, basically I was highly motivated. I I love teaching. I mean the profession of teaching is something I really like very much, I can't imagine myself doing something else and therefore I was highly motivated and enjoyed as you said the enjoyment $i$ think the enjoyment that's where it came from. Because it is something I really like to do, or I want to do I want to do very much which is teaching and therefore I always had in mind that when I go back to Libya I am not just going to teach literature, because literature is my area. I didn't just stick to that area, I studied as you said linguistics, teaching English as a foreign language, you know history of English, history of English language, English grammar whatever. All these courses I studied simply because I knew when I go back to Libya I am not just going to teach literature that is one thing. The other thing is I wanted to prepare myself, because I don't want to do things that I don't know anything about. So At least I will a little thing about everything as you can as you might imagine. The other thing is I did enjoy the way you know coming from Libya and going to the state, directly to the sate and not going to anywhere else that well opened not only one window but windows of opportunities you can see I mean it was there in front of my eyes differences between the way I was taught here as an undergraduate in Libya because most of our professors were British and the programme itself was British as a matter of a fact. And most of the people travelled abroad before us. I travelled with five other colleagues to the states I think it was probably even the first or the second Libyan contingent to study English in the united states it was a quite change. The atmosphere was open. I think I enjoyed the the educational freedom the the chance to to choose courses for example of your own you don't have to study compulsory courses or whatever. I mean you don't have to I have as I said my special area was literature you were I was given the chance to choose from many different courses, in other words you have core courses, and then you have courses you have to choose and you have elective courses. so I think that gave me kind of, as I said I enjoyed that kind of freedom to choose different courses to study. The environment itself as you said professors aaah I aaaah I enjoyed the kind of you know aaah lazy-fair attitude that was there you know coming from a very conservative educational atmosphere to a very were kind open atmosphere the relationship between teacher and student is not as conservative as or as restrictive as it was here for example. I enjoyed that as well and I think it kind of influenced my experience or that experience influenced my practice as a teacher here in Libya at the moment. it is reflected in the way treat my students or the way I deal with my students at the moment for example. I enjoyed that and I liked it very much. And the resources also available, you can imagine a young Libyan going to the sates at that time and you see the kind of open ended resources aah available to him to study to do the things he would like to do. So I enjoyed that as well. 
Me: The main points are as you can see from what you were saying, the student-teacher rapport was significant component within your graduate programme that really touched and know it has affected you as a current practicing professor at one of the Libyan university. The environment, there was no constraint or pressure on how to deal with the educational system there it was open and the extensive amount of resources that were available at that time. Would this study environment apply to the Phd as well?

Teacher B: Yeah. In a way yes, But somehow I might consider a little a bit when it comes in comparison with the states I know always say that aaah I haven't noticed that much difference between other than the internet of course, it is available when I went to Britain of course, it was available to me all the time. But I haven't noticed that much difference it was between 19821994/1995. Of course there was a progress but as a said I enjoyed my PhD programme as well but more or less it was a kind of relationship between a supervisor and myself it was very friendly very professional and friendly at the same time. Aaah as I said in enjoyed that kind of rapport between between myself and the supervisor at the same time the availability of resources and facilities it was was really good. Most of the time it was really good, I spent most of my time in the library it was a research programme. Once your proposal is accepted then you you start using facilities and resources mostly library the internet and etc etc.

Me: Was there anything you didn't like about in both programmes?

Teacher B: Aaah honestly, No I didn't find anything I didn't like. I mean you know for example when it comes to courses the pressure is there to do well for example. But then you know you take that programme and you know what it intends. I knew what I was going to expect, I knew that it was not going to be easy, but you have to work. Eeeh but eeeh I did work hard and I did enjoy myself working hard.

Me: Which ideas, concepts, theories about teaching really struck you and were significant when you were studying abroad? And why? And which didn't and why?

Teacher B: I think I can remember I concept in the state with reference to teaching I still use it and I use aaah $(3 \mathrm{sec})$ and mention it to my students the idea that $(2 \mathrm{sec})$ a teacher is not a dictator in the classroom a teacher is a facilitator in other words. I think one of the ideas I learnt over their one of the concepts as a teacher your job is to facilitate the process of learning to students it is not to dictate things. Another concept it is, I remember very well from the states of Moto that is.. in the school of education, if I am OK then your OK. That is one of the things...It implies for example, if I do my job very well as a teacher aaaah it is only natural it will drop on the students and the students will be $\mathrm{OK}$ as well. If I am OK as a teacher the student is going to be ok as a student. And I think it is kind of a, the whole concept of the teacher is not as a guru right. I think it boils down to you know one of the ideas of William Worthwell the English 
...when he talks about a poet a man speaking to men. I think it's also relevant to the teacher he is a man speaking to men. In other words you respect the students, the difference is only in age, you are older. I always tell my students the only difference within yourselves and myself is I am older and hopefully wiser. I mean because when of the problems we see all the time especially in our society teachers look down upon their students sometimes they may even can a of a behave in a very demeaning way to the students in other words they come across with that attitude that is called holy grade down attitude you know I am better, we are better and this and that. And I think this is one of the stumbling blocks we have here in the relations and teachers. And I am sure you yourself know that sometimes students have come across and tell you that they hated a course simply because they hated the teacher. And vise visa they loved the course because they loved the teacher. I think this is what I meant when I said I am ok then you're OK. It boils to that it boils down to the idea that aaah once again the idea of facilitator if you come across as a facilitator, someone who respects their intelligence, someone who who is just like them. Not talk Not talking down to them but talking to them and with them and I think you know all other issues and obstacles, probably obstacles eeem they just kind of disappear.

Me: You are telling me that a student centred approach to learning; where the student takes responsibility of their own learning, the teacher being a counsellor, a facilitator, unlike what we Libyan educational system is.

Teacher B: Yes, because we are forced to learn things off by heart. Teacher is the as I said the god like figure who does not make mistakes or hardly sleeps. Alright who kind of you know divulges the information and what you have to do imbibe it in and take it in and thank you for that. I think is one of the major problems we face today. As I said once again, sometimes you do, it is not always student-centred, but even when it is teacher-centred the main objective is, kind of as I said it facilitate, because sometimes you need to come in as a as a teacher to say things or to do things. But if the ideas when you do that simply to help students may be kind of to tiasse them to do things excite them you know in that sense then it's OK. It could be a combination sometimes, a combination of a student-centred approach and a teacher-centred. So may sometimes you resort to the traditional way of teaching, but only to help, only help and to go back to the main task which is students-centred. I didn't have any problem kind of getting into the spirit of that system. It was not like a shock to me, you know, it was something new. I was pleasantly shocked you can say.

Me: where there any concepts and theories that didn't strike you.

Teacher B: I don't know I can't think of any, but those things I mentioned where the things those were in practised most of the time the things that were in practiced at that time and I enjoyed very much. Because I think it's more important to see things done than just to read about them in a way. And I still remember one of my professors the one actually you know I consider 
as a friend as a professor and you know as someone even today kind of talk about to my student by name, why enjoyed. Why I enjoyed. I took probably three courses with that professor, because I enjoyed the way he teaches the way he deals with the students, the way he deals with his material you know.

Teacher B: Aaah only in the sense I only I did myself, every month we have a seminar we meet graduate students from other departments. There was kind of you might want to call it; you know the sense of graduate students getting together and doing things together, sometimes especially when we have seminars and conferences. So it boils down to something like cooperative learning you know, we get together and we do things together. You might call it that.

Me: Think about a course you are currently teaching, How is it going? What is good and bad about how it is progressing? Are you finding any difficulties, challenges or "hotspots?"

Teacher B: Well I am currently teaching a course entitled literary criticism to fourth year students. It is a literary course. It is very challenging in that it deals with critical theories and you know. Aaah Sometimes I call sometime the mumble jumble of the whole lot, the different changes, the critical scene, I enjoy that kind of challenge. but At the same time it is very difficult sometime to aaah to teach because one of the problems we have probably is not only that most of the times students most of them not all of them they do lack what is called the literary competence not only in English regretfully even in Arabic. You ask your students about Arabic literature background in most cases are very poor. In that of course is reflected in their in the course they learn which is critical theories or critical concepts in English. They lack them in Arabic and therefore it becomes a very daunting job to deal with that and I think it is not only here in Libya, it's almost everywhere. Because, somehow it can be related to this problem, so many people so many educators that students don't read anymore. Just like food, you know fast food all over the place. It is very, people don't want to sit and have a nice dinner for three hours or whatever. They rather grab a Big Mac you know or burger king and drive off you know. I think that's related to that because if you want to study literature literary criticism, you need to sit down and read you know. So I like the challenges as I said not because I am teaching it. I think This is where I come in I try to make things as graspable as possible, remember when I said before, that a teacher is a man speaking to men. You know that's where I come in. Aaah I don't think I succeed all the time, most of the times I fail, but not because of lack of trying. I think as I said that why I enjoy that I enjoyed that kind of challenge.

Teacher B: As I said, mind you when I say they lack the literary competence I don't mean that their linguistic competence is not there. Some of these students by the way are very competent linguistically, they very fluent. Their English is very good, but it is not the idea that knowing the language itself. I think the idea is when it comes to literature it is not the language itself we are talking about, it is also the culture of the language, the concepts, the idea that are 
there. And that's I think where the problem lies. Some of them are even better, more fluent their English is even better than the teacher him/oneself. When you listen to them, you don't you don't think you are listening to a Libyan student, you think are listening to some of them speak very very good American English, and some of them speak very English-English alright. Very good English-English. You would not detect that these are foreign students. But that is not the case, as I said there is always that difference the linguistic competence and the literacy competence. And I think that is where the problem lies in the literary competence, they do lack that kind of that strata or system by which they can actually look at a literary text and you know.

Me: Sorry is the critical think skills they are lacking

Teacher B: Yes, in way yes. not all the time but in a way yes. It boils down to this idea of being; I don't blame them by the way. It is the system itself, they were never encouraged, they were never told, never encouraged to think on their own, they were never encouraged to express themselves you know. And talk about what they think or whatever, that is the problem. As we said before, they have to learn things off by heart the things the professors or teacher says. That it From day one they were never told to think critically. So and the problem is compound in the university that's all.

Me: Believe you said that is where I come, emm could

Teacher B: That's the challenge remember when I said I love the challenge that's the challenge.

Yes So what do you do?

Teacher B: I try break things down to them, as a kind of analyse things to their littlest details. In a way the extent, I am not talking about everything, but those concepts and ideas, remember when I said I do sometimes have to come in and have to play the traditional role of the teacher and not like to but to encourage the students to come out of their shells as we might say, to express themselves to think critically. I sometimes succeed most of times shy some of them are like you know, some of them you know the culture here.

\section{Me: Yes I know}

Teacher B: Some of them would say they'll come up to my office. I really liked what you said, and I think do and they talk to you and are very good. And I say what didn't say that in class. And they say well, I would rather. They don't like to talk in public in groups for example. So there is that kind of behaviour. 
Me: I believe you said that you try to be in that course a facilitator a counsellor, what is obstructing you is the students culture and their lack of abilities. Therefore you fall back to the traditional role of the teacher that you don't actually believe in so that you can meet the students' needs.

Teacher B: You have to do it. A) you have to do it to meet the students needs, b) to to encourage them in the sense that, even when I do that, I don't do that with with that kind of attitude. Do you remember when I said that attitude that comes across from teachers that I know and that you don't know, you know. You do it in a way where actually try to relate what you are talking about to their own experiences or you even you start to prompt them with question here and there, right. You try to as I said kind of intaisse them to say things. That's what I do that's what I most of the times I do. In other words, when I lecture I don't stand at podium and giving a lecture and sometimes I come across agonising, shake them out of their places you need to do that. But basically they are good. As I said they would come up to up passively after class. I would say my god why didn't you say that in class, I was afraid to make a mistake and I was was and all of those excuses.

Me: Think about a recent lesson/class, What were the objectives? How did it go? What was good or bad about how it went? Were there any difficulties, challenges or hotspots?

Teacher B: One of the classes before the mid-year break this course of literacy criticism. We were talking about critical theories most specifically the post colonial critical theory and the ideas expressed by the proponents of that critical theory. the good thing was the concepts some of the students were able grasp these theories quite quickly simply because aah you know the idea of the third world or colonised and common art and standing out for their rights even on a literary scale. They liked that very much. But then when we stared to talk about specific about how ethnic groups or ethnic minorities sometimes. This theory for example gives the minorities the chance to speak to express themselves etc etc. Aaah becomes a little bit disconcerting simply because they they don't know, most most of the students they don't seem to know the difference between ethnic minorities and religious minorities or the concept of minorities all together. May be because this concept of minorities is not is not you know is not very well know. That is a specific point of view. The problem was or some other students for example there were interested when you have discussions and questions and answers or whatever you find some students raise their hands and I say alright lets hear what you have to say about this and that. Excuse me sir what of type you are going to give because have the mid-year exams starting this week. And there main concern is which part of what we studied today is going to be tested on and which is not. That brings you down to like Abbess Bin Furans you come down to earth, you're taking about concepts, you're talking about ideas you're talking about philosophies sometime. Then someone, not someone but a group of students might raise their hands excuses 
sir could you tell us exactly what part of the curricula in the test and which are not include and what type of test will it be an essay or MCQ. There you have it the two sides of the coin. And that's the challenge by the way, that what I meant challenge you have to make a joke about you know that and then you continue.

Teacher B: As I can gather form what you are saying that what is challenging you in the classroom is the students culture and their philosophy of learning. I trying $t$ instil in them lifelong learning skills you are trying to pass that we are not learning for test but we are here to be educated. But the students only want to know what's going to be on the exam and not the ideology behind the content. They seem not interested in what the content carries with it.

Teacher B: I think it is the whole culture as I said before we were reared up this way, this is what you learn, you learn off by heart and you are going be tested on. I don't blame them by the way. But still my idea is if I have about one hundred, if I have only five or ten, who actually enjoy learning and enjoy my teaching and enjoy the process of learning and to them the idea is not only that we're going to pass the test or whatever. here I am here in the university because the university where actually can develop as an individual as a human being you can get in touch with the culture of others you can get in touch with your culture and probably that the more you get in touch with other peoples culture probably the more you know yourself. In other words if I can find and I do find most of the times and even the minority of the students and I think that makes my day. I know thats very difficult; they are trapped the students and teachers by the way. They are trapped into a culture that still cannot escape from these constraints that it has on itself. This whole idea it's it's as it's not I said it's the general culture as well it is not only the students' culture it is part of the overall culture as well. I am only here as you said I am only here to pass to I am here to get a degree.

Me: It's the educational culture.

Teacher B: It is in the whole system, it is not just my class, or someday else's class, it is not my faculty or my university it is all over the place.

Me: It is like this kind of hierarchy.

Teacher B: You will find the minority who are really interested in learning and knowledge itself because it is a way of developing oneself as an individual as a human being. You will find a minority, as I said I am willing to accept one percent in every semester or year that they actually feel that they are just here to pass or get a degree. It is a process that starts the day you were born and ends the day you pass away.

Me: as you mentioned that the concepts from graduate studies student- teacher rapport the relationship, you mentioned the role of the teacher as being as a facilitator, consular, a helper 
rather than being a transmitter of the information. And you also mentioned the idea of cooperative learning and how it was important in the whole learning process You mentioned that such......and such........concepts had an impact on you. Have any of these ideas or concepts influenced the way you think or act as a teacher? Which ones and why? And which ones didn't? And why

Teacher B: I think the ones which you have just summarised have actually influenced me as a teacher. The idea of a the facilitator the idea of the the the teacher who is a approachable who could be approached by his or by his students. the idea of the teacher kind of a who creates a friendly environment I think all of these actually are reflected in the way I carry out my duties as a teacher. The way I deal with my students. At least I have some of the former students for example they come over and they express I mean we are talking about some of them graduated twenty years ago and they sometimes they come back and you know we sit down and we talk and they tell me the things they liked of what and the why I teach. There is a kind of feedback that I sometimes get from my former students and it does kind of help sometimes or it helps so much when it comes to that when you get that feedback aaah even the thing even the little things that I am not even aware of, the why I stand for example plus the why I talk sometime. I remember a few remarks, very funny remarks that I've stopped doing a few things that I used to because of the feedback. I think that's my own philosophy here I think as a teacher is shaped by all of those concepts that we discussed before. Aaah I was told by my students by my former students and some of my colleagues that I am that kind of person. And I know very very very well I am teacher who is approachable; my students have no problem what so ever to come to me not only with their academic affairs or problems or what over, they come to me with their most enitment personal problems, and they talk to me and they feel very feel. And they tell to my face they feel very free to talk to you than other people or whatever. I think it is reflected the way I deal with my students whether academically or on a personal level.

Me: Can you give me an example of you being a facilitator in your classroom?

Teacher B: Ok I think I can give you an example. For example one of the things I always make clear in the class that there is no monopoly for example when we talk about literature when we have a literary text, there is no monopoly on meaning, there is no monopoly on the way it is interpreted. I always make that point very clear. What I say is just one meaning. Or a meaning for example and that meaning is shaped by my own personal opinion background ideas etc etc. And each one of you if we are forty five students then there is a possibility of having forty five meanings and that I can't fault you and I can't mark you wrong if you even if you the wrong or what could be a wrong meaning. I tell them for example when it comes to the exam I can't fail you simply because you said something I don't like or you said something I don't believe in or something that I am against or different meaning. I tell them all the time I'd rather if you have 
your own meaning. Extract your own meaning form the text, if you want to adapt the things I say that's fine. But I'd rather you say something completely different. And I think the message gets get through most of the time, it get through. That if you regard that as a specific instance of being a facilitator.

Me: How do you practice cooperative learning, can you give me an example of cooperative learning being part of classroom norms or classroom practices?

Teacher B: Yes sometimes we do for example instead of coming in, when of classes before the break for example. I have the text with me and gave the text to and I said alright lets have groups for example and each group will study the text separately from other groups in the class we have different groups and then we come together and then we start discussing things how we come up with ideas together we we designate, every group designates a spokes person a male or female student and then we discuss things together. And I've become a mediator by the way, I don't even say anything, I don't even talk just can guide what the other group think. And sometimes when we have conflicting ideas, I say alright why did you say that, why did you say that and what do you think of that etc etc, and I become a mediator. So I do that, it is different sometimes from course to another in the nature of the course itself, Sometimes it necessities different types of methods or different types of methodologies or approaches.

Me: You said that you were a proponent of an eclectic approach what do you mean by it?

Teacher B: Eclectic approach that actually combines for example a teacher-oriented and student-oriented altogether or all in one. In other words you just don't do one thing because this is the most appropriate approach especially here in Libya. Do you remember when I said you have to start the class with a traditional approach by providing information for example or by providing information of text or whatever. Then you move on to the the other approaches the student the student-oriented or student-centred where you ask students question OK what do you think this? What do you think of that? Could you tell me about this? Could you tell me about that? Could you know and then you start to move from different approaches and I think that's what I meant by eclectic approach.

Me: Would you say that you practice the eclectic approach most often in your teaching practices?

Teacher B: Yes most often I can't remember I class where I used only one approach because even when you for example. Remember when I talked about cooperative leaning and then you sometimes you move on to something else. It actually creates a kind of a very interesting in the atmosphere in the class at the same time it does not become very boring, because if you use one approach from one $\mathrm{A}-\mathrm{Z}$ then it could become boring you know. And I think it it it comes with 
the experience, because sometimes you can see in the eyes of the students that things are not going anywhere. So you have to improvise. And that improvisation should not out of the blue, it should it should be you part of what you do, a methodology it has to have a methodology. It is very difficult at the beginning as a young teacher; it is very difficult to do that by the way. but then the older and wiser you get the easier it becomes.

Me: Coming from a traditional educational system, I am wonder whether you met with resistance or not? For example as Muslims we know very well the regulations and obligations of the Islamic culture, as well as the obligations and cultural norms of the Libyan culture. A) where you met with any resistance and $(B)$ where do you think this resistance rooted form/or stemmed from.

Me: Do you remember when I talked about cooperative learning and I said I divide students into groups for example. I don't when I said that I don't do that literary. I ask them, so I say alright to get into groups choose your your group, alright. I don't say you come here, you go there or whatever. So students actually choose their groups and some of the groups are mainly you or all for example I say lets break down the class into groups of five or sixes alright. Naturally speaking some of the groups will be all females and some of the groups will be males, and then you will have most of the groups. But then you will have most of the groups will be mixed you will have two males with four females or whatever. And I don't I don't interfere and I don't intervene and I don't say why or whatever. I let it be, I don't even ask or even mention why do you for example why do you have only females here. Because some of the female as you said find very difficult to work with males. But these students are actually are together for four years now and some of them may be have known each other before that. I don't divide them and I don't you say and you go there or have numbers And I don't do that. So it comes naturally those who are comfortable with each other work together in groups. I don't make comments about that and I don't force them to do that. Some of the students don't feel comfortable to working with other male students. And you know As you said tradition is of course is there.

Me: So we can say you are not interested in the dynamic of the group but what is your main focus is the outcome the product. And your sensitive to this issue.

Teacher B: As you said I am not really interested in the way it happens, the dynamics all I am interested in is the final thing the product. And I think through time probably it becomes alright I mean because the context and I sometimes I say that by the way. Sometimes do happen in class when I make comments and I say listen in the classroom it is kind of sacred place we are here to learn to study. Just like just like going to the mosque, we come to the classroom with all the respect we have for the the mosque, sometimes I say that. And aaah of course I don't interfere how they arrangement how they sit because some teachers for example say alright boys on this side or and girls on that side. I don't do that because they are old enough, they are wise 
enough to know how to sit. All I have to do, the traditional teacher comes out when someone infringes on the or the does something that infringes the rights of others or it infringes the right the whole group to learn or to teach. or to interrupt the process of teaching and learning, yes the the traditional teacher comes out And you ask them to leave. I am sensitive to the, because I am part of the culture. I am sensitive to the culture itself, being based on religion mostly, it is a religious culture. Some people might not think of it in that way. But I'm mostly sensitive to the extent that the text I choose, should not in any way infringe on that culture I mean I don't presenting other ideas and different ideas form different cultures, those ideas and those for examples concepts or whatever I always make, nobody is censoring me, but sometimes I do admit to others that I sometime I practice it on myself. I censorship I do my own censorship, I don't choose texts for example that are full of curse words or whatever, I don't do that. Because there are text that I would like to teach but I don't teach simple because I have I have got the alternative. Ok Why should I teach a text, unless I want to show that this character is very this or that or the behaviour of a culture. You have to make sure that you religious sensitivities, you have cultural sensitivities, you have gender sensitivities sometimes. So you have to be sensitive as a teacher.

Me: So in terms of your philosophy and notion of you being the facilitator if information, were you met with resistance from your students or not

Teacher B: Not Not Not so so much resisted. There were a few times where students resisted sometimes even openly, but not so much, I think the only time when someone resisted that openly was in 1984, I think I was talking about something and asked the students what do you think and one of raised his hand and that's what you think, very angrily said that's what you think. And I said you bet your sweet potatoes that's what I said. I used that I used that the American expression. I had to explain to him later on. Because he said you know he wanted me to teach to use the traditional way of teaching, I mean he came out openly listen we don't like the way you teach. He said we and I said what do you mean by we are you talking are the spokes person of the group or are you talking about yourself. No I am talking about the whole group we actually had a meeting and we don't like the way you teach etc etc. So I said alright so so we discussed dramatically and then we. He is one of my friends now. That was only incident where I can actually remember that someone actually resisted taw whole idea or business of facilitating or this business. I think Mostly the students either enjoy it or they don't express their misgivings about it.

Me: But what do you to detect the resistance how do you deal with it, what do you do to overcome this resistance, do you educate them, do you show them the positive outcomes of this approach, or do you this sounds cold and unsympathetic or do you just ignore them? 
Teacher B: No I don't ignore them. Surprisingly most of the time when I do detect. As I said it is not everybody. You do detect a few individuals here and there who are resistant to this whole idea, because that brought up in the culture we talked about. Most of the times I make jokes about it. I make jokes about myself being a kind of a outlaw, a kind of teacher who is actually on the wrong page who should be should be incarcerated, who should be imprisoned. And it works by the way. I express the idea, that you may hate me, but you'll love thrifty years from now.

Me: So you do stress that what you do in is not the normal, it is the abnormal to the Libyan educational system.

Teacher B: Oh yes all the time. Sometimes I don't have to say they will say it. For example I would say if you want to get a very good grade, if you want to get excellent or whatever, you have to say something I haven't said. You have to do something I haven't done. You have to go around and look for other thing other information; you have to provide new insights or whatever. And then they look at me alright this is not what other people say, other people want us kind of regurgitate whatever s being given to them, and I said well each scholar has their own way alright. This is how I do things. So if you want to get a very good then you have to do it the way I just mentioned. If you want to just pass then you have to learn things by heart and just kind of divulge them to me and you have no credit for that, this is what I said and you learnt by heart and I give you credit for learning things by heart, for having a photographic memory only. You pass only you pass, I am not going to fail you, but are not going to get a good or a very good, or an excellent grade. If you want to have that kind of grade then you have to say things I haven't said, do things I haven't done, even if you're wrong. This goes back to fiqueh try to overcome things or whatever and you fail or you try to answer the question and you fail, that's fine you tries. If you succeeded then you get an excellent grade simply because you tried and you succeeded. And it works most of the time it works.

Me: What have you learned by actually teaching that is different from what you learned in your graduate programme?

Teacher B: Of course there is a difference between teaching doing it and then studying about and learning about it. It is not exactly the same no matter how you learn, no matter how you study, no matter how we read, no matter whatever. in practice there are so many things, as I said you have to improvise. I think this is what I learnt from teaching you how to improvise; you have to be ready all the time on the look out to improvise. And you have to update yourself; you have to keep yourself ready all the time. To be on your toes as it were. And you like, that's what I learnt from my teaching experience. You can never sit on your lorries, you can never rely on your past experience, you can never say this is the I lesson I learnt and this is the lesson I will probably tell it everybody else. Improvise in terms of methodology, because sometime you're 
taught methods of teaching for example English methods of teaching this or that. Yes you you have to study that, you have to learn have to do it. I think most of the people who either not necessarily fail but who come to a point where actually they say well I hate this job, can't do it anymore or any long. I think those people just stick to what they've learnt. You have to keep up with things as I said you have to improvise, sometimes you. And I think it boils down to I love teaching right and I think that's why I improvise all the time. I'll repeat it again because I said it before; I can't see myself doing any other thing.

Me: Is there anything in particular that you do in your classroom today that you would label or categorise as innovation or change?

Teacher B: Within the context I am in at the moment, yeah I will probably the most of the things I do are innovative, within the context I'm in within the circumstance I have. I sometimes even call myself. I sometimes tell them that don't worry I might be crazy. So I wanted to resort to the idea even if you don't like it or whatever just think of me as a someone who's lost his marbles.

Me: so I can say that everything you do in your classroom is change, is innovative in terms of the Libyan educational system.

Teacher B: Yeah, I dint like to brag, but I think yeah that's describes. I think even though I am older and wiser but as a teacher, I think I am still a rebel, there is still a rebel inside, lurking inside all the time. In the sense I don't I don't subscribe to things I see as being obstacles, I don't subscribe to even the constraints of the culture. I am being sensitive to my culture; I am being sensitive to my society. At the same time, I have never shied away from saying or doing anything that other people deem as controversial when it comes to the way carry out my job, the way I do my job as a teacher. I mean in class when I am in class, I mean probably some people they come across you are different when you're in class that when you're out side. And I tell them when I am in class I am a performer, I am a teacher that is a different character. When I am outside on the streets that's my character that's myself that's Mohammed Hassan, the person, the father, the husband the brother, the street wise Libyan. But when I am in class I assume the character of a teacher. I laugh, I joke I make students laugh and you know. And sometimes they come across, I remember one one, two years ago female student came to me in my office and said listen I have a burning question I would like to ask you. So I said go ahead shoot, what do you have? Why are you so reserved in the corridors, during class your different. Yes I said I am different, that's why I teach. In class I am a teacher but outside the classroom I am a different person I'm a father, I'm a husband, I am friend and you know. That's what I meant when I said I am rebel inside the class. Inside the classroom anything goes no restrictions what so ever. Whatever makes students enjoy the learning teaching experience goes. Of course provided they don't infringe. By the way when I talk about restrictions I only mean religious obstacles, I don't 
pay much attention to politics, I say I've never shied away from saying things no matter what in class. Outside class is a different story. Other people don't like that, that's their way of doing things and this is my way of doing things. And I am sure there are other people like me, I am sure of that.

Me: When I asked you how do you find the implementation of new ideas in your classroom, you answered moderately difficult and you mentioned that the obstacles you encounter in implementing new ideas is culture and lack of facilities. Could you please elaborate on these two answers please?

Teacher B: Yeah because for example the the context we usually teach in is a kind of a classroom context, where sometimes I instead of teaching I would like to show the students a movie, a film, instead of teaching a play for example. I do like to do that because that play or that novel, because there is a film version of that novel or play. You would like that for example have the students that movie or film or whatever. And you can't simply because you don't have the facilities. Sometimes you have the I do have tapes for example, poetry readings, critical interviews or whatever, you know you don't have facilities available all the time to have your students listen to it. Even if you have the tape recorder or whatever, you don't have the plug where you can actually you know.

Me: Install it

Teacher B; Yeah little things like that, yes we sometimes even teach in the dark sometimes (electricity being cut off in the winter as this is very common in Libya during the winter season).

Me: In general terms, from what we have just talked about could you synthesise and explain how your graduate studies have informed what you do today as a teacher?

Teacher B: Mostly it is my MA studies in the state inform the way I teach at the moment mostly, aaah the $\mathrm{PhD}$ programme did not contribute that much. But it did contribute in the sense that I learnt more and I was able to expand my knowledge more in that sense. The things I do mostly in practice were informed by my studies in the United States.

Me: Can you explain to me how?

Teacher B: As I said it is more or less the things that just like you should do to others what's been done to you. In that sense it's like, I think what I did in the states is like, is you may call it emulate. I emulated the teachers who taught me in the states and I emulated the context in which I was a student. And I enjoyed being a student and I think I tried as much as I can to recreate that 
kind of context here in Libya in my classes. This is what I meant when I said they were informed by the, the things that were practiced either by teachers who were teaching, my interaction with other students, or taking courses with, with the activities, academic activities I was involved in that sort of thing.

Me :So you are not just trying to replicate the learning context, but also the learning experienced abroad.

Me: Do you feel there is any teaching reform from which your institution might profit?

Teacher B: We are talking about any teaching reform my institution might profit from at this moment. Would it satisfy, would it be enough if I said tones and tones tones of reforms, not just many reforms but tones and tones of reforms? I think basically you know as well as I do, we need reforms from $A$ to $Z$ whether it is the institution itself, whether it's the facilities, whether it is the relations between students and teachers, leadership in the institutions, in higher institutions. We need people who are open minded, intelligent enough, probably crazy enough. There are ways and ways in doing things and that, the more we kind of open up the better we become, that kind of thing. On all levels, demonstrative, academic you name it. We need that we need reforms. I can't think of something specific but these are in general terms.

Me: What about technology

Teacher B: It is not my obsession you know it could be imported any minute. It's not the technology I am worried about; it's the minds, the brains that would use that technology. Probably the easiest, probably the least of my worries is the technology. It is the culture behind that because most of them technophobic, it is the phobia itself, it is the culture that I am worried about, which produced that phobia. I think that the whole culture needs reform.

He mentioned that he would not teach abroad because "I want to teach here, I want to suffer here, to show my student a model of a different teacher. At least my students will say we knew I person like that one day. And for me that is success". 